\title{
Radiological Society of North America (RSNA) 3D printing Special Interest Group (SIG): guidelines for medical 3D printing and appropriateness for clinical scenarios
}

\author{
Leonid Chepelev ${ }^{1+}$, Nicole Wake ${ }^{2,3+}$, Justin Ryan ${ }^{4 \dagger}$, Waleed Althobaity ${ }^{1+}$, Ashish Gupta ${ }^{1 \dagger}$, Elsa Arribas ${ }^{5 \dagger}$, \\ Lumarie Santiago $^{5 \dagger}$, David H Ballard ${ }^{6}$, Kenneth C Wang ${ }^{7}$, William Weadock ${ }^{8}$, Ciprian N Ionita ${ }^{9}$, Dimitrios Mitsouras ${ }^{1}$, \\ Jonathan Morris ${ }^{10}$, Jane Matsumoto ${ }^{10}$, Andy Christensen ${ }^{1}$, Peter Liacouras ${ }^{11}$, Frank J Rybicki ${ }^{1 *}$, Adnan Sheikh ${ }^{1}$ \\ and RSNA Special Interest Group for 3D Printing
}

\begin{abstract}
Medical three-dimensional (3D) printing has expanded dramatically over the past three decades with growth in both facility adoption and the variety of medical applications. Consideration for each step required to create accurate 3D printed models from medical imaging data impacts patient care and management. In this paper, a writing group representing the Radiological Society of North America Special Interest Group on 3D Printing (SIG) provides recommendations that have been vetted and voted on by the SIG active membership. This body of work includes appropriate clinical use of anatomic models 3D printed for diagnostic use in the care of patients with specific medical conditions. The recommendations provide guidance for approaches and tools in medical 3D printing, from image acquisition, segmentation of the desired anatomy intended for 3D printing, creation of a 3D-printable model, and post-processing of 3D printed anatomic models for patient care.
\end{abstract}

Keywords: 3D printing, Appropriateness, Guideline, Quality, Radiology, Additive manufacturing, Anatomic model

\section{Background}

In 2016, the Radiological Society of North America (RSNA) approved a proposal to create the Special Interest Group on 3D Printing (SIG). This document fulfills two of the original SIG goals: to provide recommendations towards consistent and safe production of 3D printed models derived from medical images, and to describe a set of clinical scenarios for 3D printing is appropriate for the intended use of caring for patients with those medical conditions. This project also fills a previously unmet need for practice parameters/guidelines regarding the clinical service of anatomic modeling (3D

\footnotetext{
* Correspondence: frybicki@toh.ca

†Leonid Chepelev, Nicole Wake, Justin Ryan, Waleed Althobaity, Ashish Gupta, Elsa Arribas and Lumarie Santiago contributed equally to this work. ${ }^{1}$ Department of Radiology and The Ottawa Hospital Research Institute, University of Ottawa, Ottawa, ON, Canada

Full list of author information is available at the end of the article
}

Printing) described for proposed new billing codes, including those for the American Medical Association. These practice parameters and recommendations are not intended as comprehensive standards but do reflect several salient aspects of clinical anatomic modeling and appropriateness. The guidelines subcommittee of the SIG will maintain and devote the time and effort necessary to continually develop and update these recommendations. This subcommittee is comprised of volunteer members of the SIG who form the writing group of this document.

In its current state, medical 3D printing [1-576] has been performed for a variety of patients, but without evidence-based appropriateness guidelines. For many body parts, this document includes a comprehensive assessment of appropriateness from the medical literature, supplemented by expert opinion (SIG members) when 
there is a paucity of peer-review data. After the clinical decision to use 3D printing for patient care, there are many subsequent steps, as reviewed in prior literature $[563,566,577]$. These include image acquisition, image segmentation (demarcation of the desired 3D anatomy), creating 3D-printable file types for each segmented part, printing, and post processing of 3D medical models. This document differs from existing works, including case reports, small and larger studies, and 3D printing review articles in the literature. This is not a review article; instead of reviewing the literature or providing data regarding the clinical utility of medical 3D printing, the RSNA SIG has assembled a group of experts to begin to provide consensus recommendations on the practice of medical modeling and 3D printing, particularly for practice within healthcare facilities. 3D printing of anatomical models within a hospital has recently become recognized as point-of-care manufacturing. These recommendations create a foundational outline to provide practice recommendations for those steps required for medical 3D printing, including image acquisition, segmentation, printing, post-processing, and model verification.

\section{Methods}

\section{Consensus methodology recommendations}

The recommendations regarding medical image acquisition, image data preparation and manipulation, generation of 3D printed models, quality control, communication with referring physicians, preoperative planning using 3D printed models, and considerations regarding materials were discussed and summarized by members of the RSNA Special Interest Group for 3D Printing during several meetings, including on August 31 (Silver Spring, MD) and December 1, 2017 (Chicago, IL) after review of the relevant medical 3D printing literature [1-576] and the local clinical practice of representative members of the Special Interest Group. Relevant recommendations were further exposed to internal online discussion and summarized by a focused taskforce. The final recommendations were reviewed and vetted by all RSNA 3D printing SIG members.

\section{Appropriateness consensus guideline generation}

The Special Interest Group has initiated the quality and safety scholarship to identify those clinical situations for which 3D Printing is considered an appropriate, and not appropriate, representation of the data contained in a medical imaging examination. These documents highlight appropriateness of medical 3D printing for clinical utilization, research, scientific, and informational purposes. This work is loosely modeled after the American College of Radiology Appropriateness Criteria ${ }^{\circ}$ [553, 554] in that the guidelines committee uses an evidence-based approach at scoring. Consensus among members is used when there is a paucity of evidence.

Each category was led by a separate writing group, composed of a small group of experts in that domain of medical imaging and 3D printing. The SIG Executive committee, led by the Guidelines Chairperson, formed the review panel. Ratings were generated via by a vote of Special Interest Group members at in-person meetings. The results of the ratings follow the following 1-9 format (with 9 being the most appropriate):

$1-3$, red, rarely appropriate: There is a lack of a clear benefit or experience that shows an advantage over usual practice.

4-6, yellow, maybe appropriate: There may be times when there is an advantage, but the data is lacking, or the benefits have not been fully defined.

7-9, green, usually appropriate: Data and experience shows an advantage to $3 \mathrm{D}$ printing as a method to represent and/or extend the value of data contained in the medical imaging examination.

The supporting evidence was obtained through structured PubMed searches, as detailed in the Appendix. In rare circumstances, supporting literature was recommended directly by the members of the committee and was explicitly identified outside of the structured PubMed search results.

A subset of applications of 3D printing, including in congenital heart, vascular, craniomaxillofacial, musculoskeletal, genitounirary, and breast pathologies was selected for detailed review. All final components of this section were vetted and approved by vote of Special Interest Group members at several face-to-face meetings including on August 31 (Silver Spring, MD) and December 1, 2017 (Chicago, IL) as well as via internal posting on the SIG member intranet.

\section{Results \\ Consensus methodology recommendations Medical image acquisition}

The most common medical imaging modalities for 3D printing are computed tomography $(\mathrm{CT})$ and magnetic resonance imaging (MRI); however, any 3D imaging dataset including sonography (e.g., echocardiography) may be utilized as input data for segmentation. The international standard format for these imaging files is Digital Imaging and Communications in Medicine (DICOM). At this time, DICOM images are not routinely sent directly to a 3D printer for printing, so medical images are segmented and converted to a file type that is recognized by $3 \mathrm{D}$ printers. Common file types include Standard Tessellation Language (STL), OBJ, VRML/WRL, AMF, 3MF, and X3D. Once this functionality is implemented by $3 \mathrm{D}$ printing 
vendors, picture archiving and communication system (PACS) vendors, and at the point of care facility, it will allow 3D files in the form of STLs, for example, to be stored in a patient's medical record.

Spatial resolution and slice thickness Medical imaging data should have sufficient spatial resolution to accurately represent the anatomy to be modeled. The spatial resolution of an imaging method refers to the smallest resolvable distance between two different objects or two different features of the same object. Low spatial resolution techniques will be unable to differentiate two adjacent structures that are close together and have similar tissue properties. When the intent to produce a 3D model is known prior to a medical imaging procedure, the image acquisition should be tailored so that the anatomy in the intended 3D model can be adequately visualized. The optimal spatial resolution will depend on the anatomy being imaged.

Slice thickness, which influences the spatial resolution and image noise (discussed in the next section), can also be optimized depending on the intended use. In general, this means that the smallest anatomy of interest should be captured on multiple sequential DICOM images of a particular series. For example, if the anatomy of interest measures $3 \mathrm{~mm}$, it would be desirable for this anatomy to be captured on at least 3 sequential image slices; therefore, the slice thickness should be no greater than $1 \mathrm{~mm}$, and preferably smaller. If images are acquired with a large slice thickness, stair-step boundaries may be seen in the 3D model.

For CT, in combination with scan distance, consideration may be given regarding collimation (the thickness of the X-ray beam) and overlap. Typically, the scan distance and collimation are the same; however, if the slice distance is smaller than the collimation, there will be an overlap which may lead to improved results. Cone Beam CT has technical differences with conventional CT, and often results in a lower patient radiation exposure and subsequently less image contrast that typical clinical CT images. Image artifacts and consistency of SNR throughout the scan can also limit studies. For MRI, voxels may be isotropic or rectangular solids and the resolution may be different in the three dimensions. The size of the voxel depends on the matrix size, the field of view (FOV), and the slice thickness.

In some clinical scenarios, there are patients for which suboptimal imaging data is available, but a separate acquisition is contraindicated. If superior spatial resolution is preferred and CT data is required, that benefit should be weighed against the risk of delivering more radiation to the patient.

Signal to Noise Ratio (SNR) and Contrast to Noise Ratio (CNR) The SNR is a metric of image quality. A higher SNR, all else being equal, implies more trustworthy data for 3D printing. The CNR is the relationship of the signal intensity differences (the contrast) between two regions, scaled to noise. High contrast between various organs in the body is an important feature of medical imaging and is necessary to delineate structures for 3D printing. The SNR and CNR of images used for 3D printing should be comparable to, or superior to, those for "3D visualization", defined as the comprehensive ensemble of manipulation of a volumetric data set for viewing on a $2 \mathrm{D}$ surface such as a computer monitor [563].

If the SNR and/or CNR are inconsistent, or suboptimal, the risks of inaccurate segmentation must be weighed against those of rescanning the patient. Regarding high noise data, a judgment call must be made to determine whether the segmentation operator is capable of delineating the data (e.g. in the case of a cone beam CT image series).

In $\mathrm{CT}$, the X-ray tube voltage may also be adjusted to maximize the signal. A lower $\mathrm{kV}$ can be used to increase the enhancement of iodine contrast when building vascular models. In addition, the raw data reconstruction parameters selected may affect the appearance of specific anatomical structures. For example, the reconstruction kernel (image filter) impacts both the spatial resolution and image noise, which must be balanced, based on the application. Typically, kernel options range from "sharp" to "smooth." Sharpening filters increase edge sharpness at a cost of increasing noise while smoothing filters reduce noise content in images by also decrease edge sharpness. For models with fine structures, such as the temporal bone, a sharp kernel is preferred; and for larger, low contrast models, a smooth kernel is more appropriate. CT is considered the imaging modality of choice for bone imaging and is often used to produce 3D anatomical models of hard tissue structures such as bone. In MRI, the SNR may be improved by performing a volume acquisition (at the expense of time), decreasing noise by reducing the bandwidth, altering the echo time or repeat time, increasing the FOV, decreasing the matrix size, or increasing the slice thickness.

Image artifact The sub-volume of the imaging dataset that will be 3D printed is defined in this document as the printing Region of Interest (ROI). All medical images contain artifact, and image processing steps should be taken to minimize artifact. The ROI should be small enough to enable confident segmentation for 3D printing. There are cases for which medical interpretation is possible (see Image interpretation Section), but 3D printing can be limited by the presence of artifact, motion, or other spatial or noise limitations in DICOM images. When this is the case, we recommend that the 
model be annotated with documentation of those parts of the ROI where segmentation quality may be limited.

Image interpretation Medical images acquired for a clinical indication should be interpreted with the interpretation being incorporated into the patient medical record. The interpretation should include the ROI being considered for printing. Often, interpretation of the ROI incorporates $3 \mathrm{D}$ visualization to enable or enhance diagnosis. Examples of 3D visualization include multi-planar reformatting, maximum intensity projections, and volume rendering. Such interpretations are currently billable in the United States under CPT codes 76376 and 76377.

\section{Image data preparation and manipulation Image segmentation}

Image segmentation is necessary to create $3 \mathrm{D}$ printable files from medical images. The segmentation process, which subdivides medical images into anatomical regions, typically begins by importing a set of DICOM images into dedicated image post-processing software. Anatomical regions are selected using a combination of automated and semi-automated tools. Once the desired ROI for 3D printing has been selected, data is interpolated and a surface-based 3D model which describes the $3 \mathrm{D}$ geometry of that volume is calculated. To date, the most common, widely used, and accepted file format for medical 3D printed objects is the STL file.

STL files are composed of triangular faces, and the number of these faces can affect anatomical accuracy of a model. Each lab should determine the appropriate number of faces/triangles for their medical models to adequately represent anatomy. Operators should be aware of any reduction, smoothing, or further file manipulation or optimization within the segmentation software when creating and exporting the STL file.

The contours of the STL file should be routinely checked against the source medical imaging data; typical segmentation software packages allow the final STL to be re-imported and its contours displayed over the original DICOM images. This option can be used to verify the surface accuracy of an anatomical model STL file. Additional file formats noted above should also meet the same criteria.

\section{Segmentation and Computer Aided Design (CAD) software}

Medical image processing software is required to generate a file format amenable to 3D printing. The RSNA 3D printing SIG concurs with the FDA that software that has been favorably evaluated by the FDA be used to translate medical images into formats amenable to $3 \mathrm{D}$ printing for all aspects of patient care, defined by the SIG as all interactions with healthcare professionals, or patients and their families, related to medical care. The
SIG recommends that software used for segmentation is FDA cleared to produce 3D Printed models suitable for diagnostic use, specifically using the FDA definition of diagnostic use and noting that FDA cleared software for $3 \mathrm{D}$ printed models will also include machines and materials validated for this intended use. At the time of manuscript submission, the FDA has approved one complete system, consisting of software through the printing process, for medical model production.

\section{File storage and descriptors}

Files stored within a repository should contain or be linked to a set of corresponding descriptors, including those pertaining to image acquisition and further imaging processing. Descriptors should be supported by standardized terminology from a consensus vocabulary; the SIG acknowledges that this vocabulary represents a current, unmet need. If the descriptors are not within digital files, this information should be otherwise archived.

\section{Reference to file manipulation and alteration}

Data from medical images undergo alterations in the design of the physical model. These changes have been categorized into Minor and Major alterations [578], with the latter generally representing changes that could impact clinical care. When modifications include major changes, the operator should verify that both the digital file and 3D printed model is labeled/ identified appropriately.

\section{Generation of 3D printed model 3D printing}

There are many different 3D printing technologies, each differing in the way that the final 3D printed model is created. When $3 \mathrm{D}$ printed models are generated from medical images, the resolution of the $3 \mathrm{D}$ printer should be equal to, or superior to that of the clinical images used to segment the model. Similar to the DICOM acquisition stage, it is preferable that printed layers be a multiplier of the smallest geometry of interest. For example, if the smallest anatomical object of interest on the $3 \mathrm{D}$ model is $1 \mathrm{~mm}$, this object should be printed on at least 3 layers of the model. Due to the nature of medical models, and the need for sub-millimeter accuracy, a layer thickness of no more than one-third of a millimeter is recommended, and preferably less than or equal to one-eighth of a millimeter. In addition to the layer thickness of the 3D printing hardware, the in-plane $(x-y)$ resolution should be known, with a target of less than one-quarter of a millimeter. The values above are global recommendations may not be applicable in all cases. If a model requires a higher or lower accuracy, these parameters should be modified accordingly. 
The medical model should include a patient identifier or an internal unique identification number that can be tracked back to the patient and date of the image acquisition. Labels can be incorporated (3D printed) into the model itself. Labels should be externally attached to the model if size or location does not allow for printed labeling. Printed models are assumed to be of anatomic size (1:1) unless a scaling factor is otherwise noted. Additional identifiers such as model sidedness (left, right) should be noted, as appropriate. Institutional guidelines should be used to verify models are free of protected health information, or models are handled appropriately in accordance to Health Insurance Portability and Accountability Act (HIPAA) guidelines.

\section{Post-processing printed models}

Post-processing steps should not alter the intended morphology and desired accuracy of the part, but instead should only enhance the utility (including clarity and transparency) and/or durability of the model. It should be noted that finishing may slightly alter the dimensional accuracy of a part, but this variation should be minimal (or within the desired global accuracy of the part) and the benefits (for example: strength and clarity) should outweigh the dimensional change. All support materials and residual manufacturing materials and/or substances should be removed as completely as possible. If all supporting material is not capable of being removed, this should be noted and presented to the requesting provider. Should the model be damaged either during or after post-processing and cleaning, repairs should be performed in a manner that reconstitutes the quality to which the original model adhered. If these repairs are not possible, the model should be reprinted. Any damage should be noted to the provider and the option to reprint should be presented. Cleaning solution concentration and saturation levels should be monitored and maintained in accordance to manufacture recommendations.

\section{Model inspection}

The model should be inspected by the $3 \mathrm{D}$ printing laboratory before clinical use. For cases where the model may be limited by a known image artifact, the model will be noted with any areas of concern. Qualitative and/or quantitative measures to confirm that the $3 \mathrm{D}$ printed model matches the desired input data will be taken, including but not limited to expert subjective assessment and objective fitting to the original volume submitted for printing. This can be done on a per part basis, per build basis, or in accordance with an additional internal protocol of the 3D lab. Some examples of qualitative assessments could include comparing the model to a digital representation or printed picture of the model and inspecting the model for printing imperfections or inaccuracies. Some examples of quantitative inspections could include measurements of a test specimen, measurements of the model, or scanning and comparing the model back to the original DICOM data sets.

\section{The U.S. Food and Drug Administration (FDA)}

The U.S. Food and Drug Administration (FDA) ensures the safety and efficacy of personalized devices in the United States of America. 3D Printing falls under the auspices of The Center for Devices and Radiological Health (CDRH). There have been four FDA benchmarks related to $3 \mathrm{D}$ printing and medical devices from 2014 to 2018.

First, in October 2014, the FDA held a public workshop entitled "Additive Manufacturing of Medical Devices: An Interactive Discussion on the Technical Considerations of 3D Printing". Second, the FDA published "Additively Manufactured Medical Products The FDA Perspective" [579]. Third, in December 2017, the FDA published "Technical Considerations for Additive Manufactured Devices" [580]. This perspective included insights regarding 3D printing data manipulation and hardware for modeling patient-specific anatomy. Fourth, the FDA commented on the publication "Maintaining Safety and Efficacy for 3D Printing in Medicine" [578]. This paper uses a similar, logical 3-step format of these consensus recommendations, and then develops different suggestions for regulatory models that depend on how much, if at all, the anatomical data is modified before 3D printing. On August 31st, 2017, the RSNA SIG and the FDA engaged in a joint meeting to discuss 3D printed anatomic models. The intended output of this meeting is a co-published white paper that will form the next benchmark.

\section{Quality control program}

Due to environmental factors and material properties, model morphology is expected to change over time. As part of a complete quality control program, 3D printers should undergo regular accuracy testing, including test prints, preventative maintenance, and recalibration [581, 582]. Laboratories may develop a process using a phantom to ensure regular quality standards for their printers. If the reference standard is known or assumed, mathematical operations [583] can be applied equally to those volumes in the ROI to determine the overall accuracy of the model, including not only potential manual errors from segmentation, but also generation of the final data set including digital post-processing steps such as smoothing.

\section{Delivery and discussion with referring physicians}

3D printed models represent an advanced form of communication of the data in medical images, and may 
include the summation of data from multiple sources. Extensive multidisciplinary teaching opportunities for 3D printing have been realized [584-586]. Physicians should have an opportunity to discuss the salient features and intended use of all models. Any concerns about the model or segmentation process, if not discussed previously, should be noted to the provider at the time of delivery. Where possible, annotations detailing critical points of model anatomy should be stored both within the digital record of the model, and physically placed on the 3D printed model. One example is annotation of a subtle fracture that may not otherwise be represented in either or both, the segmented, or the $3 \mathrm{D}$ printed model.

\section{Pre-operative planning}

"Pre-operative planning" with 3D printing refers to virtual surgical planning (also called digital templating, digital surgical planning, virtual planning, computerized planning, computer-assisted surgical simulation). This detailed planning of the intervention occurs in the digital space. There are times when the simulation itself is the end product, and the interventionist acquires valuable information regarding patient anatomy and medical devices to be used to increase confidence and knowledge before surgery. For these cases the digital plan is transferred to patient care by way of 3D printed templates, guides, or models. This type of planning usually involves major changes to the digital model while utilizing original patient contours. This necessitates the systematic application of the 3D printing recommendations outlined above to the models used for virtual surgical planning as a minimum requirement.

\section{Material biocompatibility, cleaning, and sterilization}

For anatomical models and surgical guides/templates/ jigs potentially entering a surgical field, material biocompatibility, cleaning, and sterilization are vitally important. The details are beyond the scope of this document. However, biocompatibility of materials depends on several factors including base material, the $3 \mathrm{D}$ printing process (and any variations), any post-processing techniques, and hospital cleaning and sterilization methods and requirements. Manufacturers should provide cleaning recommendations and specifications for materials which have been formally tested for biocompatibility and sterility, and these specifications should be followed by the facility. Additional internal sterilization policies may exist depending on the hospital.

\section{Appropriateness of 3D printing (anatomic modeling) for selected clinical scenarios}

This section provides evidence-based guidelines, supplemented by expert opinion when there is a paucity of peer-review data, to define and support the use of 3D printing for patients with a variety of conditions, including congenital heart, vascular, craniomaxillofacial, musculoskeletal, genitounirary, and breast pathologies (Table 1).

\section{Discussion}

Reviews that include the types of 3D printers commonly used in medicine have been published [563, 584]. Regarding image post-processing and software, several tutorials are available for step-by-step training. The following discussion includes the specific descriptions from the SIG writing group for each clinical group of clinical scenarios considered for appropriateness.

\section{Congenital heart disease}

Congenital heart diseases (CHD) are the most common significant birth defects. Substantial literature supports the benefit of $3 \mathrm{D}$ printing for patients with congenital heart disease [1-7]. Regarding improved outcomes, precise preoperative understanding of the complex anatomy from a printed model may obviate or shorten lengthy exploration, and therefore operation and cardiopulmonary bypass time can be reduced.

These recommendations utilize and conform to the CHD nomenclature defined by the European Association for Cardio-Thoracic Surgery / Society of Thoracic Surgery (EACTS-STS) version of the International Pediatric and Congenital Cardiac Code (IPCCC), except as where noted otherwise. The clinical scenarios defined by the IPCCC include the following: Septal Defects, Pulmonary Venous Anomalies, Cor Triatriatum, Pulmonary Venous Stenosis, Right Heart Lesions, Left Heart Lesions, Single Ventricle, Transposition of the Great Arteries, DORV, DOLV.

Structured searches were performed using the US National Library of Medicine (PubMed), which enabled the querying and retrieval of appropriate clinical documents supporting the appropriateness of 3D printing-enabled technologies for each specific diagnosis. The search results were reviewed by experts and some references were removed and some were relocated to different categories. As noted above, references outside of the structured searches were added but noted and approved by the writing group. As a general rule, the benefits of 3D printing to define and rehearse an intervention increase with the overall degree of complexity of disease.

\section{Craniomaxillofacial pathologies}

The International Classification of Diseases, Tenth Revision (ICD-10) [555] descriptions and categorization were used to categorize the clinical scenarios for rating craniomaxillofacial conditions. Four major groups were used as the starting point; 1) Craniomaxillofacial Trauma, 2) Congenital 
Table 1 Ratings Summary: Appropriateness Guidelines (scoring system defined in Methods) for patients who present with a variety of medical conditions, and for whom 3D Printing is often considered

\begin{tabular}{|c|c|c|}
\hline Scenario & Rating & References \\
\hline \multicolumn{3}{|l|}{ Congenital Heart Disease } \\
\hline Atrial Septal Defect, Large & 2 & \multirow[t]{2}{*}{$1-7$} \\
\hline Atrial Septal Defect, Small or Spontaneously Closed & 3 & \\
\hline Ventricular Septal Defect, Complex & 5 & \multirow[t]{3}{*}{$8-16$} \\
\hline Ventricular Septal Defect, Large Noncomplex & 3 & \\
\hline Ventricular Septal Defect, Small & 3 & \\
\hline Atrioventricular Canal & 4 & - \\
\hline Aortopulmonary Window & 6 & - \\
\hline Truncus Arteriosus & 9 & - \\
\hline Partial Anomalous Pulmonary Pulmonary Venous Connection (PAPVR) & 8 & - \\
\hline Total Anomalous Pulmonary Venous Connection (TAPVR) & 8 & - \\
\hline Cor Triatriatum & 6 & - \\
\hline Pulmonary Venous Stenosis & 3 & - \\
\hline Tetralogy of Fallot, NOS & 6 & \multirow[t]{2}{*}{$11,17,18$} \\
\hline Tetralogy of Fallot, with major aortopulmonary collateral arteries & 7 & \\
\hline Tricuspid Valve Disease and Ebstein's Anomaly & 4 & - \\
\hline RVOT Obstruction and/or Pulmonary Stenosis & 4 & 12,16 \\
\hline Hypoplastic Left Heart Syndrome & 5 & $9-11,19-24$ \\
\hline Shone's syndrome & 5 & - \\
\hline Double Inlet Left Ventricle & 7 & - \\
\hline Double Inlet Right Ventricle & 7 & - \\
\hline Mitral atresia & 5 & - \\
\hline Tricuspid atresia & 4 & - \\
\hline Unbalanced AV canal & 7 & - \\
\hline Single ventricle (general) & 6 & $25-27$ \\
\hline Congenitally Corrected TGA (levo-TGA) & 7 & 23,28 \\
\hline Transposition of the Great Arteries (dextro-TGA) & 7 & 29 \\
\hline Double Outlet Right Ventricle & 9 & $\begin{array}{c}9-12,19 \\
20,23 \\
24,30\end{array}$ \\
\hline Double Outlet Left Ventricle & 9 & - \\
\hline \multicolumn{3}{|l|}{ Craniomaxillofacial } \\
\hline Skull Fractures, Simple & 1 & \multirow[t]{2}{*}{$31-43$} \\
\hline Skull Fractures, Complex & 7 & \\
\hline Facial Fractures, Simple & 4 & \multirow{2}{*}{$\begin{array}{c}32,35-37,44- \\
69\end{array}$} \\
\hline Facial Fractures, Complex & 8 & \\
\hline Mandibular Fractures, Simple & 2 & \multirow{2}{*}{$\begin{array}{c}34,36,53,70- \\
87 \\
\end{array}$} \\
\hline Mandibular Fractures, Complex & 8 & \\
\hline Congenital Malformations of Skull \& Facial Bones, Simple & 5 & \multirow{2}{*}{$\begin{array}{c}32,33,53,60 \\
88-122\end{array}$} \\
\hline Congenital Malformations of Skull \& Facial Bones, Complex & 9 & \\
\hline Cleft Lip and Palate, Simple & 3 & \multirow[t]{2}{*}{$123-135$} \\
\hline Cleft Lip and Palate, Complex & 7 & \\
\hline Ear Malformations, Simple & 4 & \multirow[t]{2}{*}{$136-146$} \\
\hline Ear Malformations, Complex & 8 & \\
\hline Osteochondroplasias, Simple & 5 & \multirow[t]{2}{*}{$53,147-156$} \\
\hline Osteochondroplasias, Complex & 7 & \\
\hline Dentofacial Anomalies Including Malocclusion, Simple & 7 & \multirow[b]{2}{*}{\begin{tabular}{|c|}
$36,53,79,81$ \\
$92,93,98,99$ \\
$101-103,107$ \\
$108,110,117$ \\
120,123 \\
$157-201$ \\
\end{tabular}} \\
\hline Dentofacial Anomalies Including Malocclusion, Complex & 9 & \\
\hline Other Diseases of Jaws, Simple & 3 & \multirow[t]{2}{*}{$150,202-207$} \\
\hline Other Diseases of Jaws, Complex & 8 & \\
\hline Temporomandibular Joint Disorders, Simple & 1 & \multirow{2}{*}{$\begin{array}{c}32,36,208- \\
243\end{array}$} \\
\hline Temporomandibular Joint Disorders, Complex & 9 & \\
\hline Benign Neoplasms (Bone), Simple & 3 & \multirow[t]{2}{*}{244,245} \\
\hline Benign Neoplasms (Bone), Complex & 8 & \\
\hline Benign Neoplasms (Soft Tissue), Simple & 1 & - \\
\hline Benign Neoplasms (Soft Tissue), Complex & 4 & - \\
\hline Malignant Neoplasms (Bone), Simple & 7 & \multirow[b]{2}{*}{$\begin{array}{c}36,55,72,73, \\
82,88,107 \\
111,114,161 \\
202-205 \\
246-300\end{array}$} \\
\hline Malignant Neoplasms (Bone), Complex & 9 & \\
\hline Malignant Neoplasms (Soft Tissue), Simple & 3 & \multirow{2}{*}{$\begin{array}{c}55,150,204, \\
247-250,278, \\
279,287,290 \\
301,302\end{array}$} \\
\hline Malignant Neoplasms (Soft Tissue), Complex & 8 & \\
\hline
\end{tabular}


Table 1 Ratings Summary: Appropriateness Guidelines (scoring system defined in Methods) for patients who present with a variety of medical conditions, and for whom 3D Printing is often considered (Continued)

\begin{tabular}{|c|c|c|}
\hline \multicolumn{3}{|l|}{ Genitourinary } \\
\hline Urolithiasis, Surgical Management & 7 & \multirow[t]{2}{*}{$303-309$} \\
\hline Urolithiasis, Medical Management & 1 & \\
\hline Renal Cancer (Including Malignant Cystic Neoplasms) & 9 & $308,310-324$ \\
\hline Renal Cysts (Benign) & 4 & - \\
\hline Lower Tract Tumors (Bladder and Urethra) & 3 & - \\
\hline Upper Tract Tumors (Pyelocalyceal Cavities and Ureter) & 3 & - \\
\hline Adrenal Disease & 3 & 325 \\
\hline Penile Cancer & 1 & - \\
\hline Testicular Cancer & 1 & - \\
\hline Prostate Cancer & 8 & $326-334$ \\
\hline Ovarian Disease, NOS & 1 & - \\
\hline Uterine and Cervical Disease, NOS & 6 & $335-342$ \\
\hline Vaginal Cancer & 1 & 339,343 \\
\hline Genitourinary Trauma & 1 & - \\
\hline Genitourinary Reconstruction & 4 & - \\
\hline Pediatric Infection and Reflux & 1 & 344 \\
\hline Pediatric Retroperitoneal Genitourinary Tumors & 7 & - \\
\hline \multicolumn{3}{|l|}{ Musculoskeletal } \\
\hline Simple Fracture & 1 & \multirow[t]{7}{*}{$345-406$} \\
\hline Acute Complex Long Bone Fracture & 2 & \\
\hline Acute Complex Intraarticular Fracture & 4 & \\
\hline Complex, Acetabular Fracture & 8 & \\
\hline Vertebral Fracture, Non-Pathological & 1 & \\
\hline Vertebral Fracture, Pathological & 4 & \\
\hline Fracture Malunion & 7 & \\
\hline Heterotrophic Ossification, NOS & 6 & - \\
\hline Ligamentous Injury, NOS & 2 & 407,408 \\
\hline Hip Dysplasia & 8 & $389,409-414$ \\
\hline Bone/Soft Tissue Neoplasm, With Joint \& Neurovascular Involvement & 8 & \multirow{2}{*}{$\begin{array}{c}324,353,415- \\
443\end{array}$} \\
\hline Bone/Soft Tissue Neoplasm, Without Joint \& Neurovascular Involvement & 6 & \\
\hline Arthritis, Not Otherwise Specified & 6 & $358,444-453$ \\
\hline Scoliosis, Secondary to Congenital Vertebral Anomaly & 7 & \multirow[t]{4}{*}{$438,454-463$} \\
\hline Scoliosis, Severe/Marked & 5 & \\
\hline Scoliosis, Thoracic Kyphosis & 3 & \\
\hline Scoliosis, None of the Above & 1 & \\
\hline \multicolumn{3}{|l|}{ Vascular } \\
\hline Aortic Dissection, Medical Management & 1 & \multirow[t]{6}{*}{$464-499$} \\
\hline Aortic Dissection, Interventional Management Consideration & 5 & \\
\hline Aortic Aneurysm, Medical Management & 1 & \\
\hline Aortic Aneurysm, Consideration for Endovascular vs Open Repair & 5 & \\
\hline Design of Patient-Specific Aortic Stents & 7 & \\
\hline Aortic Pseudoaneurysm & 5 & \\
\hline Peripheral Aneurysm, Medical Management & 1 & \multirow[t]{2}{*}{$500-505$} \\
\hline Peripheral Aneurysm, Consideration of Endovascular vs Open Repair & 5 & \\
\hline Stenosis, Patient-specific Simulations & 3 & $506-508$ \\
\hline Vascular Malformations, Medical Management & 1 & \multirow[t]{5}{*}{509} \\
\hline Vascular Malformations, Interventional Consideration, Acquired & 4 & \\
\hline Vascular Malformations, Interventional Consideration, Congenital & 6 & \\
\hline Vascular Malformations, Interventional Consideration, Rings & 6 & \\
\hline Vascular Malformations, Interventional Consideration, Slings & 8 & \\
\hline Varices, Medical Management, Peripheral & 1 & \multirow[t]{3}{*}{-} \\
\hline Varices, Medical Management, Retroperitoneal & 3 & \\
\hline Varices, Intervention Planning & 5 & \\
\hline Carotid, Stenosis & 1 & \multirow[t]{4}{*}{$510-514$} \\
\hline Carotid, Dissection & 1 & \\
\hline Carotid, Pseudoaneurysm & 4 & \\
\hline Carotid, Post-endarterectomy & 1 & \\
\hline Intracranial Stenosis & 3 & \multirow[t]{4}{*}{$501,515-545$} \\
\hline Intracranial Aneurysm & 5 & \\
\hline Intracranial Dural AV Fistula & 3 & \\
\hline Intracranial Arteriovenous Malformation & 3 & \\
\hline \multicolumn{3}{|l|}{ Breast } \\
\hline Benign Breast Lesions & 1 & - \\
\hline High-Risk Breast Lesions & 5 & - \\
\hline Breast Cancer & 6 & $546-552$ \\
\hline
\end{tabular}


Malformations, 3) Acquired/Developmental Deformities and 4) Neoplasms. Further sub-groups were formed underneath the major groupings. Additional clarification for "simple" versus "complex" diagnoses within a particular group was given based on inherent differences in appropriateness ratings between subgroups of patients in these groups. Further language describing each diagnostic grouping helps describe the difference between a simple and a complex case in each subcategory.

Structured searches were performed using the US National Library of Medicine (PubMed), which enabled the querying and retrieval of appropriate clinical documents supporting the appropriateness of 3D printing-enabled technologies for a specific condition. The search results were reviewed by experts and some references were removed because they were not relevant. A small number of references were added because they were found to be relevant, but not appearing using the stated search string. As noted above, these were vetted by the writing group before inclusion. Clinical scenarios that were only dental or only brain have not been included. The authors recognize that these include many important clinical scenarios of for 3D printing, and the goal is to include them in upcoming documents.

Craniomaxillofacial (CMF) conditions for the purposes of this document encompass several different surgical specialties all working in the head and neck area with both pediatric and adult patients. These include oral and maxillofacial surgery, craniofacial surgery, plastic surgery, microvascular surgery, pediatric neurosurgery and otolaryngology. Use of 3D printing-enabled technologies to aid clinical care in the craniomaxillofacial area has been seen from the very advent of 3D printing in the late 1980s [556, 557]. Even before the commercialization of stereolithography there were surgeons, engineers and researchers figuring out more manual ways of converting medical imaging datasets into 3D models [558]. The fit seems clear, CMF surgery has both a functional component, and for most cases an aesthetic component, where the form carries importance along with the functional restoration. In the CMF arena, the use of anatomical models of anatomy is primarily derived from CT and MRI datasets, and also from an increasing volume of cone beam CT datasets. Patient-specific anatomical models are the baseline, but for many of these applications the value of these technologies has been found in either, a) patient-matched implants (for instance temporomandibular joint reconstruction), or b) virtual surgery combined with templates and guides (for instance orthognathic surgery). The scenarios to follow were thought of in this way, with some of them relying heavily on anatomical models alone and some of them relying with increasing importance on the role that digital planning combined with patient-matched implants or templating is playing.

\section{Genitourinary pathologies}

The genitourinary conditions have been organized anatomically, recognizing that common genitourinary interventions are largely based on anatomic considerations. The complication rate after major genitourinary surgeries is reflected in the complexity of the lesion. For example, more complex kidney tumors are associated with longer operative times, warm ischemia times, and greater blood loss [559]. High kidney tumor complexity can also be correlated to the risk of major postoperative complications requiring a secondary intervention [560].

There is a growing body of literature that supports the benefits to patients from 3D printed models. Specifically, 3D printed models may improve comprehension of anatomy and facilitate pre-surgical planning for complex surgical cases, ultimately reducing operation times and improving patient outcomes.

This document describes and provides rating for the clinical scenarios related to 3D printing of genitourinary pathology [561, 562]. Structured searches were performed using the US National Library of Medicine (PubMed), which enabled the querying and retrieval of appropriated clinical documents supporting the appropriateness of $3 \mathrm{D}$ printing for a specific diagnosis. As a general rule, the benefits of $3 \mathrm{D}$ printing to define and rehearse a genitourinary intervention increases with the overall degree of complexity of the pathology that is represented by the physical model based on a medical imaging study performed in a radiology department.

\section{Musculoskeletal pathologies}

The role of 3D printed models in addressing musculoskeletal pathologies can vary depending on a specific clinical scenario, ranging from aiding in informed consent to use in preoperative planning. Custom fixation plates, surgical osteotomy guides and implants can also be generated from 3D data, allowing for virtual surgery and design of a custom implant that is modeled after the contralateral healthy side. In addition, mock surgeries can be performed on the physical 3D models, allowing for more intuitive problem solving and measurements preoperatively. Such planning alters surgical management for some patients, either by delaying intervention, or by suggesting an alternative approach. Pre-surgical planning can also decrease operating room time and the number of devices and tools that need to be tried and subsequently wasted and/or re-sterilized. In this sense, 3D printing has proven useful for demonstrating musculoskeletal pathology and for planning interventions.

Based on the accumulating evidence, the use of 3D printed models can positively impact numerous metrics 
associated with musculoskeletal interventions, including patient and physician satisfaction, operative time, blood loss, and the various direct and indirect costs associated with patient-centered decision making regarding management of complex disease. At present, the musculoskeletal pathologies with potential and established 3D printing-enabled management have been broadly categorized into fractures, chronic osseous abnormalities, degenerative disorders, neoplastic pathologies, scoliosis, and miscellaneous specific applications including ligamentous injury and heterotopic ossification.

\section{Vascular pathologies}

3D printing has been shown to be useful for understanding the vascular anatomy, evaluation of hemodynamics, treatment planning (surgical and endovascular) as well as preclinical testing of devices. It has also been used for medical education and procedural training on vascular models [563-566]. There are several clinical scenarios for which $3 \mathrm{D}$ printing has been used in the care of patients with vascular disease. Because of the nature of vascular pathology, dissection, aneurysm, and stenosis are often treated with medical management and "watchful waiting"; most patients follow this algorithm, and there is little to no role for 3D printing. However, some patients have a clinical presentation and non-invasive tests that warrant intervention, while others progress from watchful waiting to planned intervention. For many of these patients, 3D printing is appropriate. Of note, coronary $3 \mathrm{D}$ printing, and cardiac printing in general falls outside the scope of this document. These clinical scenarios will be discussed in future documents.

Most aortic dissections are treated medically, and for these patients there is no indication for 3D printing. However, 3D printing may be appropriate for planning intervention in complex dissections, and in particular dissections that also have enlargement. Models have been used for planning and simulation of stent deployment [495]. Simulation on models can help in identifying the best projections for angiography, best catheter and wire combinations to navigate the anatomy, in for determining appropriate balloon and stent size as well as position.

Endovascular repair of complex aortic aneurysm involving the origin of branches, extreme angulations, complex neck anatomy, and short landing zones can be quite challenging. Use of 3D printed models can aid understanding of complex anatomy, device selection, and design of prosthesis best suited for patient's anatomy. These models have shown to be useful in planning procedures and increase operator confidence [491]. 3D printed models have also been used to precisely place fenestrations on stent grafts to treat complex aneurysms $[479,567]$. In addition, graft replicas can be tested on patient specific 3D model for suitability before being deployed in patients.

Aortic surgeries, especially in the region of aortic arch and upper abdominal aorta can be quite challenging due to origin of branches, angulation and complex aneurysm neck anatomy. 3D printed models have shown to improve surgeons' understanding of anatomy and help preoperative planning [485]. Further, 3D printed models can potentially also be used to plan and simulate surgical and endovascular interventions on visceral aneurysms [502, 503]. These models can also be used for designing [486] and testing [568, 576] endovascular devices like catheters, coils, balloons, and stents.

\section{Breast pathologies}

Breast cancer is the most common solid malignancy in women in the United States [570]. The overall lifetime risk of developing breast cancer for women in the United States is $12.4 \%$. Advancements in diagnostic tests and treatments have led to decreasing death rates of $1.8 \%$ per year from 2005 to 2014 [ 570,571$]$. Understanding the extent of disease at the time of diagnosis allows appropriate staging and determination of prognosis and survival, in addition to selection of suitable surgical options [572]. Benefits from 3D printed models and its role as an aid to clinical care has been increasingly described in the literature. 3D printed models have the ability of depicting the extent of disease and relationships of sensitive anatomy, thereby possibly reducing operating time, enhancing utilization of new oncoplastic techniques, and improving patient outcomes.

Benign breast diseases are common and include a wide range of entities [573]. The most common of these entities, fibrocystic change, is clinically observed in up to $50 \%$ of women and found histologically in $90 \%$ of women [573]. Fibroadenomas are the next most common benign breast disease occurring in 15-23\% of women [574]. Surgical management of these entities may be needed in cases where cosmesis is altered or when symptom relief is needed. Surgical management may impact developing breast tissue in young women leading to alterations in its proper development [575]. Therefore, careful understanding of the anatomy may minimize the deleterious effects of surgery in benign breast disease.

\section{Conclusions}

3D printing will play an increasingly important role in enabling precision medicine. This document addresses the clinical scenarios where pathology complexity necessitates a transformation of clinical imaging data into a physical model. Adoption of common clinical standards regarding appropriate use, information and material management, 
and quality control are needed to ensure the greatest possible clinical benefit from3D printing.

This work provides the first comprehensive literature-based guideline document regarding the implementation of 3D printing in clinical practice and details the appropriate scenarios for numerous clinical applications of $3 \mathrm{D}$ printing. It is anticipated that this consensus guideline document, created by the members of the RSNA 3D printing special group, will provide the initial reference for method and clinical application standardization. The document and will be substantially expanded and refined, based on expanding clinical applications.

\section{Appendix}

Search Methodology and Search Results

Structured searches were performed using the US National Library of Medicine (PubMed), which enabled the querying and retrieval of appropriated clinical documents regarding the appropriateness of $3 \mathrm{D}$ printing in each of the scenarios.

Congenital Heart Disease (Retrieved August 2017)

Atrial Septal Defect (ASD): Large; small or spontaneously closed

PubMed Search: ((3D printing) AND (ASD)) OR ((rapid prototyping) AND (ASD)) OR ((3D printing) AND (atrial septal defect)) OR ((rapid prototyping) AND (atrial septal defect))

Results: [1-7]

Ventricular Septal Defect (VSD): complex; large (noncomplex); small

PubMed Search: ((3D printing) AND (VSD)) OR ((rapid prototyping) AND (VSD)) OR ((3D printing) AND (ventricular septal defect)) OR ((rapid prototyping) AND (ventricular septal defect))

Results: [8-16]

Atrioventricular Canal (AV Canal)

PubMed Search: ((3D printing) AND (AVSD)) OR ((rapid prototyping) AND (AVSD)) OR ((3D printing) AND (atrioventricular septal defect)) OR ((rapid prototyping) AND (atrioventricular septal defect)) OR ((3D printing) AND (AV Canal)) OR ((rapid prototyping) AND (AV Canal)) OR ((3D printing) AND (atrioventricular canal)) OR ((rapid prototyping) AND (atrioventricular canal))

Results: None

\section{Aortopulmonary window (AP Window)}

PubMed Search: ((3D printing) AND (AP window)) OR ((rapid prototyping) AND (AP Window)) OR ((3D printing) AND (aortopulmonary window)) OR ((rapid prototyping) AND (aortopulmonary window))

Results: None

Truncus Arteriosus
PubMed search: ((3D printing) AND truncus) OR ((rapid prototyping) AND truncus)

Results: None

Partial Anomalous Pulmonary Venous Connection (PAPVR)

PubMed search: ((3D printing) AND (Anomalous pulmonary)) OR ((rapid prototyping) AND (Anomalous pulmonary)) OR ((3D printing) AND TAPVR) OR ((rapid prototyping) AND TAPVR) OR ((3D printing) AND PAPVR) OR ((rapid prototyping) AND PAPVR)

Results: None

Total Anomalous Pulmonary Venous Connection (TAPVR)

PubMed search: ((3D printing) AND (Anomalous pulmonary)) OR ((rapid prototyping) AND (Anomalous pulmonary)) OR ((3D printing) AND TAPVR) OR ((rapid prototyping) AND TAPVR) OR ((3D printing) AND PAPVR) OR ((rapid prototyping) AND PAPVR)

Results: None

Cor Triatriatum

PubMed search: ((3D printing) AND (Cor Triatriatum)) OR ((rapid prototyping) AND (Cor Triatriatum))

Results: None

\section{Pulmonary Venous Stenosis}

PubMed search: ((3D printing) AND (pulmonary venous stenosis)) OR ((rapid prototyping) AND ((pulmonary venous stenosis)) OR ((3D printing) AND (pulmonary vein stenosis)) OR ((rapid prototyping) AND ((pulmonary vein stenosis))

Results: None

Tetralogy of Fallot (TOF): NOS; accompanied with major aortopulmonary collateral arteries

PubMed search: ((3D printing) AND TOF) OR ((rapid prototyping) AND TOF) OR ((3D printing) AND tetralogy) OR ((rapid prototyping) AND tetralogy)

Results: $[11,17]$ Outside of Search, suggested by SIG Members: [18]

Tricuspid Valve Disease and Ebstein's Anomaly

PubMed search: ((3D printing) AND ebstein) OR ((rapid prototyping) AND ebstein) OR ((3D printing) AND ebsteins) OR ((rapid prototyping) AND ebsteins) OR ((3D printing) AND ebstein's) OR ((rapid prototyping) AND ebstein's) OR ((3D printing) AND (tricuspid valve disease)) OR ((rapid prototyping) AND (tricuspid valve disease))

Results: None

RVOT Obstruction and/or Pulmonary Stenosis

PubMed search: ((3D printing) AND (RVOT obstruction)) OR ((rapid prototyping) AND (RVOT obstruction)) OR ((3D printing) AND (pulmonary stenosis)) OR ((rapid prototyping) AND (pulmonary stenosis))

Results: $[12,16]$

Hypoplastic Left Heart Syndrome

PubMed search: ((3D printing) AND HLHS) OR ((rapid prototyping) AND HLHS) OR ((3D printing) 
AND (hypoplastic left)) OR ((rapid prototyping) AND (hypoplastic left))

Results: [9-11, 19-24]

\section{Shone's Syndrome}

PubMed search: ((3D printing) AND shones) OR ((rapid prototyping) AND shones) OR ((3D printing) AND shone's) OR ((rapid prototyping) AND shone's)

Results: None

\section{Double Inlet Left Ventricle}

PubMed search: ((3D printing) AND DILV) OR ((rapid prototyping) AND DILV) OR ((3D printing) AND (double inlet left)) OR ((rapid prototyping) AND (double inlet left))

Results: None

\section{Double Inlet Right Ventricle}

PubMed search: ((3D printing) AND DIRV) OR ((rapid prototyping) AND DIRV) OR ((3D printing) AND (double inlet right)) OR ((rapid prototyping) AND (double inlet right))

\section{Results: None}

\section{Mitral atresia}

PubMed search: ((3D printing) AND (mitral atresia))

OR ((rapid prototyping) AND (mitral atresia))

Results: None

\section{Tricuspid atresia}

PubMed search: ((3D printing) AND (tricuspid atresia)) OR ((rapid prototyping) AND (tricuspid atresia))

Results: None

\section{Unbalanced AV canal}

PubMed search: ((3D printing) AND unbalanced) OR ((rapid prototyping) AND unbalanced)

Results: None

Single ventricle (general)

PubMed search: ((3D printing) AND SV) OR ((rapid prototyping) AND SV) OR ((3D printing) AND (single ventricle)) OR ((rapid prototyping) AND (single ventricle))

Results: [25-27]

\section{Congenitally Corrected TGA (levo-TGA)}

PubMed search: ((3D printing) AND (L-TGA)) OR ((rapid prototyping) AND (L-TGA)) OR ((3D printing) AND LTGA) OR ((rapid prototyping) AND LTGA) OR ((3D printing) AND (levo-transposition)) OR ((rapid prototyping) AND (levo-transposition)) OR ((3D printing) AND (l-transposition)) OR ((rapid prototyping) AND (1-transposition)) OR ((3D printing) AND CCTG A) OR ((rapid prototyping) AND CCTGA) OR ((3D printing) AND (CC-TGA)) OR ((rapid prototyping) AND (CC-TGA)) OR ((3D printing) AND (congenitally corrected transposition)) OR ((rapid prototyping) AND (congenitally corrected transposition)) OR ((3D printing) AND (congenitally corrected transposition)) OR ((rapid prototyping) AND (congenitally corrected transposition)) OR ((3D printing) AND (CC-transposition)) OR ((rapid prototyping) AND (CC-transposition))
Results: $[23,28]$

Transposition of the Great Arteries (dextro-TGA)

PubMed search: ((3D printing) AND (D-TGA)) OR ((rapid prototyping) AND (D-TGA)) OR ((3D printing) AND DTGA) OR ((rapid prototyping) AND DTGA) OR ((3D printing) AND (dextro-transposition)) OR ((rapid prototyping) AND (dextro-transposition)) OR ((3D printing) AND (d-transposition)) OR ((rapid prototyping) AND (d-transposition))

Results: [29]

\section{Double Outlet Right Ventricle}

PubMed search: ((3D printing) AND DORV) OR ((rapid prototyping) AND DORV) OR ((3D printing) AND (double outlet)) OR ((rapid prototyping) AND (double outlet))

Results: [9-12, 19, 20, 23, 24, 30]

\section{Double Outlet Left Ventricle}

PubMed search: ((3D printing) AND DOLV) OR ((rapid prototyping) AND DOLV) OR ((3D printing) AND (double outlet left)) OR ((rapid prototyping) AND (double outlet left))

Results: None

Craniomaxillofacial (Retrieved August 2017)

Skull Fractures: Fractures of the cranium include the frontal bone, frontal sinus, parietal, sphenoid, temporal, occipital and mastoid bone. Simple fractures would be non-displaced and may not need surgery. Complex fractures may be comminuted and most likely require surgery early for decompression and/or later for cranial reconstruction. Any violation of the dura or brain requires immediate surgery. ICD-10: S02.0 Fracture of Vault of Skull, S02.1 Fracture of Base of Skull

PubMed Search: ((3D Printing) AND (Skull Fracture)) OR ((Rapid Prototyping) AND (Skull Fracture))

Results: [31-43]

Facial Fractures: Description: Facial fractures include fractures of the maxilla, zygoma, nasal bones, and frontal bone in addition to the orbit, which is composed of the orbital surface of the maxillary bone, lamina papyracea of the ethmoid bone, lacrimal bone, greater and lesser wings of the sphenoid bone, orbital process of the zygomatic bone, the orbital process of the palatine bone, and the pars orbitalis of the frontal bone. Non-displaced fractures often heal uneventfully and may be managed non-surgically. Displaced fractures---either linear or comminuted---generally require operative repair to avoid functional or esthetic complications. High energy injuries, such as those seen with unrestrained motor vehicle collisions or gunshot wounds, often result in greater three-dimensional disruption and displacement than low energy injuries, which are often the result of assaults and ground level falls. Patient-matched implants may be required for reconstruction of complex injuries, particularly those involving the orbit and zygoma. 
ICD-10: S02.2 Fracture of Nasal Bones, S02.3 Fracture of Orbital Floor, S02.4 Fracture of Malar, Maxillary and Zygoma Bones

PubMed Search: ((3D Printing) AND (Facial Fracture)) OR ((Rapid Prototyping) AND (Facial Fracture))

Results: [31-43]

Mandible Fractures: Mandible fractures include fractures to the condyle, ramus, coronoid process, mandibular angle, body of the mandible or symphysis. Linear fractures are likely to be less three-dimensional as compared to comminuted fractures, which are often significantly displaced. Depending on the complexity of the fracture, the degree of dislocation and the location, open reduction and internal fixation with titanium plates and screws may be required. Secondary reconstruction of complex post-traumatic deformity may also require patient-matched implants. ICD-10: S02.6 Fracture of Mandible (body), S02.61 Fracture of Condylar Process of Mandible, S02.62 Fracture of Subcondylar Process of Mandible, S02.63 Fracture of Coronoid Process of Mandible, S02.64 Fracture of Ramus of Mandible, S02.65 Fracture of Angle of Mandible, S02.66 Fracture of Symphysis of Mandible

PubMed Search: ((3D Printing) AND (Mandible Fracture)) OR ((Rapid Prototyping) AND (Mandible Fracture))

Results: [32, 35-37, 44-69]

Congenital Malformations of Skull \& Facial Bones: Syndromal or non-syndromal cases characterized mainly by anomalies which may vary from mild to severe and may present with asymmetric involvement of the skull and facial bones. In simple craniosynostosis one or more sutures may be involved. In complex or syndromal craniosynostosis patients may be programmed genetically to grow abnormally and require repeated surgical operations until growth is complete including cranial vault, facial-orbital advancement including maxillae and mandible surgery after eruption of the secondary dentition. Congenital birth defects characterized by incomplete development or absence of face structures, usually affecting one side of the face. Simple cases would include those such as positional plagiocephaly which most likely involve non-surgical treatment. Complex cases for facial reconstruction (for craniofacial macrosomia or hypertelorism, for instance) or total vault reconstruction in an infant require extensive planning and surgical care. Secondary reconstruction in the growing child or adult may require continued surgical care as the skeleton develops further before reaching skeletal maturity. ICD-10: Q75.0 Craniosynostosis, Q75.1 Craniofacial Dysostosis, Q75.2 Hypertelorism, Q75.3 Macrocephaly, Q75.4 Mandibulofacial Dysostosis, Q75.5 Oculomandibular Dysostosis, Q67.0 Congenital Facial Asymmetry, Q67.3 Plagiocephaly

PubMed Search: ((3D Printing) AND (craniosynostosis)) OR ((Rapid Prototyping) AND (craniosynostosis)) OR ((3D
Printing) AND (Hypertelorism)) OR ((Rapid Prototyping) AND (Hypertelorism)) OR ((3D Printing) AND (Plagiocephaly)) OR ((Rapid Prototyping) AND (Plagiocephaly)) OR ((3D Printing) AND (Facial Asymmetry)) OR ((Rapid Prototyping) AND (Facial Asymmetry))

Results: [32, 33, 53, 60, 88-122]

Cleft Lip \& Palate: Cleft lip and cleft palate are birth defects that affect the upper lip, nose, alveolus, soft and or hard palate. The problem can range from a small notch in the lip (simple) to a unilateral or bilateral complete or incomplete involvement of lip, alveolar bone, soft and hard palate with displacement of the palatal muscles. The functional problems associated with cleft lip and/or palate include problems with eating, speech, and eustachian tube malfunction and middle ear effusion requiring grommet tube insertion into the ear drum. Growth may be abnormal requiring jaw surgery. Surgery involves alveolar bone grafting, lip and nose repair, palate repair including palatal muscle repair and closure of the palatal cleft. Later secondary surgery may be necessary. ICD-10: Q35.1 Cleft Hard Palate, Q35.3 Cleft Soft Palate, Q35.5 Cleft Hard Palate and Cleft Soft Palate, Q36.0 Cleft Lip, Bilateral, Q36.1 Cleft Lip, Median, Q36.9 Cleft Lip, Unilateral

PubMed Search: ((3D Printing) AND (Cleft Palate)) OR ((Rapid Prototyping) AND (Cleft Palate)) OR ((3D Printing) AND (Cleft Lip)) OR ((Rapid Prototyping) AND (Cleft Lip))

Results: [123-135]

Ear Malformations: Malformations of the ear can include missing portions of the ear, misshapen portions of the ear, malpositioned ears, large ears (macrotia) or small/missing ears (microtia). Simple cases may require surgical excision of extra tissue or a procedure to restrict prominence. Complex cases are typically very complex surgical cases and may require total auricular reconstruction with autogenous tissues. ICD-10: Q17.1 Macrotia, Q17.2 Microtia

PubMed Search: ((3D Printing) AND (Microtia)) OR ((Rapid Prototyping) AND (Microtia)) OR ((3D Printing) AND (Macrotia)) OR ((Rapid Prototyping) AND (Macrotia))

Results: [136-146]

Osteochondroplasias: Osteogenesis imperfecta (OI) is a genetic disorder in which bones break easily. Fibrous Dysplasia of the craniomaxillofacial skeleton may result in benign overgrowth of tissue which is fibrous and lacking calcium. Fibrous dysplasia may impact skeletal appearance but the complex cases begin to compromise other vital structures/organs such as the optic nerve and the brain. Simple cases of OI may include bony fractures which will be handled such as in the Trauma (Group A, II or III classification). Complex fibrous dysplasia cases can be very difficult surgically and require three- 
dimensional removal/sculpting of the mass while paying close attention to close-by vital structures. Surgical replacement of tumor resection can be very complex. ICD-10: Q78.0 Osteogenesis Imperfecta, Q78.1 Polyostotic Fibrous Dysplasia

PubMed Search: ((3D Printing) AND (Osteogenesis Imperfecta)) OR ((Rapid Prototyping) AND (Osteogenesis Imperfecta)) OR ((3D Printing) AND (Fibrous Dysplasia)) OR ((Rapid Prototyping) AND (Fibrous Dysplasia))

Results: [53, 147-156]

Dentofacial Anomalies Including Malocclusion: Dentofacial anomalies can include over or undergrowth of either the upper jaw (maxilla) or the lower jaw (mandible). Malocclusion happens when the teeth are not approximating in a way that allows for normal function and can be any combination of one jaw being smaller, larger or asymmetric as compared to the other. Simple cases may involve surgical repositioning of only one of the jaws and typically symmetrical movements. Complex cases typically involve bimaxillary surgery with highly complex movements of both jaws based upon the clinical and radiographic examination. ICD-10: M26.01 Maxillary hyperplasia, M26.02 Maxillary hypoplasia, M26.03 Mandibular hyperplasia, M26.04 Mandibular hypoplasia, M26.05 Macrogenia, M26.06 Microgenia, M26.07 Excessive tuberosity of jaw, M26.1 Anomalies of Jaw-Cranial Base Relationship, M26.11 Maxillary asymmetry, M26.211 Malocclusion Angle Class I, M26.212 Malocclusion Angle Class II, M26.213 Malocclusion Angle Class III, M26.22 Open Occlusal Relationship, M26.220 Open Anterior Occlusal Relationship, M26.221 Open Posterior Occlusal Relationship

PubMed Search: ((3D Printing) AND (Orthognathic Surgery)) OR ((Rapid Prototyping) AND (Orthognathic Surgery)) OR ((3D Printing) AND (Maxillary Hyperplasia)) OR ((Rapid Prototyping) AND (Maxillary Hyperplasia)) OR ((3D Printing) AND (Maxillary Asymmetry)) OR ((Rapid Prototyping) AND (Maxillary Asymmetry)) OR ((3D Printing) AND (Malocclusion)) OR ((Rapid Prototyping) AND (Malocclusion)) OR ((3D Printing) AND (Anterior Open Bite)) OR ((Rapid Prototyping) AND (Anterior Open Bite)) OR ((3D Printing) AND (Posterior Open Bite)) OR ((Rapid Prototyping) AND (posterior open bite)) OR ((3D Printing) AND (virtual surgical planning)) OR ((Rapid Prototyping) AND (virtual surgical planning))

Results: $[36,53,79,81,92,93,98,99,101-103,107$, $108,110,117,120,123,157-201]$

Other Diseases of Jaws: Other diseases of jaws include inflammatory, infectious, vascular or iatrogenic processes in which bone is remodeled or eroded, such as osteoradionecrosis and osteomyelitis. Bony lesions such as giant cell lesions and benign cysts may require partial resection of the jaw. Uncomplicated cases may require simple excision. Complicated and destructive lesions may involve segmental resection of the mandible or maxilla and reconstruction, typically with autogenous tissues supported by rigid fixation. Secondary reconstruction with patient-matched implants or further free flaps may be required for complex cases. ICD-10: M27.1 Giant Cell Granuloma, Central, M27.2 Inflammatory Conditions of Jaws (osteoradionecrosis, osteomyelitis, others), M27.3 Alveolitis of Jaws

PubMed Search: ((3D Printing) AND (Giant Cell Granuloma Jaw)) OR ((Rapid Prototyping) AND (Giant Cell Granuloma Jaw)) OR ((3D Printing) AND (Osteoradionecrosis)) OR ((Rapid Prototyping) AND (Osteoradionecrosis)) OR ((3D Printing) AND (Osteomyelitis)) OR ((Rapid Prototyping) AND (Osteomyelitis)) OR ((3D Printing) AND (Alveolitis)) OR ((Rapid Prototyping) AND (Alveolitis))

Results: [150, 202-207]

Temporomandibular Joint Disorders: Temporomandibular joint disorders relate to a variety of conditions affecting the anatomic and functional characteristics of the temporomandibular joint. Factors contributing to the complexity of temporomandibular diseases are its relation to dentition and mastication and the symptomatic effects in other areas which account for referred pain to the joint. Common diseases are developmental abnormalities, trauma, subluxation, luxation, arthritis, and neoplasia. Simple cases may not need surgical intervention or may require arthroscopy. Cases that involve loss or gain of vertical dimension in the condyle and result in loss of jaw function (malocclusion or range of motion) may require joint total joint replacement and will often rely on patient-matched implants for reconstruction of the joint(s). Complex conditions such as ankylosis of the joint require careful surgical intervention to avoid surrounding vital structures such as nerves and vasculature. ICD-10: M26.601 Right temporomandibular joint disorder, unspecified, M26.602 Left temporomandibular joint disorder, unspecified, M26.603 Bilateral temporomandibular joint disorder, unspecified

PubMed Search: ((3D Printing) AND (Temporomandibular Joint)) OR ((Rapid Prototyping) AND (Temporomandibular Joint)) OR ((Stereolithography) AND (Temporomandibular Joint)) OR ((CAD-CAM) and (Temporomandibular Joint))

Results: [32, 36, 208-243]

Benign Neoplasms (Bone): Bony benign neoplasms of the craniomaxillofacial area may involve the skull, maxilla, orbit, sinuses and mandible. These can range from simple cases where excision of a mass may be required to very complex cases requiring three-dimensional surgical excision and reconstruction. Reconstruction for complex cases may require autogenous tissue or a free flap and may at times also require patient-matched implants 
or fixation plates. ICD-10: D16.4 Benign neoplasm of bones of skull and face, D16.5 Benign neoplasm of lower jaw bone

PubMed Search: ((3D Printing) AND (Benign Facial Neoplasm)) OR ((Rapid Prototyping) AND (Benign Facial Neoplasm)) OR ((3D Printing) AND (Benign Jaw Neoplasm)) OR ((Rapid Prototyping) AND (Benign Jaw Neoplasm))

Results: [244, 245]

Benign Neoplasms (Soft Tissue): Benign soft tissue neoplasms of the craniomaxillofacial area include lesions of parotid or salivary glands, the lip, the floor of mouth, other parts of the mouth, tonsil, oropharynx, nasopharynx and hypopharynx. Other cutaneous lesions include neurofibromas, gliomas, dermoids, hemangiomas, lymphangiomas and many other rarer tumors. Diagnosis and excision is indicated in all these lesions when possible. Complex cases can include resection and reconstruction of soft tissue and hard tissue concomitantly. Reconstruction for complex cases may require autogenous tissue or a free flap and may at times also require patient-matched implants or rigid fixation. ICD-10: D11.0 Benign neoplasm of parotid gland, D11.7 Benign neoplasm of other major salivary glands, D10.0 Benign neoplasm of lip, D10.1 Benign neoplasm of tongue, D10.2 Benign neoplasm of floor of mouth, D10.3 Benign neoplasm of other and unspecified parts of mouth, D10.4 Benign neoplasm of tonsil, D10.5 Benign neoplasm of other parts of oropharynx, D10.6 Benign neoplasm of nasopharynx, D10.7 Benign neoplasm of hypopharynx, D10.9 Benign neoplasm of pharynx, unspecified

PubMed Search: ((3D Printing) AND (Benign Parotid Neoplasm)) OR ((Rapid Prototyping) AND (Benign Parotid Neoplasm)) OR ((3D Printing) AND (Benign Salivary Gland Neoplasm)) OR ((Rapid Prototyping) AND (Benign Salivary Gland Neoplasm)) OR ((3D Printing) AND (Benign Neoplasm Tonsil)) OR ((Rapid Prototyping) AND (Benign Neoplasm Tonsil)) OR ((3D Printing) AND (Benign Neoplasm Oropharynx)) OR ((Rapid Prototyping) AND (Benign Neoplasm Oropharynx)) OR ((3D Printing) AND (Benign Neoplasm Nasopharynx)) OR ((Rapid Prototyping) AND (Benign Neoplasm Nasopharynx)) OR ((3D Printing) AND (Benign Neoplasm Hypopharynx)) OR ((Rapid Prototyping) AND (Benign Neoplasm Hypopharynx))

Results: No Relevant Papers

Malignant Neoplasms (Bone): Malignant neoplasms of bone which can occur in the craniomaxillofacial region almost always require complex surgical intervention. Many times bone and soft tissue are involved in these cases and the resections encompass a margin of uninvolved tissue to prevent recurrence. The difference between simple and complex may relate to the size of the area to be resected/reconstructed, the three-dimensionality of the affected area or its approximation to vital structures. Reconstruction for complex cases most times require a free flap and may at times also require patient-matched implants or patient-matched rigid fixation. ICD-10: C41.0 Malignant neoplasm of bones of skull and face, C41.1 Malignant neoplasm of mandible

PubMed Search: ((3D Printing) AND (Malignant Neoplasm Skull)) OR ((Rapid Prototyping) AND (Malignant Neoplasm Skull)) OR ((3D Printing) AND (Malignant Neoplasm Mandible)) OR ((Rapid Prototyping) AND (Malignant Neoplasm Mandible)) OR ((virtual surgical planning) AND (Malignant Neoplasm Mandible)) OR ((patient matched implant) AND (Malignant Neoplasm Mandible))

Results: [36, 55, 72, 73, 82, 88, 107, 111, 114, 161, 202-205, 246-300]

Malignant Neoplasms (Soft Tissue): Malignant neoplasms of the soft tissue within the craniomaxillofacial region include cancers of the oral cavity (e.g. tongue, floor of mouth maxillary and mandibular gingiva), oropharynx, hypopharynx, orbit, skull base and larynx. Simple cases may only require biopsy while complex cases can include composite resection and reconstruction of soft tissue and hard tissue concomitantly. Reconstruction for complex cases may require autogenous tissue or a free flap and may at times also require patient-matched implants or rigid fixation. ICD-10: C00 Malignant Neoplasm of Lip, C01 Malignant Neoplasm of Base of Tongue, C04 Malignant Neoplasm of Floor of Mouth, C05 Malignant Neoplasm of Palate, C30 Malignant neoplasm of nasal cavity and middle ear, C31 Malignant neoplasm of accessory sinuses, C32 Malignant neoplasm of larynx, C33 Malignant neoplasm of trachea, D00.0 Carcinoma in situ of lip, oral cavity and pharynx, D00.1 Carcinoma in situ of esophagus

PubMed Search: ((3D Printing) AND (Malignant Neoplasm Lip)) OR ((Rapid Prototyping) AND (Malignant Neoplasm Lip)) OR ((3D Printing) AND (Malignant Neoplasm Tongue)) OR ((Rapid Prototyping) AND (Malignant Neoplasm Tongue)) OR ((3D Printing) AND (Malignant Neoplasm Palate)) OR ((Rapid Prototyping) AND (Malignant Neoplasm Palate)) OR ((3D Printing) AND (Malignant Neoplasm Sinus)) OR ((Rapid Prototyping) AND (Malignant Neoplasm Sinus)) OR ((3D Printing) AND (Malignant Neoplasm Larynx)) OR ((Rapid Prototyping) AND (Malignant Neoplasm Larynx)) OR ((3D Printing) AND (Malignant Neoplasm Trachea)) OR ((Rapid Prototyping) AND (Malignant Neoplasm Trachea)) OR ((3D Printing) AND (Carcinoma Lip)) OR ((Rapid Prototyping) AND (Carcinoma Lip)) OR ((3D Printing) AND (Carcinoma Pharynx)) OR ((Rapid Prototyping) AND (Carcinoma Pharynx)) OR ((3D Printing) AND (Carcinoma esophagus)) OR ((Rapid Prototyping) AND (Carcinoma Esophagus)) OR ((3D 
Printing) AND (Carcinoma Oral Cavity)) OR ((Rapid Prototyping) AND (Carcinoma Oral Cavity)) OR ((virtual surgical planning) AND (Malignant Neoplasm Base of Tongue)) OR ((patient matched implant) AND (Malignant Neoplasm Base of Tongue))

Results: [55, 150, 204, 247-250, 278, 279, 287, 290, 301, 302]

Genitourinary (Retrieved August 2017)

Urolithiasis, Surgical or Medical Management: Calculi or stones that form in the urinary tract, affecting the kidneys, ureters, bladder or urethra is common and increasing in prevalence due to a variety of proposed factors including obesity, dietary changes, and global warming. Terms associated with urolithiasis include kidney stones, renal stones, renal calculus disease, nephrolithiasis, calculi.

PubMed Search: (3D printing AND urolithiasis) OR (3D printing AND kidney stones) OR (3D printing AND renal stones) OR (3D printing AND renal calculus disease) OR (3D printing AND nephrolithiasis) OR (3D printing AND calculi) OR (rapid prototyping AND urolithiasis) OR (rapid prototyping AND kidney stones) OR (rapid prototyping AND renal stones) OR (rapid prototyping AND renal calculus disease) OR (rapid prototyping AND nephrolithiasis) OR (rapid prototyping AND calculi)

Results: [303-309]

Renal Cancer: Renal cancer is common, with renal cell carcinoma (RCC) accounting for approximately $3.5 \%$ of all malignancies [562]. In the US, there is predicted to be 63,990 new diagnoses of RCC and 14,400 kidney cancer related deaths in 2017. Surgical resection is the standard of care for RCC, with minimally invasive partial nephrectomy the treatment of choice for localized lesions [561].

PubMed Search: (3D printing AND kidney cancer) OR (rapid prototyping and kidney cancer) OR (3D printing AND renal cancer) OR (rapid prototyping AND renal cancer) OR (3D printing AND renal mass) OR (3D printing AND kidney mass) OR (rapid prototyping AND renal mass) OR (rapid prototyping AND kidney mass) OR (3D printing AND renal cell carcinoma) OR (3D printing AND RCC) OR (rapid prototyping AND renal cell carcinoma) OR (rapid prototyping AND RCC)

Results: [308, 310-324]

The terms renal lymphoma, angiomyolipoma (AML) and renal oncocytoma generated no results when searched with 3D printing or rapid prototyping.

Renal Cysts: Renal cysts are common; they are heterogeneous in both origin and pathogenesis; and most are simple and are usually of little clinical significance. Cystic renal disease may be sporadic, from congenital anomalies of the kidney and urinary tract that result in abnormal development of the renal parenchyma, or inherited, due to abnormal cilium signaling in tubular epithelial cells [561]. Inherited cystic renal diseases are now included in the group of diseases termed ciliopathies. Renal cysts are characterized based on the Bosniak classification system which divides cystic renal masses into five categories based on imaging characteristics. Simple cysts are considered Bosniak 1, minimally complex are Bosniak 2, intermediate are Bosniak 3, and malignant are Bosniak 4. Bosniak 3 and 4 lesions undergoing surgical treatment such as partial nephrectomy or radiofrequency ablation should be grouped in the renal cancer group described in the previous section.

PubMed Search: (3D printing AND Bosniak cystic lesions) or (rapid prototyping AND Bosniak cystic lesions) OR (3D printing AND Bosniak) OR (rapid prototyping AND Bosniak) OR (3D printing AND renal cysts) OR (rapid prototyping AND renal cysts) OR (3D printing AND kidney cyst) OR (rapid prototyping AND kidney cyst) OR (3D printing AND, cystic renal dysplasia) OR (rapid prototyping AND cystic renal dysplasia) OR (3D printing AND polycystic kidney disease) OR (rapid prototyping AND polycystic kidney disease)

\section{Results: None}

Lower Tract Tumors (bladder and urethra) and Upper Tract Tumors (pyelocaliceal cavities and ureter): Urothelial carcinomas can be located in the lower (bladder and urethra) or the upper (pyelocalyceal cavities and ureter) urinary tract. Bladder cancer accounts for the majority of urothelial malignancies. In 2017, there are estimated to be 79,030 new cases of bladder cancer in the United States, 60,490 in men, making it the 4th most prevalent cancer in men [562]. Cancer of the ureter is uncommon and occurs most often in older adults who have been previously treated for bladder cancer. Transitional cell carcinoma is the most common histology observed.

PubMed Search: 3D printing AND urothelial malignancy OR rapid prototyping AND urothelial malignancy, 3D printing AND urothelial malignancies OR rapid prototyping AND urothelial malignancies, 3D printing AND urothelial carcinoma OR rapid prototyping AND urothelial carcinoma, 3D printing AND transitional cell carcinoma OR rapid prototyping AND transitional cell carcinoma, 3D printing AND bladder malignancy OR rapid prototyping AND bladder malignancy, 3D printing AND bladder malignancies OR rapid prototyping AND bladder malignancies, (3D printing AND bladder cancer OR rapid prototyping AND bladder cancer, 3D printing AND bladder neoplasm OR rapid prototyping AND bladder neoplasm, 3D printing AND bladder mass OR rapid prototyping AND bladder mass

Results: None Relevant 
PubMed Search: (3D printing AND ureteral malignancy) OR (3D printing AND ureteral malignancies) OR (rapid prototyping AND ureteral malignancy) OR (rapid prototyping and ureteral malignancies) OR (3D printing AND intrarenal collecting system malignancies) OR (rapid prototyping AND intrarenal collecting system malignancies) OR (3D printing AND pyelocaliceal) OR (rapid prototyping AND pyelocaliceal) OR (3D printing AND pyelocalyceal) OR (rapid prototyping AND pyelocalyceal)

Results: None Relevant

Adrenal Disease: The adrenal glands may be affected by a variety of pathologies, the majority of which are benign. Causes of adrenal gland disorders include genetic mutations, tumors, infections, regulatory pathologies, or certain medications.

PubMed search: (3D printing AND adrenal disease) OR (rapid prototyping AND adrenal disease) OR (3D printing AND adrenal gland) OR (rapid prototyping AND adrenal gland)

Results: [325]

Penile Cancer: Cancer of the penis is an uncommon lesion occurring almost entirely in uncircumcised men. An important pathological process in penile cancer, is squamous cell carcinoma, which is caused by the human papillomavirus (HPV).

PubMed Search: (3D printing AND penile cancer) OR (rapid prototyping AND penile cancer)

Results: None

Testicular Cancer: The majorities (95\%) of testicular tumors are derived from germ cells and all masses of the testes are considered malignant until proven otherwise [562].

PubMed Search: (3D printing AND testicular cancer) OR (rapid prototyping AND testicular cancer)

Results: None

Prostate Cancer: Prostate cancer is the most common cancer in American men, accounting for almost 1 in 5 new diagnoses [583]. Men diagnosed with prostate cancer have three primary treatment options including active surveillance, surgery, and radiation.

PubMed Search: (3D printing AND prostate cancer) OR (rapid prototyping AND prostate cancer)

Results: [326-334]

Ovarian Disease: Ovarian disease includes ovarian cancer and ovarian cysts, as well as polycystic ovarian syndrome.

PubMed Search: (3D printing AND ovarian tumor) OR (rapid prototyping AND ovarian tumor) OR (3D printing AND ovarian cancer) OR (rapid prototyping AND ovarian cancer)

Results: None Relevant

PubMed Search: (3D printing AND polycystic ovarian disease) OR (3D printing AND PCOD) OR (rapid prototyping AND polycystic ovarian disease) OR (rapid prototyping AND PCOD)

Results: None

Uterine and Cervical Disease: The uterine corpus is composed of endometrial mucosa and the underlying smooth muscle myometrium. Frequent and significant uterine disorders include endometriosis, adenomyosis, abnormal uterine bleeding, and lesions of the endometrium and myometrium including endometrial hyperplasia, endometrial carcinomas, endometrial polyps, and smooth muscle tumors.

PubMed Search: (3D printing AND uterine cancer) OR (rapid prototyping AND uterine cancer) OR (3D printing AND cervical cancer) OR (rapid prototyping AND cervical cancer)

Results: [335-342]

The terms endometrial adenocarcinoma, leiomyoma (uterine fibroids), leiomyosarcoma, and endometrial stromal sarcoma generated no results when searched with 3D printing or rapid prototyping.

PubMed Search: (3D printing AND endometriosis) OR (rapid prototyping AND endometriosis)

Results: [342]

PubMed Search: (3D printing AND endometritis) OR (3D printing AND adenomyosis) OR (3D printing AND uterine bleeding) OR (rapid prototyping AND endometritis) OR (rapid prototyping AND adenomyosis) OR (rapid prototyping) AND (uterine bleeding)

Results: None

\section{Vaginal Cancer}

PubMed Search: 3D printing AND vaginal tumor OR rapid prototyping AND vaginal tumor OR 3D printing AND vaginal cancer OR rapid prototyping AND vaginal cancer

Results: [339, 343]

Genitourinary Reconstruction: Genitourinary reconstruction encompasses a broad range of surgical procedures whose purpose is to correct congenital or acquired abnormalities. Terms: genitourinary conditions, genitourinary disorders, genitourinary anomalies, genitourinary abnormalities, genital conditions, genital disorders, genital anomalies, genital abnormalities.

PubMed Search: (3D printing AND genitourinary reconstruction) OR (rapid prototyping AND genitourinary reconstruction) OR (3D printing AND genitourinary disorders) OR (rapid prototyping AND genitourinary disorders) OR (3D printing AND genitourinary disorder) OR (rapid prototyping AND genitourinary disorder) OR (3D printing AND genitourinary anomaly) OR (rapid prototyping AND genitourinary anomaly) OR (3D printing AND genitourinary anomalies) OR (rapid prototyping AND genitourinary anomalies) OR (3D printing AND genitourinary abnormalities) OR (rapid prototyping AND genitourinary abnormalities) OR (3D printing 
AND genitourinary abnormality) OR (rapid prototyping AND genitourinary abnormality) OR (3D printing AND genital condition) OR (rapid prototyping AND genital condition) OR (3D printing AND genital anomaly) OR (rapid prototyping AND genital anomaly) OR (3D printing AND genital anomalies) OR (rapid prototyping AND genital anomalies) OR (3D printing AND genitourinary abnormalities) OR (rapid prototyping AND genitourinary abnormalities) OR (3D printing AND genitourinary abnormality) OR (rapid prototyping AND genitourinary abnormality)

\section{Results: None Relevant}

Genitourinary Trauma: Injury to the genitourinary tract is a common occurrence after both blunt and penetrating trauma. Terms: genitourinary injury, urinary tract trauma, renal trauma, kidney trauma (renal lacerations, renal collecting system injury, renal vascular injury), ureteral trauma, bladder trauma, urethral trauma, adrenal trauma, scrotal trauma.

PubMed Search: (3D printing AND genitourinary trauma) OR (rapid prototyping AND genitourinary trauma) OR (3D printing AND genitourinary injury) OR (additive manufacturing AND genitourinary injury) OR (3D printing AND urinary tract trauma) OR (additive manufacturing AND urinary tract trauma) OR (3D printing AND renal trauma) OR (rapid prototyping AND renal trauma) OR (3D printing AND kidney trauma) OR (rapid prototyping AND kidney trauma) OR (3D printing AND renal laceration) OR (rapid prototyping AND renal laceration) OR (3D printing AND renal collecting system injury) OR (rapid prototyping AND renal collecting system injury) OR (3D printing AND renal vascular injury) OR (rapid prototyping AND renal vascular injury) OR (3D printing AND ureteral trauma) OR (additive manufacturing AND ureteral trauma) OR (3D printing AND ureteral injury) OR (additive manufacturing AND ureteral injury) OR (3D printing AND bladder injury) OR (rapid prototyping AND bladder injury) OR (3D printing AND bladder trauma) OR (rapid prototyping AND bladder trauma) OR (3D printing AND adrenal trauma AND rapid prototyping AND adrenal trauma) OR (3d printing AND adrenal injury) OR (3D printing AND scrotal trauma) OR (rapid prototyping AND scrotal trauma) OR (3d printing AND scrotal injury)

Results: None Relevant

Pediatric Infection and Reflux: Acute pyelonephritis is inflammation of the kidney, usually bacterial in origin. Terms: vesicoureteral reflux (VUR), urinary tract infection (UTI), acute pyelonephritis

PubMed search: (3D printing AND vesicoureteral reflux) OR (rapid prototyping AND vesicoureteral reflux) OR (3D printing AND VUR) OR (rapid prototyping AND VUR)

Results: [344]
No results for PubMed search with 3D printing OR rapid prototyping AND the following: urinary tract infection, UTI, or pyelonephritis

Pediatric Retroperitoneal Genitourinary Tumors: The terms included Wilms tumor, nephroblastoma, and genitourinary tumor.

PubMed Search: (3D printing AND pediatric genitourinary tumor) OR (rapid prototyping AND pediatric genitourinary tumor) OR (3D printing AND Wilms tumor) OR (rapid prototyping AND Wilms tumor) OR (3D printing AND nephroblastoma) OR (rapid prototyping AND nephroblastoma)

Results: None Relevant

Musculoskeletal (Retrieved February 2017)

Fracture: Simple, Acute Complex Long Bone, Acute Complex Intraarticular, Complex, Acetabular, Non-Pathological Vertebral, Pathological Vertebral, Fracture Malunion.

PubMed Search: (("printing, three-dimensional” $[\mathrm{MeSH}$ Terms] OR ("printing”[All Fields] AND "three-dimensional"[All Fields]) OR "three-dimensional printing"[All Fields] OR ("3d"[All Fields] AND "printing"[All Fields]) OR "3d printing"[All Fields]) OR (rapid[All Fields] AND prototyping[All Fields])) AND (("fractures, bone"[MeSH Terms] OR ("fractures"[All Fields] AND "bone"[All Fields]) OR "bone fractures"[All Fields] OR "fracture"[All Fields]) OR malunion[All Fields])

Results: [345-406]

\section{Heterotopic Ossification}

PubMed Search: (“"printing, three-dimensional”[MeSH Terms] OR ("printing”[All Fields] AND "three-dimensional"[All Fields]) OR "three-dimensional printing"[All Fields] OR ("3d"[All Fields] AND "printing"[All Fields]) OR "3d printing"[All Fields]) OR (rapid[All Fields] AND prototyping[All Fields])) AND ("ossification, heterotopic"[MeSH Terms] OR ("ossification"[All Fields] AND "heterotopic"[All Fields]) OR "heterotopic ossification"[All Fields] OR ("heterotopic"[All Fields] AND "ossification"[All Fields]))

Results: None relevant

\section{Ligamentous Injury}

PubMed Search: (("printing, three-dimensional” $[\mathrm{MeSH}$ Terms] OR ("printing"[All Fields] AND "three-dimensional"[All Fields]) OR "three-dimensional printing"[All Fields] OR ("3d"[All Fields] AND "printing"[All Fields]) OR "3d printing"[All Fields]) OR (rapid[All Fields] AND prototyping[All Fields])) AND (“"tendons”[MeSH Terms] OR “tendons"[All Fields] OR "tendon"[All Fields]) OR ("ligaments"[MeSH Terms] OR "ligaments"[All Fields] OR "ligament"[All Fields]))

Results: [407, 408]

\section{Hip Dysplasia}

PubMed Search: (("printing, three-dimensional” $[\mathrm{MeSH}$

Terms] OR ("printing"[All Fields] AND "three- 
dimensional"[All Fields]) OR "three-dimensional printing"[All Fields] OR ("3d"[All Fields] AND "printing"[All Fields]) OR “3d printing”[All Fields]) OR (rapid[All Fields] AND prototyping[All Fields])) AND ("hip dislocation"[MeSH Terms] OR ("hip"[All Fields] AND "dislocation"[All Fields]) OR "hip dislocation"[All Fields] OR ("hip"[All Fields] AND "dysplasia"[All Fields]) OR "hip dysplasia"[All Fields])

Results: [389, 409-414]

Bone or Soft Tissues Neoplasm: With or Without Joint and Neurovascular Involvement

PubMed Search: (("printing, three-dimensional” $[\mathrm{MeSH}$ Terms] OR ("printing”[All Fields] AND "three-dimensional"[All Fields]) OR "three-dimensional printing"[All Fields] OR ("3d"[All Fields] AND "printing"[All Fields]) OR "3d printing"[All Fields]) OR (rapid[All Fields] AND prototyping[All Fields])) AND ("bone neoplasms"[MeSH Terms] OR ("bone"[All Fields] AND "neoplasms"[All Fields]) OR "bone neoplasms"[All Fields] OR ("bone"[All Fields] AND "tumor"[All Fields]) OR "bone tumor"[All Fields])

Results: [324, 353, 415-443]

\section{Arthritis, Not Otherwise Specified}

PubMed Search: (“"printing, three-dimensional” $[\mathrm{MeSH}$ Terms] OR ("printing”[All Fields] AND "three-dimensional"[All Fields]) OR "three-dimensional printing"[All Fields] OR ("3d"[All Fields] AND "printing”[All Fields]) OR "3d printing"[All Fields]) OR (rapid[All Fields] AND prototyping[All Fields])) AND ("arthritis"[MeSH Terms] OR "arthritis"[All Fields])

Results: [358, 444-453]

Scoliosis: Secondary to Congenital Vertebral Anomaly, Severe/Marked, Thoracic Kyphosis, None of the Above

PubMed Search: (("printing, three-dimensional” $[\mathrm{MeSH}$ Terms] OR ("printing”[All Fields] AND "three-dimensional"[All Fields]) OR "three-dimensional printing"[All Fields] OR ("3d"[All Fields] AND "printing"[All Fields]) OR "3d printing"[All Fields]) OR (rapid[All Fields] AND prototyping[All Fields])) AND ("scoliosis"[MeSH Terms] OR "scoliosis"[All Fields])

Results: [438, 454-463]

Vascular (Retrieved: Initial November 2017, Updated June 2018)

Aortic Pathologies: Dissection, Aneurysm, Stenting, Pseudoaneurysm

PubMed Search: (("printing, three-dimensional”[MeSH Terms] OR ("printing”[All Fields] AND "three-dimensional"[All Fields]) OR "three-dimensional printing"[All Fields] OR ("3d"[All Fields] AND "printing"[All Fields]) OR "3d printing"[All Fields]) OR (rapid[All Fields] AND prototyping[All Fields])) AND (("aneurysm, dissecting"[MeSH Terms] OR ("aneurysm"[All Fields] AND "dissecting"[All Fields]) OR "dissecting aneurysm"[All Fields]
OR ("aortic"[All Fields] AND “dissection"[All Fields]) OR "aortic dissection"[All Fields]) OR ("aortic aneurysm"[MeSH Terms] OR ("aortic"[All Fields] AND "aneurysm"[All Fields]) OR "aortic aneurysm"[All Fields]) OR ((“aorta”[MeSH Terms] OR "aorta”[All Fields] OR "aortic"[All Fields]) AND ("stents"[MeSH Terms] OR "stents"[All Fields] OR "stent"[All Fields])) OR (("aorta" [MeSH Terms] OR "aorta"[All Fields] OR "aortic"[All Fields]) AND ("aneurysm, false" [MeSH Terms] OR ("aneurysm"[All Fields] AND "false"[All Fields]) OR "false aneurysm"[All Fields] OR "pseudoaneurysm"[All Fields])))

Results: [464-499]

\section{Peripheral Aneurysm}

PubMed Search: (“"printing, three-dimensional” $[\mathrm{MeSH}$ Terms] OR ("printing”[All Fields] AND "three-dimensional"[All Fields]) OR "three-dimensional printing"[All Fields] OR ("3d"[All Fields] AND "printing"[All Fields]) OR "3d printing"[All Fields]) OR (Rapid[All Fields] AND Prototyping[All Fields])) AND ((“arteries”[MeSH Terms] OR "arteries"[All Fields] OR "arterial”[All Fields]) AND ("aneurysm"[MeSH Terms] OR "aneurysm"[All Fields])) Results: [500-505]

Stenosis, Arterial, Extracranial, for Patient-Specific Simulations

PubMed Search: (("printing, three-dimensional”[MeSH Terms] OR ("printing”[All Fields] AND "three-dimensional"[All Fields]) OR "three-dimensional printing"[All Fields] OR ("3d"[All Fields] AND "printing”[All Fields]) OR “3d printing”[All Fields]) OR (Rapid[All Fields] AND Prototyping[All Fields])) AND (("constriction, pathologic" [MeSH Terms] OR ("constriction"[All Fields] AND "pathologic"[All Fields]) OR "pathologic constriction"[All Fields] OR "stenosis"[All Fields]) OR ("peripheral arterial disease" [MeSH Terms] OR ("peripheral"[All Fields] AND "arterial”[All Fields] AND "disease"[All Fields]) OR "peripheral arterial disease"[All Fields]))

Results: [506-508]

Vascular Malformations: Acquired, Congenital, Rings, Slings, For Interventional Consideration - Excluding congenital heart disease and intracranial pathologies.

PubMed Search: (("printing, three-dimensional”[MeSH Terms] OR ("printing”[All Fields] AND "three-dimensional"[All Fields]) OR "three-dimensional printing"[All Fields] OR ("3d"[All Fields] AND "printing"[All Fields]) OR “3d printing”[All Fields]) OR (Rapid[All Fields] AND Prototyping[All Fields])) AND (("vascular malformations"[MeSH Terms] OR ("vascular"[All Fields] AND "malformations"[All Fields]) OR "vascular malformations"[All Fields] OR ("vascular" [All Fields] AND "malformation"[All Fields]) OR "vascular malformation"[All Fields]) OR ("vascular ring"[MeSH Terms] OR ("vascular"[All Fields] AND "ring"[All Fields]) OR "vascular 
ring"[All Fields]) OR ("vascular ring"[MeSH Terms] OR ("vascular"[All Fields] AND "ring"[All Fields]) OR "vascular ring"[All Fields] OR ("vascular"[All Fields] AND "sling"[All Fields]) OR "vascular sling"[All Fields]))

Results: [509]

Varices: Peripheral for Medical Management, Retroperitoneal for Medical Management, Intervention Planning

PubMed Search: (("printing, three-dimensional”[MeSH Terms] OR ("printing"[All Fields] AND "three-dimensional"[All Fields]) OR "three-dimensional printing"[All Fields] OR ("3d"[All Fields] AND "printing"[All Fields]) OR "3d printing”[All Fields]) OR (Rapid[All Fields] AND Prototyping[All Fields])) AND ((“varicose veins”[MeSH Terms] OR ("varicose"[All Fields] AND "veins"[All Fields]) OR "varicose veins"[All Fields] OR "varices"[All Fields]) OR ("varicose veins" [MeSH Terms] OR ("varicose"[All Fields] AND "veins"[All Fields]) OR "varicose veins"[All Fields] OR "varix"[All Fields]) OR varicose[All Fields])

Results: None

Carotid Pathologies: Stenosis, Dissection, Pseudoaneurysm, Post-Endarterectomy

PubMed Search: (("printing, three-dimensional”[MeSH Terms] OR ("printing”[All Fields] AND "three-dimensional"[All Fields]) OR "three-dimensional printing"[All Fields] OR ("3d"[All Fields] AND "printing”[All Fields]) OR "3d printing”[All Fields]) OR (Rapid[All Fields] AND Prototyping[All Fields])) AND carotid[All Fields]

Results: [510-514]

Intracranial Pathologies: Stenosis, Aneurysm, Dural AV Fistula, Arteriovenous Malformation

PubMed Search: (("printing, three-dimensional” $[\mathrm{MeSH}$ Terms] OR ("printing”[All Fields] AND "three-dimensional"[All Fields]) OR "three-dimensional printing"[All Fields] OR ("3d"[All Fields] AND "printing"[All Fields]) OR "3d printing"[All Fields]) OR (Rapid[All Fields] AND Prototyping[All Fields])) AND ((“constriction, pathologic"[MeSH Terms] OR ("constriction"[All Fields] AND "pathologic"[All Fields]) OR "pathologic constriction"[All Fields] OR "stenosis"[All Fields]) OR ("aneurysm" [MeSH Terms] OR "aneurysm"[All Fields]) OR (Dural[All Fields] AND ("arteriovenous fistula" [MeSH Terms] OR ("arteriovenous"[All Fields] AND "fistula"[All Fields]) OR "arteriovenous fistula"[All Fields] OR ("av"[All Fields] AND "fistula"[All Fields]) OR "av fistula"[All Fields])) OR ("arteriovenous malformations"[MeSH Terms] OR ("arteriovenous"[All Fields] AND "malformations"[All Fields]) OR "arteriovenous malformations"[All Fields] OR ("arteriovenous"[All Fields] AND "malformation"[All Fields]) OR "arteriovenous malformation"[All Fields]))

Results: [501, 515-545]

Breast (Retrieved November 2017)
Benign breast lesions: Benign breast lesions include fibrocystic change, benign breast masses, inflammatory, and peripartum conditions.

PubMed Search: ((3D printing) AND (fibrocystic change)) OR ((3D printing) AND (benign breast masses)) OR ((3D printing) AND (mastitis)) OR ((3D printing) AND (galactocele)) OR ((rapid prototyping) AND (fibrocystic change)) OR ((rapid prototyping) AND (benign breast masses)) OR ((rapid prototyping) AND (mastitis) OR ((rapid prototyping) AND (galactocele))

Results: None

High risk breast lesions: High risk lesions include flat epithelial atypia, atypical ductal hyperplasia, lobular neoplasia, radial scar, papillary lesions and mucocele-like lesions.

PubMed Search: ((3D printing) AND (flat epithelial atypia)) OR ((3D printing) AND (atypical ductal hyperplasia)) OR ((3D printing) AND (lobular neoplasia)) OR ((3D printing) AND (radial scar)) OR ((3D printing) AND (papillary lesions) OR ((3D printing) AND (mucocele-like lesions)) OR ((rapid prototyping) AND (flat epithelial atypia)) OR ((rapid prototyping) AND (atypical ductal hyperplasia)) OR ((rapid prototyping) AND (lobular neoplasia) OR ((rapid prototyping) AND (radial scar)) OR ((rapid prototyping) AND (papillary lesions)) OR ((rapid prototyping) AND (mucocele-like lesions))

Results: No results found.

Breast cancer: Malignant breast lesions included ductal carcinoma in situ ductal (DCIS) and invasive breast carcinomas. Use in breast malignancies with chest wall involvement and/or nipple-areolar complex involvement, evaluation of tumor-breast size ratio, and tumors where oncoplastic surgery is considered.

PubMed Search: ((3D printing) AND (breast cancer) OR ((rapid prototyping) AND (breast cancer))

Results: [546-552]

\footnotetext{
Abbreviations

3D: Three-dimensional; ACR: American College of Radiology; ASD: Atrial septal defect; AV: Atrioventricular; CAD: Computer aided design;

$\mathrm{CDRH}$ : The center for devices and radiological health; CHD: Congenital heart disease; CMF: Craniomaxillofacial; CNR: Contrast to noise ratio;

CT: Computed tomography; DICOM: Digital imaging and communications in medicine; DOLV: Double-outlet left ventricle; DORV: Double-outlet right ventricle; EACTS-STS: European Association for Cardio-Thoracic Surgery / Society of Thoracic Surgery; FDA: The United States Food and Drug Administration; FOV: Field of view; HIPAA: Health Insurance Portability and Accountability Act; ICD-10: International Classification of Diseases, Tenth Revision; IPCCC: International Pediatric and Congenital Cardiac Code; MRI: Magnetic resonance imaging; NOS: Not otherwise specified; PACS: Picture archiving and communication system; PAPVR: Partial anomalous pulmonary venous return; ROI: Region of interest; RSNA: Radiological Society of North America; RVOT: Right ventricular outflow tract; SIG: Special Interest Group; SNR: Signal to noise ratio; STL: Standard tessellation language; TAPVR: Total anomalous pulmonary venous return; TGA: Transposition of
} 
the great arteries; VRML: Virtual reality markup language; VSD: Ventricular septal defect

\section{Acknowledgements}

\section{RSNA SIG Faculty Members (July 15, 2018)}

Abraham Levitin, MD, Beachwood, OH, United States

Adam C. Zoga, MD, Dept of Radiology, Thomas Jefferson University Hospital, Philadelphia, PA, United States

Alejandro A. Espinoza, PhD, Dept of Orthopedic Surgery, Rush University

Medical Center, Chicago, IL, United States

Alexander J. Chien, MD, Chino Hills, CA, United States

Amar B. Shah, MD, New York, NY, United States

Ambroise Mathurin Dzogang Temdemno, MD, CARIM, Yaounde, Cameroon Amin S. Chaoui, MD, Wellesley, MA, United States

Amy E. Alexander, MS, Dept of Radiology, Mayo Clinic, Rochester, MN, United States Anand V. Rao, MD, Brookfield, WI, United States

Anne Garcia, Opheart, Houston, TX, United States

Angel R Colon, MD, Mayaguez, PR, United States

Antoine Leimgruber, MD, MS, Pully, VD, Switzerland

Antoine M. Vanderhofstadt, MD, Brussels, Belgium

Asra Khan-Bonenberger, MD, Orlando, FL, United States

Attilio A. Guazzoni, MD, Dept of Radiology, San Biagio Hospital,

Domodossola, VB, Italy

Barbara L. McComb, MD, Ponte Vedra, FL, United States

Benjamin E. Tubb, MD, PhD, San Antonio, TX, United States

Benjamin Johnson, 3DSystems, Littleton, CO, United States

Benjamin M. Howe, MD, Dept of Radiology, Mayo Clinic, Rochester, MN, United States

Berdoudi Rabah, MD, Dept of Radiology, Imagerie Medicale du Charollais,

Paray-le-Monial, France

Bernadette M. Greenwood, BS, RT, Desert Medical Imaging, Indian Wells, CA, United States

Beth A. Ripley, MD, PhD, Dept of Radiology, University of Washington,

Seattle, WA, United States

Beth M. Kline-Fath, MD, Dept of Radiology (MLC 5031), Children's Hospital

Medical Center, Cincinnati, $\mathrm{OH}$, United States

Brent Chanin, BEng, Mediprint.us, Chester, NY, United States

Brian A. Tweddale, MD, Doylestown, PA, United States

Brian McNamee, MD, Coeur D Alene, ID, United States

Bruce M. Barack, MD, Los Angeles, CA, United States

Bruce M. Shuckett, MD, Toronto, ON, Canada

Bryan Crutchfield, Materialise, Plymouth, MI, United States

Carina L. Butler, MD, Lexington, KY, United States

Carlin A. Ridpath, MD, Springfield, MO, United States

Carlos I. Hernandez Rojas, MD, Lima 27, Peru

Carlos Torres, MD, Ottawa, ON, Canada

Carolina A. Souza, MD, Ottawa, ON, Canada

Chen C. Hoffmann, MD, Dept of Diagnostic Radiology, Ramat-Gan, Israel

Cheryl L. Kirby, MD, Cherry Hill, NJ, United States

Ching-Lan Wu, MD, Dept of Radiology, Taipei Veterans General Hospital,

Taipei, Taiwan

Chris Letrong, RT, ARRT, San Jose, CA, United States

Christina Kotsarini, MD, PhD, Glasgow, United Kingdom

Christine J. Kim, MD, Dept of Neuroradiology, Brigham and Women's

Hospital, Boston, MA, United States

Christopher A. Swingle, DO, Saint Louis, MO, United States

Christopher E. Smith, MD, Rch Palos Vrd, CA, United States

Christopher Wilke, MD, Dept of Radiation Oncology, Univ of Minnesota

School of Medicine, Minneapolis, MN, United States

Christopher Yurko, MD, Vallejo, CA, United States

Claudio Silva, MD, Radiology Department, Clinica Alemana, Facultad de

Medicina Clinica Alemana Universidad del Desarrollo, Santiago, Chile

Colin M. Wilson, MA, Dept of Radiology, University of New Mexico,

Albuquerque, NM, United States

Craig S. Howard, MD, Hattiesburg, MS, United States

Damodaran Arul Selvam, MD, Dept of Radiology, Malcolm Randall VA

Medical Center, Gainesville, FL, United States

Dana A. Fuller, MD, Dallas, TX, United States

Daniel A. Crawford, MSc, BSC, Dept of Medical 3D Printing, Axial3D, Belfast,

Antrim, United Kingdom
Daniel Davis, RT, BS, Denver, CO, United States

Daniel LaRussa, PhD, Department of Radiology, The University of Ottawa Faculty of Medicine, Ottawa, ON, Canada

Daniel S. Madsen, MD, Dept of Interventional Radiology, San Antonio Military

Med Ctr, Fort Sam Houston, TX, United States

Daniele Marin, MD, Cary, NC, United States

Darshit Thakrar, MD, Dept of Pediatric Radiology, Childrens Hospital of

Pittsburgh of UPMC, Pittsburgh, PA, United States

Dave Nuthals, Vital Images, Minnetonka, MN, United States

David Dreizin, MD, Dept of Radiology \& Nuclear Medicine, University of

Maryland Medical Center, Baltimore, MD, United States

David M. Hough, MD, Rochester, MN, United States

David MacCutcheon, TeraRecon, Foster City, MA, United States

Daya Vora, MD, Troy, MI, United States

Deborah E. Starkey, RT, Medical Radiation Sciences, Queensland University of

Technology, Brisbane, QLD, Australia

Denis Samama, MD, Service d'Imagerie Medicale, Neuilly-sur-Seine, France

Derek L. West, MD, Dept of Radiology, Emory University, Atlanta, GA, United

States

Diane M. Twickler, MD, Dept of Radiology, Univ of Texas Southwestern

Medical Ctr, Dallas, TX, United States

Donald S. Emerson, MD, Memphis, TN, United States

Dong Xu, MD, PhD, Dept of Ultrasound, Zhejiang Cancer Hospital, Hangzhou, Zhejiang, China

Dorothy J. Shum, MD, Dept of Radiology, University of California San

Francisco, San Francisco, CA, United States

Eddy D. Lucas, MD, Wichita, KS, United States

Eduardo M. Rosa, MD, Radiologica Los Volcanes, Puerto Montt, Decima

Region, Chile

Edward A. Del Grosso, MD, Granville, OH, United States

Edward P. Quigley, III, MD, PhD, Salt Lake City, UT, United States

Edward Stefanowicz, MBA, RT, Dept of Radiology, Geisinger Health System,

Danville, PA, United States

Enrique R. Escobar, MD, Melilla, Spain

Eric M. Baumel, MD, Digital Imaging Diagnostics PLC, Wellington, FL, United

States

Eric Teil, MD, Tresserve, France

Erik W. Stromeyer, MD, Miami Beach, FL, United States

Ernest J. Ferris, MD, Little Rock, AR, United States

Fabrizio D'Alessandro, MD, Massa, Ron, Italy

Fadi Toonsi, MBBS, FRCPC, Jeddah, Saudi Arabia

Faisal M. Shah, MD, Scotch Plains, NJ, United States

Fernando A. Alvarado Sr, MD, Dept of Radiology, Diagnos, Machala, El Oro,

Ecuador

Francesco Potito, MD, Dept of MRI CT, Centro Radiologico Potito,

Campobasso, CB, Italy

Frank S. Bonelli, MD, PhD, Rockford, IL, United States

Freddy Drews, MD, Avon Lake, OH, United States

Gaetano T. Pastena, MD, MBA, Glenmont, NY, United States

Gary W. Kerber, MD, Urbana, IL, United States

Gene Kitamura, MD, Dept of Radiology, UPMC, Pittsburgh, PA, United States

George Antaki, MD, Riverview, FL, United States

Georgina A. Viyella, MD, Santo Domingo, Dominican Republic

Gerard P. Farrar, MD, Hemlock, MI, United States

Gloria M. Rapoport, MD, Forest Hills, NY, United States

Gul Moonis, MD, South Orange, NJ, United States

H. Henry Guo, MD, Fremont, CA, United States

Halemane S. Ganesh, MD, Lexington, KY, United States

Han N. Ta, MD, Newport Coast, CA, United States

Haraldur Bjarnason, MD, Dept of Vascular \& Interventional Radiology, Mayo

Clinic, Rochester, MN, United States

Hemant T. Patel, MD, Samved Hospital, Ahmedabad, India

Hongju Son, MD, Dept of Radiology, Einstein Healthcare Network,

Philadelphia, PA, United States

Hui J. Chen, MD, San Francisco, CA, United States

Hyun-Ju Lee, MD, PhD, Dept of Radiology, Seoul National University Hospital,

Seoul, Korea, Republic of

Irini M. Youssef, MD, MPH, Hollidaysburg, PA, United States

Jack M. Drew, MD, Littleton, CO, United States

Jaime Ribeiro Barbosa, MD, Instituto de Radiologia Pres Prudente, Presidente

Prudente, SP, Brazil 
James B. Allison, MD, Richmond, VT, United States James Shin, MD, MSc, New York, NY, United States Jared V. Grice, DMP, Nashville, TN, United States Jaroslaw Ast, MD, Poznan, Wielkopolska, Poland Jayanthi Parthasarathy BDS, PhD, Nationwide Children's Hospital, Columbus, $\mathrm{OH}$, United States

Jeffrey A. Haithcock, MD, Colleyville, TX, United States

Jeffrey A. Sodergren, MD, Mountain Top, PA, United States

Jeffrey D. Hirsch, MD, Lutherville, MD, United States

Jesus D. Buonomo, MD, Gurabo, PR, United States

Joaquim M. Farinhas, MD, Tampa, FL, United States

Joel M. Stein, MD, PhD, Div of Neuroradiology, Hospital of the University of Pennsylvania, Philadelphia, PA, United States

Johannes Goerich, MD, Eberbach, Baden, Germany

John A. Skinner, MD, Dept of Radiology, Mayo Clinic, Rochester, MN, United

States

John G. O'Rourke, MBBS, Sydney, NSW, Australia

John Oh, MD, Las Vegas, NV, United States

John P. Knoedler Jr., MD, North Oaks, MN, United States

Jonathan A. Aziza, MD, Thornhill, ON, Canada

Jonathan M. Ford, PhD, Dept of Radiology, University of South Florida College of Medicine, Tampa, FL, United States

Jorge E. Salazar, MD, UT Medical Group Inc., Memphis, TN, United States Jose A. Barriocanal, MD, PhD, Chattanooga, TN, United States

Jose A. Maldonado, MD, San Juan, PR, United States

Joseph Johnnie, MS, BEng, Medivators, Conroe, TX, United States

Joseph M. Aulino, MD, Brentwood, TN, United States

Josephine Pressacco, MD, PhD, Dept of Diagnostic Radiology (D5-113),

MUHC/Montreal General Hospital, Montreal, QC, Canada

Judy H. Song, MD, Medstar Georgetown University Hospital, Washington, DC, United States

Juergen Brandt, MD, Arnsberg, Germany

Julie S. Lee, MD, Seattle, WA, United States

Juling Ong I, MBBS, Dept of Plastic Surgery/3D Facility, Great Ormond Street Hospital for Children, London, United Kingdom

Justin Sutherland, PhD, Department of Radiology, The University of Ottawa

Faculty of Medicine, Ottawa, ON, Canada

Karen K. Moeller, MD, Louisville, KY, United States

Katherine Weimer, 3D Systems - Healthcare, Littleton, CO, United States

Kathleen G. Oxner, MD, Greenville, SC, United States

Kathryn E. Pflug, MD, Dept of Radiology, Lakeview Regional Medical Center,

Covington, LA, United States

Kelly D. Smith, MD, Mitchell, SD, United States

Kelly Oppe, RT, Dept of Radiology, Carle Foundation Hospital, Urbana, IL, United States

Kenneth A. Buckwalter, MD, Indiana University, Indianapolis, IN, United States Kenneth L. Sandock, MD, Tucson, AZ, United States

Kent R. Thielen, MD, Department of Radiology, Mayo Clinic, Rochester, MN, United States

Kevin A. Lugo, MBA, ARRT, Raleigh, NC, United States

Kevin J. Roche, MD, New Hope, PA, United States

Kevin L. Pope, MD, Breast Center of Northwest Arkansas, Fayetteville, AR, United States

Keyur Mehta, MD, Montefiore Medical Center, Bronx, NY, United States

Kimberly Torluemke, 3D Systems, Healthcare, Littleton, CO, United States Kirby K. Wong, MBBS, MPH, Sydney, NSW, Australia

Klaus Kubin, MD, CT/MR Institutes, Medical Center Schallmoos, Salzburg,

Austria

Kranthi K. Kolli, PhD, MS, New York, NY, United States

Kristi B. Oatis, MD, Lexington, KY, United States

Kwok-chung Lai, MBChB, FRCR, Dept of Radiology \& Imaging, Queen

Elizabeth Hospital, Kowloon, Hong Kong

Lance E. Reinsmith, MD, San Antonio, TX, United States

Lauralyn McDaniel, MBA, SME, Dearborn, MI, United States

Leizle E. Talangbayan, MD, Long Branch, NJ, United States

Leszek J. Jaszczak, MD, Williston, ND, United States

Ligia Cardona, MD, Santo Domingo, Distrito Nacional, Dominican Republic

Lincoln Wong, MD, Omaha, NE, United States

Liza Nellyta, MD, Department of Radiology, RS Awal Bros Pekanbaru,

Pekanbaru, Riau, Indonesia
Louis T. Kircos, DDS, PhD, San Rafael, CA, United States

Luc Lacoursiere, MD, FRCPC, Quebec, QC, Canada

Luca Remonda, MD, Aarau, Aargau, Switzerland

Lucas M. Sheldon, MD, Niceville, FL, United States

Luigi Grazioli, MD, Servizio di Radiologia, University of Brescia/Spedali Civili Brescia, Brescia, BS, Italy

Luis A. Campos, MD, Lima 33, Lima, Peru

Luis A. Rodriguez Palomares, MD, Delegacion: Benito Juarez, Mexico City,

Mexico

Mamdouh E. Rayan, MD, MSc, Chicago, IL, United States

Marc J. Gollub, MD, New York, NY, United States

Margaret O. Brown, MD, Walton, KY, United States

Mariah N. Geritano, MSc, Brookline, MA, United States

Mariam Thomas, MD, Los Angeles, CA, United States

Mariano Sturla, MD, Castelar, Buenos Aires, Argentina

Mark A. Smith, MS, ARRT, Columbus, OH, United States

Mark D. Alson, MD, Fresno, CA, United States

Mark E. Sharafinski Jr., MD, Madison, WI, United States

Marshall B. Hay, MD, Portage, MI, United States

Mary Ellen Wickum, MS, Cambridge, MA, United States

Mary Hu, MD, MS, Flushing, NY, United States

Mary L. Christie, Rockland, MA, United States

Mashael K. Alrujaib, FRCR, FRCPC, Dept of Radiology (MBC-28), King Faisal

Specialist Hospital, Riyadh, Central Region, Saudi Arabia

Matthew Allen, MD, Redding Cancer Treatment Center, Redding, CA, United

States

Mayola C. Boykin, MD, Ashland, KY, United States

Melanie Gillies, BSc, Coolangatta, QLD, Australia

Michael D. Maloney, MD, Yreka, CA, United States

Michael Gaisford, Stratasys, Cambridge, MA, United States

Michael L. Richardson, MD, Dept of Radiology, University of Washington,

Seattle, WA, United States

Michael T. McGuire, MD, Jersey City, NJ, United States

Michael T. Miller, MD, Pittsford, NY, United States

Michael W. Itagaki, MD, MBA, Bellevue, WA, United States

Michel Berube, MD, Chicoutimi, QC, Canada

Michel D. Dumas, MD, Abilene, TX, United States

Michelle L. Walker, MS, Clearwater, FL, United States

Mohammad Eghtedari, MD, PhD, San Diego, CA, United States

Muge Ozhabes, MD, Marina Del Rey, CA, United States

Nathaniel Reichek, MD, Fort Salonga, NY, United States

Naveen K. Gowda, MD, Dept of Radiology, St. Lukes Hospital, Duluth, MN, United States

Nicholas C. Fraley, MD, Oro Valley, AZ, United States

Nicholas G. Rhodes, MD, Rochester, MN, United States

Nopporn Beokhaimook, MD, Nonthaburi, Thailand

Pamela A. Rowntree, RT, Medical Radiation Sciences, Queensland University

of Technology, Brisbane, Qld, Australia

Pascal Fontaine, DVM, MSC, Montreal, QC, Canada

Patricia A. Rhyner, MD, Atlanta, GA, United States

Patrick Chang, MD, Dept of Radiology, Kaiser South San Francisco Medical

Ctr, San Francisco, CA, United States

Paul E. Lizotte, DO, MA, Valley Center, CA, United States

Paulo M. Bernardes, MD, Rio de Janeiro, RJ, Brazil

Pedro E. Diaz, MD, Guaynabo, PR, United States

Pen-An Liao, MD, Taipei City, Taiwan

Perla M. Salgado, MD, Cuernavaca, Morelos, Mexico

Peter M. Van Ooijen, MSc, PhD, Dept of Radiology, University Medical Center of Groningen, Groningen, Netherlands

Peter Piechocniski, Memorial Sloan Kettering Cancer Center, New York City, NY, United States

Philip S. Lim, MD, Dept of Radiology, Abington Memorial Hospital, Abington,

PA, United States

Philipp Brantner, MD, Binningen, Switzerland

Philippe Grouwels, MD, Hasselt, Belgium

Phillip D. Baker, MD, PhD, Dept of Radiology, Legacy Good Samaritan

Hospital, Portland, OR, United States

Prasad S. Dalvie, MD, Dept of Radiology, University of Wisconsin, Madison,

WI, United States

Qurashi M. Ali Fadlelseed, MD, PhD, National College for Med \& Technical

Studies, Kitarfoum, Sudan 
R. Scott Rader, PhD, GE Healthcare, Marlborough, MA, United States Rajaram E. Reddy, MD, St Catherines, ON, Canada

Rami M. Shorti, PhD, Intermountain Healthcare, South Jordan, UT, United States Ramin Javan, MD, Washington, DC, United States

Randolph K. Otto, MD, Edmonds, WA, United States Raphael J. Alcuri, MD, Whitesboro, NY, United States

Rasim C. Oz, MD, Baltimore, MD, United States

Richard A. Levy, MD, Saugerties, NY, United States

Richard E. Barlow, MD, Sandy Springs, GA, United States

Richard K. Brown, MD, Dept of Nuclear Medicine, University of Michigan, Ann Arbor, MI, United States

Richard Shoenfeld, MD, Mountain Lks, NJ, United States

Rikesh J. Makanji, MD, Tampa, FL, United States

Robert A. Posniak, MD, Windermere, FL, United States

Robert L. Falk, MD, Prospect, KY, United States

Robert M. DeWitt, MD, APO, AE, United States

Robert S. Redlich, MD, Hudson, OH, United States

Robyn A. Pugash, MD, Dept of Medical Imaging, Sunnybrook HSC, Toronto, ON, Canada

Roy G. Bryan Jr., MD, MBA, Radiology, Santa Barbara Cottage Hospital, Santa Barbara, CA, United States

Salim S. Merchant, FRANZCR, Melbourne, VIC, Australia

Sang Joon Park, PhD, Seoul National University Hospital, Seoul, Korea, Republic of

Sang-Sun Han, MD, Dept of Oral \& Maxillofacial Radiology, Yonsei University College of Dentistry, Seoul, Korea, Republic of

Sanjay M. Mallya, DDS, PhD, Dept of Oral \& Maxillofacial Radiology, UCLA

School of Dentistry, Los Angeles, CA, United States

Sanjay P. Prabhu, MBBS, FRCR, Dept of Pediatric Neuroradiology, Childrens Hospital Boston, Boston, MA, United States

Sankar P. Sinha, MBBS, FRCR, Nuneaton, Warwickshire, United Kingdom

Sanket Chauhan, MD, Dept of Surgery, Baylor University Medical Center,

Dallas, TX, United States

Satinder S. Rekhi Jr., MD, Manorville, NY, United States

Scott H. Faro, MD, Haddonfield, NJ, United States

Scott T. Williams, MD, San Juan Capo, CA, United States

Sepideh Sefidbakht, MD, Powel, $\mathrm{OH}$, United States

Sergio A. Gonzalez, MD, El Paso, TX, United States

Seth J. Berkowitz, MD, Brookline, MA, United States

Shannon N. Zingula, MD, Dept of Radiology, Mayo Clinic, Rochester, MN, United States

Shannon R. Kirk, MD, Loma Linda University, Loma Linda, CA, United States

Sharon W. Gould, MD, Kemblesville, PA, United States

Shuai Leng, PhD, Dept of Radiology, Mayo Clinic, Rochester, MN, United States

Sidney D. Machefsky, MD, University Cy, MO, United States

Sofiane Derrouis, MD, Neuchatel, Switzerland

Srini Malini, MD, Womens Specialists of Houston at TCH, Texas Childrens

Hospital Pavilion for Women, Houston, TX, United States

Stephane Khazoom, MD, Chambly, QC, Canada

Stephen E. Russek, PhD, NIST, Boulder, CO, United States

Steven C. Horii, MD, Dept of Radiology, University of Pennsylvania Medical

Center, Philadelphia, PA, United States

Steven R. Parmett, MD, Teaneck, NJ, United States

Sumit Pruthi, MBBS, Dept of Radiology, Vanderbilt Childrens Hospital,

Nashville, TN, United States

Summer J. Decker, PhD, Dept of Radiology, University of South Florida

College of Medicine, Tampa, FL, United States

Tan M. Nguyen, MD, Dept of Radiology, Sacramento, CA, United States

Terence J. O'Loughlin, MD, Provincetown, MA, United States

Terry C. Lynch, MD, Dept of Radiology, San Francisco General Hospital, San Francisco, CA, United States

Timothy L. Auran, MD, San Luis Obispo, CA, United States

Todd Goldstein, PhD, Northwell Health, USA, NY, United States

Todd Pietila, Materialise, Plymouth, MI, United States

Tone Lindgren, MD, Pelham, NY, United States

Tracy S. Chen, DO, MPH, Carmel, CA, United States

Vartan M. Malian, MD, Roseville, CA, United States

Vicente Gilsanz, MD, PhD, Dept of Radiology, Childrens Hospital Los Angeles,

Los Angeles, CA, United States

Victor A. McCoy, MD, Prairieville, LA, United States

Vijay Jayaram, MBBS, PhD, Enfield, Middlesex, United Kingdom
Vinicius V. Alves, Niteroi, RJ, Brazil

W. Brian Hyslop, MD, PhD, Dept of Radiology, University of North Carolina, Chapel Hill, NC, United States

Wael M. Abdalla, MD, Presby South Tower, Henderson, NV, United States

Walter A. Carpenter, MD, PhD, Atlanta, GA, United States

Wellington Eddy Reynaldo Paez Zumarraga, MD, Quito, Ecuador

William D. Boswell Jr., MD, Dept of Diagnostic Radiology, City of Hope

National Medical Center, Duarte, CA, United States

William Prows, Intermountain Healthcare, Murray, UT, United States

Xing-Jun Gao, MD, Department of Radiology, Xinyang Central Hospital,

Xinyang, Henan, China

Yeong Shyan Lee, MBBCh, Department of Diagnostic Radiology (Basement

1), Singapore, Singapore

Yiwen Chen, PhD, Dept of 3D Printing Med Research, China Medical

University Hospital, Taichung City, Taiwan

Yoshimi Anzai, MD, Dept of Radiology, University of Utah, Salt Lake Cty, UT, United States

Zheng Jin, MS, New York, NY, United States

\section{Trainee Members (July 15, 2018)}

Adrian A. Negreros-Osuna, MD, Massachusetts General Hospital, Boston, MA, United States

Andreas Giannopoulos, MD, University Hospital Zurich, Zurich, Switzerland Andres Vasquez, MD, MSc, New York, NY, United States

Boris Kumaev, DO, University of Florida, Jacksonville, FL, United States

Carissa M. White, MD, Venice, CA, United States

Eduardo Hernandez-Rangel, MD, University of California, Santa Ana, CA,

United States

Elias Kikano, MD, Mayfield Heights, OH, United States

Elisa Spoldi, DVM, University of Florida College of Veterinary Med, Gainesville,

FL, United States

Jessica D. Shand Smith, MBChB, Edinburgh, United Kingdom

Justin Kerby, II, MD, MS, Wichita, KS, United States

Kirk P. Langheinz, MD, Lafayette General Medical Center - Cancer Center of Acadiana, Lafayette, LA, United States

Luis G. Ricardez, MD, Hospital Civil de Culiacan, Culiacan, Sinaloa, Mexico

Michael Bartellas, MS, St Johns, NL, Canada

Narayana Vamyanmane Dhananjaya Kotebagilu, MBBS, MBA, Abhayahasta

Multispeciality Hospital, Bengaluru, Karnataka, India

Sadia R. Qamar, MBBS, Vancouver General Hospital, UBC, Vancouver, BC,

Canada

Sherazad Islam, MD, Glenview, IL, United States

Vasanthakumar Venugopal, MD, New Delhi, Delhi, India

Vjekoslav Kopacin, MD, Osijek, Croatia

Yu-hui Huang, MS, Chicago, IL, United States

\section{Affiliated Contributors (non-members of the Special Interest Group)}

Jeffrey P Jacobs, MD, Division of Cardiovascular Surgery and Director of the Andrews/Daicoff Cardiovascular Program, Johns Hopkins All Children's Heart Institute, St Petersburg, FL

Kenneth E. Salyer, MD, World Craniofacial Foundation, Dallas, TX, US and Texas A\&M University, Dallas, TX, US

R. Bryan Bell, MD, DDS, Providence Head and Neck Cancer Program,

Providence Cancer Institute, Portland, OR, US and Head \& Neck Surgical

Associates, Portland, OR, US

\section{Authors' contributions}

All primary authors edited, reviewed, and approved this manuscript. All included special interest group member coauthors, listed in the Acknowledgements section, were provided with the final manuscript for review and approved its publication.

\section{Competing interests}

The primary authors declare no competing interests. RSNA Special Interest Group for 3D Printing includes a variety of industry representatives with voting privileges, including representatives from Materialise Inc., Stratasys, 3D Systems, and TeraRecon, as detailed in the Acknowledgements section.

\section{Publisher's Note}

Springer Nature remains neutral with regard to jurisdictional claims in published maps and institutional affiliations. 


\section{Author details}

${ }^{1}$ Department of Radiology and The Ottawa Hospital Research Institute, University of Ottawa, Ottawa, ON, Canada. ${ }^{2}$ Center for Advanced Imaging Innovation and Research (CAI2R), Bernard and Irene Schwartz Center for Biomedical Imaging, Department of Radiology, NYU School of Medicine, New York, NY, USA. 'Sackler Institute of Graduate Biomedical Sciences, NYU School of Medicine, New York, NY, USA. ${ }^{4}$ Rady Children's Hospital, San Diego, CA, USA. ${ }^{5}$ Department of Diagnostic Radiology, Division of Diagnostic Imaging, The University of Texas MD Anderson Cancer Center, Houston, TX, USA. ${ }^{6}$ Mallinckrodt Institute of Radiology, Washington University School of Medicine, Saint Louis, MO, USA. 'Baltimore VA Medical Center, University of Maryland Medical Center, Baltimore, MD, USA. ${ }^{8}$ Department of Radiology and Frankel Cardiovascular Center, University of Michigan, Ann Arbor, MI, USA. ${ }^{9}$ Department of Neurosurgery, State University of New York Buffalo, Buffalo, NY, USA. ${ }^{10}$ Department of Radiology, Mayo Clinic, Rochester, MN, USA. ${ }^{11} 3 \mathrm{D}$ Medical Applications Center, Walter Reed National Military Medical Center, Washington, DC, USA.

\section{Received: 7 August 2018 Accepted: 19 September 2018}

\section{Published online: 21 November 2018}

\section{References}

1. Chaowu Y, Hua L, Xin S. Three-dimensional printing as an aid in Transcatheter closure of Secundum atrial septal defect with rim deficiency. Circulation. 2016;133(17):e608-10.

2. Faganello G, Campana C, Belgrano M, Russo G, Pozzi M, Cioffi G, Lenarda AD. Three dimensional printing of an atrial septal defect: is it multimodality imaging? Int J Cardiovasc Imaging. 2016;32(3):427-8.

3. Luo H, Xu Y, Wang Z, Liu Y, Gao C. Three-dimensional printing modelguided percutaneous closure of atrial septal defect. Arq Bras Cardiol. 2017; 108(5):484-5.

4. Qiu X, Lü B, Xu N, Yan CW, Ouyang WB, Liu Y, Zhang FW, Yue ZQ, Pang K, Pan XB. Feasibility of device closure for multiple atrial septal defects using 3D printing and ultrasound-guided intervention technique. Zhonghua Yi Xue Za Zhi. 2017:97(16):1214-7.

5. Wang Z, Liu Y, Xu Y, Gao C, Chen Y, Luo H. Three-dimensional printingguided percutaneous transcatheter closure of secundum atrial septal defect with rim deficiency: first-in-human series. Cardiol J. 2016;23(6):599-603.

6. Wang $\mathrm{Z}$, Luo H, Gao C, Xu Y. Three-dimensional printing model for the postoperative follow-up of atrial septal defect. Int J Cardiol. 2016;222:891-2.

7. Yang $F$, Zheng $H$, Lyu J, Yang $X$, Yang Y, Pang Y, Liang F, Zhang G, Xu Z, Jiang S, Lyu B, Meng F, Hao B. A case of transcatheter closure of inferior vena cava type atrial septal defect with patent ductus arteriosus occlusion device guided by 3D printing technology. Zhonghua Xin Xue Guan Bing Za Zhi. 2015;43(7):631-3.

8. Bhatla P, Mosca RS, Tretter JT. Altering management decisions with gained anatomical insight from a 3D printed model of a complex ventricular septal defect. Cardiol Young. 2017;27(2):377-80.

9. Bhatla P, Tretter JT, Ludomirsky A, Argilla M, Latson LA, Chakravarti S, Barker PC, Yoo S-J, McElhinney DB, Wake N, Mosca RS. Utility and scope of rapid prototyping in patients with complex muscular ventricular septal defects or double-outlet right ventricle: does it Alter Management decisions? Pediatr Cardiol. 2017;38(1):103-14.

10. Faroogi KM, Uppu SC, Nguyen K, Srivastava S, Ko HH, Choueiter N, Wollstein A, Parness IA, Narula J, Sanz J, Nielsen JC. Application of virtual three-dimensional models for simultaneous visualization of Intracardiac anatomic relationships in double outlet right ventricle. Pediatr Cardiol. 2015;37(1):90-8.

11. Garekar S, Bharati A, Chokhandre M, Mali S, Trivedi B, Changela VP, Solanki N, Gaikwad S, Agarwal V. Clinical application and multidisciplinary assessment of three dimensional printing in double outlet right ventricle with remote ventricular septal defect. World J Pediatr Congenit Heart Surg. 2016;7(3):344-50.

12. Hadeed $K$, Dulac $Y, A c a r P$. Three-dimensional printing of a complex $C H D$ to plan surgical repair. Cardiol Young. 2016;26(7):1432-4.

13. Ngan EM, Rebeyka IM, Ross DB, Hirji M, Wolfaardt JF, Seelaus R, Grosvenor A, Noga ML. The rapid prototyping of anatomic models in pulmonary atresia. J Thorac Cardiovasc Surg. 2006;132(2):264-9.

14. Olivieri LU, Krieger A, Loke Y-H, Nath DS, Kim PCW, Sable CA. Threedimensional printing of intracardiac defects from three-dimensional echocardiographic images: feasibility and relative accuracy. J Am Soc Echocardiogr. 2015;28(4):392-7.
15. Sodian R, Weber S, Markert M, Rassoulian D, Kaczmarek I, Lueth TC, Reichart B, Daebritz S. Stereolithographic models for surgical planning in congenital heart surgery. Ann Thorac Surg. 2007:83(5):1854-7.

16. Valverde I, Gomez G, Gonzalez A, Suarez-Mejias C, Adsuar A, Coserria JF, Uribe S, Gomez-Cia T, Hosseinpour AR. Three-dimensional patient-specific cardiac model for surgical planning in Nikaidoh procedure. Cardiol Young. 2015;25(4):698-704.

17. Schievano S, Migliavacca F, Coats L, Khambadkone S, Carminati M, Wilson N, Deanfield JE, Bonhoeffer P, Taylor AM. Percutaneous pulmonary valve implantation based on rapid prototyping of right ventricular outflow tract and pulmonary trunk from MR data. Radiology. 2007;242(2):490-7.

18. Ryan JR, Moe TG, Richardson R, Frakes DH, Nigro JJ, Pophal S. A novel approach to neonatal Management of Tetralogy of Fallot, with pulmonary atresia, and multiple Aortopulmonary collaterals. JACC Cardiovasc Imaging. 2015;8(1):103-4

19. Bhatla P, Tretter JT, Chikkabyrappa S, Chakravarti S, Mosca RS. Surgical planning for a complex double-outlet right ventricle using 3D printing. Echocardiography. 2017;34(5):802-4.

20. Faroogi KM, Gonzalez-Lengua C, Shenoy R, Sanz J, Nguyen K. Use of a three dimensional printed cardiac model to assess suitability for biventricular repair. World J Pediatr Congenit Heart Surg. 2016;7(3):414-6.

21. Faroogi KM, Nielsen JC, Uppu SC, Srivastava S, Parness IA, Sanz J, Nguyen K. Use of 3-dimensional printing to demonstrate complex intracardiac relationships in double-outlet right ventricle for surgical planning. Circ Cardiovasc Imaging. 2015;8(5):e003043. https://doi.org/10.1161/ CIRCIMAGING.114.003043.

22. Dydynski PB, Kiper C, Kozik D, Keller BB, Austin E, Holland B. Threedimensional reconstruction of Intracardiac anatomy using CTA and surgical planning for double outlet right ventricle: early experience at a tertiary care congenital heart center. World J Pediatr Congenit Heart Surg. 2016;7(4):46774. https://doi.org/10.1177/2150135116651399.

23. Kappanayil M, Koneti NR, Kannan RR, Kottayil BP, Kumar K. Threedimensional-printed cardiac prototypes aid surgical decision-making and preoperative planning in selected cases of complex congenital heart diseases: early experience and proof of concept in a resource-limited environment. Ann Pediatr Cardiol. 2017;10(2):117-25.

24. Karsenty C, Hadeed K, Acar P. Congenital heart disease: recent technical advances in three-dimensional echocardiography. Presse Med. 2017;46(5):482-9.

25. Biglino G, Giardini A, Hsia T-Y, Figliola R, Taylor AM, Schievano S, MOCHA Collaborative Group. Modeling single ventricle physiology: review of engineering tools to study first stage palliation of hypoplastic left heart syndrome. Front Pediatr. 2013;1:31.

26. Kutty S, Rathod RH, Danford DA, Celermajer DS. Role of imaging in the evaluation of single ventricle with the Fontan palliation. Heart. 2016;102(3): 174-83.

27. Smith ML, McGuinness J, O'Reilly MK, Nolke L, Murray JG, Jones JFX. The role of 3D printing in preoperative planning for heart transplantation in complex congenital heart disease. Ir J Med Sci. 2017;186(3):753-6.

28. Gosnell J, Pietila T, Samuel BP, Kurup HKN, Haw MP, Vettukattil J. Integration of computed tomography and three-dimensional echocardiography for hybrid three-dimensional printing in congenital heart disease. J Digit Imaging. 2016;29(6):665-9.

29. Olivieri L, Krieger A, Chen MY, Kim P, Kanter JP. 3D heart model guides complex stent angioplasty of pulmonary venous baffle obstruction in a mustard repair of D-TGA. Int J Cardiol. 2014;172(2):e297-8.

30. Mottl-Link S, Hübler M, Kühne T, Rietdorf U, Krueger JJ, Schnackenburg B, De Simone R, Berger F, Juraszek A, Meinzer HP, Karck M, Hetzer R, Wolf I. Physical models aiding in complex congenital heart surgery. Ann Thorac Surg. 2007:86:273-7. https://doi.org/10.1016/j.athoracsur.2007.06.001.

31. Aung SC, Tan BK, Foo CL, Lee ST. Selective laser sintering: application of a rapid prototyping method in craniomaxillofacial reconstructive surgery. Ann Acad Med Singap. 1999;28(5):739-43.

32. Cheung LK, Wong MC, Wong LL. Refinement of facial reconstructive surgery by stereo-model planning. Ann R Australas Coll Dent Surg. 2002;16:129-32.

33. Schantz JT, Hutmacher DW, Lam CX, Brinkmann M, Wong KM, Lim TC, Chou N, Guldberg RE, Teoh SH. Repair of calvarial defects with customised tissueengineered bone grafts II. Evaluation of cellular efficiency and efficacy in vivo. Tissue Eng. 2003:9 Suppl 1:S127-39.

34. Wagner JD, Baack B, Brown GA, Kelly J. Rapid 3-dimensional prototyping for surgical repair of maxillofacial fractures: a technical note. J Oral Maxillofac Surg. 2004;62(7):898-901. 
35. Cao D, Yu Z, Chai G, Liu J, Mu X. Application of EH compound artificial bone material combined with computerized three-dimensional reconstruction in craniomaxillofacial surgery. J Craniofac Surg. 2010;21(2):440-3.

36. Levine JP, Patel A, Saadeh PB, Hirsch DL. Computer-aided design and manufacturing in craniomaxillofacial surgery: the new state of the art. J Craniofac Surg. 2012;23(1):288-93.

37. Cui J, Chen L, Guan X, Ye L, Wang H, Liu L. Surgical planning, threedimensional model surgery and preshaped implants in treatment of bilateral craniomaxillofacial post-traumatic deformities. J Oral Maxillofac Surg. 2014;72(6):1138.e1-14.

38. Kaur H, Nanda A, Koli D, Verma M, Singh H, Bishnoi I, Pathak P, Gupta A. An alternate vista in rehabilitation of cranial defects: combining digital and manual techniques to fabricate a hybrid Cranioplast. J Craniofac Surg. 2015;26(4):1313-5.

39. Xie Y, Rustom LE, McDermott AM, Boerckel JD, Johnson AJ, Alleyne AG, Hoelzle DJ. Net shape fabrication of calcium phosphate scaffolds with multiple material domains. Biofabrication. 2016;8(1):015005.

40. Florentino VG, Mendonça DS, Bezerra AV, Silva Lde F, Pontes RF, Melo CV, Mello Mde J, de Aguiar AS. Reconstruction of frontal bone with custom-made prosthesis using rapid prototyping. J Craniofac Surg. 2016;27(4):e354-6.

41. Shao H, Ke X, Liu A, Sun M, He Y, Yang X, Fu J, Liu Y, Zhang L, Yang G, Xu S, Gou Z. Bone regeneration in 3D printing bioactive ceramic scaffolds with improved tissue/material interface pore architecture in thin-wall bone defect. Biofabrication. 2017;9(2):025003.

42. Gao F, Wang Q, Liu C, Xiong B, Luo T. Individualized 3D printed model-assisted posterior screw fixation for the treatment of craniovertebral junction abnormality: a retrospective study. J Neurosurg Spine. 2017;27(1):29-34.

43. Edwards J, Rogers T. The accuracy and applicability of 3D modeling and printing blunt force cranial injuries. J Forensic Sci. 2018;3(3):683-91.

44. Murray DJ, Edwards G, Mainprize JG, Antonyshyn O. Optimizing craniofacial osteotomies: applications of haptic and rapid prototyping technology. J Oral Maxillofac Surg. 2008;66(8):1766-72.

45. Kozakiewicz M, Elgalal M, Loba P, Komuński P, Arkuszewski P, BroniarczykLoba A, Stefańczyk L. Clinical application of 3D pre-bent titanium implants for orbital floor fractures. J Craniomaxillofac Surg. 2009;37(4):229-34

46. Li WZ, Zhang MC, Li SP, Zhang LT, Huang Y. Application of computer-aided three-dimensional skull model with rapid prototyping technique in repair of zygomatico-orbito-maxillary complex fracture. Int J Med Robot. 2009;5(2):158-63.

47. Tang W, Guo L, Long J, Wang H, Lin Y, Liu L, Tian W. Individual design and rapid prototyping in reconstruction of orbital wall defects. J Oral Maxillofac Surg. 2010;68(3):562-70.

48. Herlin C, Koppe M, Béziat JL, Gleizal A. Rapid prototyping in craniofacial surgery: using a positioning guide after zygomatic osteotomy - a case report. J Craniomaxillofac Surg. 2011;39(5):376-9.

49. Feng F, Wang H, Guan X, Tian W, Jing W, Long J, Tang W, Liu L. Mirror imaging and preshaped titanium plates in the treatment of unilateral malar and zygomatic arch fractures. Oral Surg Oral Med Oral Pathol Oral Radiol Endod. 2011;112(2):188-94.

50. An JG, Zhang Y, He Y, Li JM. Application of 3-D skull models and guide plates in the treatment of unilateral orbitozygomatic deformity after fracture. Zhonghua Zheng Xing Wai Ke Za Zhi. 2011;27(2):81-5.

51. He LS, Shang HT, Bai SZ, Bo B. Digital surgical technology in reconstruction of orbital frame. Zhonghua Kou Qiang Yi Xue Za Zhi. 2011;46(8):452-7.

52. Li J, Li P, Lu H, Shen L, Tian W, Long J, Tang W. Digital design and individually fabricated titanium implants for the reconstruction of traumatic zygomatico-orbital defects. J Craniofac Surg. 2013;24(2):363-8.

53. Fang JJ, Liu JK, Wu TC, Lee JW, Kuo TH. Complex facial deformity reconstruction with a surgical guide incorporating a built-in occlusal stent as the positioning reference. J Craniofac Surg. 2013;24(3):e260-5.

54. Liu XZ, Shu DL, Ran W, Guo B, Liao X. Digital surgical templates for managing high-energy zygomaticomaxillary complex injuries associated with orbital volume change: a quantitative assessment. J Oral Maxillofac Surg. 2013;71(10):1712-23.

55. Ernoult C, Bouletreau P, Meyer C, Aubry S, Breton P, Bachelet JT. Reconstruction assisted by 3D printing in maxillofacial surgery. Rev Stomatol Chir Maxillofac Chir Orale. 2015;116(2):95-102.

56. Park SW, Choi JW, Koh KS, Oh TS. Mirror-imaged rapid prototype skull model and pre-molded synthetic scaffold to achieve optimal orbital cavity reconstruction. J Oral Maxillofac Surg. 2015;73(8):1540-53.

57. D'Souza N, Mainprize J, Edwards G, Binhammer P, Antonyshyn O. Teaching facial fracture repair: a novel method of surgical skills training using threedimensional biomodels. Plast Surg (Oakv). 2015;23(2):81-6.
58. Tabaković SZ, Konstantinović VS, Radosavljević R, Movrin D, Hadžistević M, Hatab N. Application of computer-aided designing and rapid prototyping Technologies in Reconstruction of blowout fractures of the orbital floor. J Craniofac Surg. 2015;26(5):1558-63.

59. Sun L, Xiao J, Lan Y, Xiong Y, Zhang L, Zhou H, Zhang L. Reconstruction of the orbital fracture with enophthalmos using customized titanium mesh combined with Medpor. Hua Xi Kou Qiang Yi Xue Za Zhi. 2015; 33(3):272-5.

60. Podolsky DJ, Mainprize JG, Edwards GP, Antonyshyn OM. Patient-specific orbital implants: development and implementation of Technology for More Accurate Orbital Reconstruction. J Craniofac Surg. 2016;27(1):131-3.

61. Huang L, Lin L, Wang Z, Shi B, Zhu X, Qiu Y, Huang Y, Yu X, Liao Y. Personalized reconstruction of traumatic orbital defects based on precise three-dimensional orientation and measurements of the globe. J Craniofac Surg. 2017;28(1):172-9.

62. Williams JV, Revington PJ. Novel use of an aerospace selective laser sintering machine for rapid prototyping of an orbital blowout fracture. Int J Oral Maxillofac Surg. 2010;39(2):182-4.

63. Kozakiewicz M, Elgalal M, Piotr L, Broniarczyk-Loba A, Stefanczyk L. Treatment with individual orbital wall implants in humans - 1-year ophthalmologic evaluation. J Craniomaxillofac Surg. 2011;39(1):30-6.

64. Li P, Tang W, Li J, Tian DW. Preliminary application of virtual simulation and reposition template for zygomatico-orbitomaxillary complex fracture. J Craniofac Surg. 2012;23(5):1436-9.

65. Ciprandi MT, Primo BT, Gassen HT, Closs LQ, Hernandez PA, Silva AN Jr. Calcium phosphate cement in orbital reconstructions. J Craniofac Surg. 2012;23(1):145-8.

66. Huang YH, Seelaus R, Zhao L, Patel PK, Cohen M. Virtual surgical planning and $3 \mathrm{D}$ printing in prosthetic orbital reconstruction with percutaneous implants: a technical case report. Int Med Case Rep J. 2016;9:341-5.

67. Herford AS, Miller M, Lauritano F, Cervino G, Signorino F, Maiorana C. The use of virtual surgical planning and navigation in the treatment of orbital trauma. Chin J Traumatol. 2017;20(1):9-13.

68. Tetsworth K, Block S, Glatt V. Putting 3D modelling and 3D printing into practice: virtual surgery and preoperative planning to reconstruct complex post-traumatic skeletal deformities and defects. SICOT J. 2017;3:16.

69. Veit JA, Thierauf J, Egner K, Wiggenhauser S, Friedrich D, Greve J, Schuler PJ, Hoffmann TK, Schramm A. Virtual planning of prosthetic treatment of the orbit. Laryngorhinootologie. 2017;96(6):374-9.

70. Li J, Hsu Y, Luo E, Khadka A, Hu J. Computer-aided design and manufacturing and rapid prototyped nanoscale hydroxyapatite/polyamide (n-HA/PA) construction for condylar defect caused by mandibular angle ostectomy. Aesthet Plast Surg. 2011;35(4):636-40.

71. Wang G, Li J, Khadka A, Hsu Y, Li W, Hu J. CAD/CAM and rapid prototyped titanium for reconstruction of ramus defect and condylar fracture caused by mandibular reduction. Oral Surg Oral Med Oral Pathol Oral Radiol. 2012; 113(3):356-61.

72. Prisman E, Haerle SK, Irish JC, Daly M, Miles B, Chan H. Value of preoperative mandibular plating in reconstruction of the mandible. Head Neck. 2014; 36(6):828-33.

73. Yamada H, Nakaoka K, Horiuchi T, Kumagai K, Ikawa T, Shigeta Y, Imamura E, lino M, Ogawa T, Hamada Y. Mandibular reconstruction using custom-made titanium mesh tray and particulate cancellous bone and marrow harvested from bilateral posterior ilia. J Plast Surg Hand Surg. 2014;48(3):183-90.

74. Xu X, Deng RX, Deng SM, Yang JL, Chen J. Application of three dimensional model in treatment of superolateral dislocation of mandibular condyle. Zhejiang Da Xue Xue Bao Yi Xue Ban. 2014;43(5):572-6.

75. Dong Z, Li Q, Bai S, Zhang L. Application of 3-dimensional printing technology to Kirschner wire fixation of adolescent condyle fracture. J Oral Maxillofac Surg. 2015;73(10):1970-6.

76. Fowell C, Edmondson S, Martin T, Praveen P. Rapid prototyping and patient-specific pre-contoured reconstruction plate for comminuted fractures of the mandible. Br J Oral Maxillofac Surg. 2015;53(10):1035-7.

77. el-Gengehi M, Seif SA. Evaluation of the accuracy of computer-guided mandibular fracture reduction. J Craniofac Surg. 2015;26(5):1587-91.

78. Qin M, Liu Y, Wang L, He J, Xuan M, Hua C, Li D, Jin Z, Wang X. Design and optimization of the fixing plate for customized mandible implants. J Craniomaxillofac Surg. 2015;43(7):1296-302.

79. Qu Z, Wang Q, Feng X, Sheng L, Ma W, Qu W. Application of 3D printing technique in bilateral sagittal split osteotomy. Hua Xi Kou Qiang Yi Xue Za Zhi. 2015;33(5):504-8. 
80. Voss JO, Varjas V, Raguse JD, Thieme N, Richards RG, Kamer L. Computed tomography-based virtual fracture reduction techniques in bimandibular fractures. J Craniomaxillofac Surg. 2016;44(2):177-85.

81. van de Velde WL, Schepers $\mathrm{RH}$, van Minnen B. The 3D-printed dental splint: a valuable tool in the surgical treatment of malocclusion after polytrauma. Ned Tijdschr Tandheelkd. 2016;123(1):19-23.

82. Yamada H, Nakaoka K, Sonoyama T, Kumagai K, Ikawa T, Shigeta Y, Harada N, Kawamura N, Ogawa T, Hamada Y. Clinical usefulness of mandibular reconstruction using custom-made titanium mesh tray and autogenous particulate cancellous bone and marrow harvested from tibia and/or Ilia. J Craniofac Surg. 2016;27(3):586-92.

83. Druelle C, Touzet-Roumazeille S, Raoul G, Ferri J, Nicot R. How to produce pre-shaped rigid arch bars using low-cost 3D printing technology- a technical note. J Stomatol Oral Maxillofac Surg. 2017;118:213-6.

84. Ma J, Ma L, Wang Z, Zhu X, Wang W. The use of 3D-printed titanium mesh tray in treating complex comminuted mandibular fractures: a case report. Medicine (Baltimore). 2017;96(27):e7250.

85. Wu CH, Lin YS, Liu YS, Lin CL. Biomechanical evaluation of a novel hybrid reconstruction plate for mandible segmental defects: a finite element analysis and fatigue testing. J Craniomaxillofac Surg. 2017:45:1671-80.

86. Brito NM, Soares RS, Monteiro EL, Martins SC, Cavalcante JR, Grempel RG, Neto JA. Additive manufacturing for surgical planning of mandibular fracture. Acta Stomatol Croat. 2016;50(4):348-53.

87. Ciocca L, Mazzoni S, Fantini M, Persiani F, Baldissara P, Marchetti C, Scotti R. A CAD/CAM-prototyped anatomical condylar prosthesis connected to a custom-made bone plate to support a fibula free flap. Med Biol Eng Comput. 2012;50(7):743-9. https://doi.org/10.1007/s11517-012-0898-4.

88. Lindner A, Rasse M, Wolf HP, Millesi W, Eglmeier R, Friede I. Indications and use of stereolithographic skull reconstructions in oromaxillofacial surgery. Radiologe. 1995;35(9):578-82.

89. McGurk M, Amis AA, Potamianos P, Goodger NM. Rapid prototyping techniques for anatomical modelling in medicine. Ann R Coll Surg Engl. 1997;79(3):169-74.

90. Petzold R, Zeilhofer HF, Kalender WA. Rapid protyping technology in medicine-basics and applications. Comput Med Imaging Graph. 1999;23(5):277-84.

91. Girod S, Teschner M, Schrell U, Kevekordes B, Girod B. Computer-aided 3-D simulation and prediction of craniofacial surgery: a new approach. J Craniomaxillofac Surg. 2001;29(3):156-8.

92. Paeng JY, Lee JH, Lee JH, Kim MJ. Condyle as the point of rotation for 3-D planning of distraction osteogenesis for hemifacial microsomia. J Craniomaxillofac Surg. 2007;35(2):91-102.

93. Robiony M, Salvo I, Costa F, Zerman N, Bazzocchi M, Toso F, Bandera C, Filippi S, Felice M, Politi M. Virtual reality surgical planning for maxillofacial distraction osteogenesis: the role of reverse engineering rapid prototyping and cooperative work. J Oral Maxillofac Surg. 2007;65(6):1198-208.

94. McGurk M, Slabberti HD, Amis A, McDonald F. A preliminary report of a case using an intra-oral distraction device. Br Dent J. 1997;183(2):63-6.

95. Klammert U, Böhm H, Schweitzer T, Würzler K, Gbureck U, Reuther J, Kübler A. Multi-directional Le fort III midfacial distraction using an individual prefabricated device. J Craniomaxillofac Surg. 2009:37(4):210-5.

96. Zhou L, He L, Shang H, Liu G, Zhao J, Liu Y. Correction of hemifacial microsomia with the help of mirror imaging and a rapid prototyping technique: case report. Br J Oral Maxillofac Surg. 2009;47(6):486-8.

97. Olszewski $\mathrm{R}$, Reychler $\mathrm{H}$. Three-dimensional surgical guide for frontal-nasalethmoid-vomer disjunction in Le fort III osteotomy. J Craniofac Surg. 2011; 22(5):1791-2.

98. Gao QW, Song HF, Xu MH, Liu CM, Chai JK. Mandibular-driven simultaneous maxillo-mandibular distraction for hemifacial microsomia with rapid prototyping technology. Zhonghua Zheng Xing Wai Ke Za Zhi. 2013;29(6): 431-4.

99. Seres L, Varga E Jr, Kocsis A, Rasko Z, Bago B, Varga E, Piffko J. Correction of a severe facial asymmetry with computerized planning and with the use of a rapid prototyped surgical template: a case report/technique article. Head Face Med. 2014;10:27.

100. Engel M, Hoffmann J, Castrillon-Oberndorfer G, Freudlsperger C. The value of three-dimensional printing modelling for surgical correction of orbital hypertelorism. Oral Maxillofac Surg. 2015;19(1):91-5.

101. Kang SH, Kim MK, You TK, Lee JY. Modification of planned postoperative occlusion in orthognathic surgery, based on computer-aided design/ computer-aided manufacturing-engineered preoperative surgical simulation. J Oral Maxillofac Surg. 2015;73(1):134-51.
102. Yin L, Tang X, Shi L, Yin H, Zhang Z. Mandibular distraction combined with orthognathic techniques for the correction of severe adult mandibular hypoplasia. J Craniofac Surg. 2014;25(6):1947-52.

103. Mazzoni S, Bianchi A, Schiariti G, Badiali G, Marchetti C. Computer-aided design and computer-aided manufacturing cutting guides and customized titanium plates are useful in upper maxilla waferless repositioning. J Oral Maxillofac Surg. 2015;73(4):701-7

104. Shi L, Liu W, Yin L, Feng S, Xu S, Zhang ZY. Surgical guide assistant mandibular distraction osteogenesis and sagittal split osteotomy in the treatment of hemifacial microsomia. J Craniofac Surg. 2015;26(2):498-500.

105. Xu H, Zhang C, Shim YH, Li H, Cao D. Combined use of rapid-prototyping model and surgical guide in correction of mandibular asymmetry malformation patients with normal occlusal relationship. J Craniofac Surg. 2015;26(2):418-21

106. Soleman J, Thieringer F, Beinemann J, Kunz C, Guzman R. Computer-assisted virtual planning and surgical template fabrication for frontoorbital advancement. Neurosurg Focus. 2015;38(5):E5.

107. Li Y, Jiang Y, Ye B, Hu J, Chen Q, Zhu S. Treatment of Dentofacial deformities secondary to Osteochondroma of the mandibular condyle using virtual surgical planning and 3-dimensional printed surgical templates. J Oral Maxillofac Surg. 2016;74(2):349-68.

108. Ying B, Ye N, Jiang Y, Liu Y, Hu J, Zhu S. Correction of facial asymmetry associated with vertical maxillary excess and mandibular prognathism by combined orthognathic surgery and guiding templates and splints fabricated by rapid prototyping technique. Int J Oral Maxillofac Surg. 2015; 44(11):1330-6.

109. Chai G, Tan A, Yao CA, Magee WP 3rd, Junjun P, Zhu M, Bogari M, Hsu Y, Xu $H$, Zhang $Y$. Treating parry-Romberg syndrome using three-dimensional scanning and printing and the anterolateral thigh dermal Adipofascial flap. J Craniofac Surg. 2015;26(6):1826-9.

110. Seres L, Kocsis A, Varga E, Raskó Z, Virág V, Bagó B, Varga E, Piffkó J. Surgery on virtual model and 3-dimensional printing of a surgical wafer for the correction of a severe mandibular asymmetry. Fogorv Sz. 2015;108(2):45-52.

111. Steinbacher DM. Three-dimensional analysis and surgical planning in Craniomaxillofacial surgery. J Oral Maxillofac Surg. 2015;73(12 Suppl):S40-56.

112. Fiaschi $P$, Pavanello M, Imperato A, Dallolio V, Accogli A, Capra V, Consales A, Cama A, Piatelli G. Surgical results of cranioplasty with a polymethylmethacrylate customized cranial implant in pediatric patients: a single-center experience. J Neurosurg Pediatr. 2016;17(6):705-10.

113. Di Rocco F, Szathmari A, Mottolese C. Wire fixation of internal distractor for cranial vault remodeling. Childs Nerv Syst. 2016;32(6):1131-3.

114. Ikawa T, Shigeta Y, Hirabayashi R, Hirai S, Hirai K, Harada N, Kawamura N, Ogawa T. Computer assisted mandibular reconstruction using a custommade titan mesh tray and removable denture based on the top-down treatment technique. J Prosthodont Res. 2016;60(4):321-31.

115. Lee UL, Kwon JS, Woo SH, Choi YJ. Simultaneous Bimaxillary surgery and mandibular reconstruction with a 3-dimensional printed titanium implant fabricated by Electron beam melting: a preliminary mechanical testing of the printed mandible. J Oral Maxillofac Surg. 2016;74(7):1501.e1-1501.e15.

116. Emodi O, Shilo D, Israel Y, Rachmiel A. Three-dimensional planning and printing of guides and templates for reconstruction of the mandibular ramus and condyle using autogenous costochondral grafts. Br J Oral Maxillofac Surg. 2017;55(1):102-4.

117. Hatamleh M, Turner C, Bhamrah G, Mack G, Osher J. Improved virtual planning for Bimaxillary orthognathic surgery. J Craniofac Surg. 2016;27(6): e568-73.

118. Eley KA, Watt-Smith SR, Golding SJ. 'Black Bone' MRI: a novel imaging technique for 3D printing. Dentomaxillofac Radiol. 2017;46(3):20160407.

119. LoPresti M, Daniels B, Buchanan EP, Monson L, Lam S. Virtual surgical planning and $3 \mathrm{D}$ printing in repeat calvarial vault reconstruction for craniosynostosis: technical note. J Neurosurg Pediatr. 2017;19(4):490-4.

120. Rubio-Palau J, Prieto-Gundin A, Cazalla AA, Serrano MB, Fructuoso GG, Ferrandis FP, Baró AR. Three-dimensional planning in craniomaxillofacial surgery. Ann Maxillofac Surg. 2016;6(2):281-6.

121. Wang L, Tian D, Sun X, Xiao Y, Chen L, Wu G. The precise repositioning instrument for Genioplasty and a three-dimensional printing technique for treatment of complex facial asymmetry. Aesthet Plast Surg. 2017;41(4):919-29.

122. Jiménez Ormabera B, Díez Valle R, Zaratiegui Fernández J, Llorente Ortega M, Unamuno Iñurritegui $X$, Tejada Solís S. 3D printing in neurosurgery: a specific model for patients with craniosynostosis. Neurocirugia (Astur). 2017; 28(6):260-5 
123. Salles F, Anchieta M, Costa Bezerra P, Torres ML, Queiroz E, Faber J. Complete and isolated congenital aglossia: case report and treatment of sequelae using rapid prototyping models. Oral Surg Oral Med Oral Pathol Oral Radiol Endod. 2008;105(3):e41-7.

124. Yu Q, Gong X, Wang GM, Yu ZY, Qian YF, Shen G. A novel technique for presurgical nasoalveolar molding using computer-aided reverse engineering and rapid prototyping. J Craniofac Surg. 2011;22(1):142-6.

125. Zgong X, Yu Q, Yu ZY, Wang GM, Qian YF. Presurgical alveolar molding using computer aided design in infants with unilateral complete cleft lip and palate. Shanghai Kou Qiang Yi Xue. 2012;21(2):180-4.

126. Gong X, Yu Q. Correction of maxillary deformity in infants with bilateral cleft lip and palate using computer-assisted design. Oral Surg Oral Med Oral Pathol Oral Radiol. 2012;114(5 Suppl):S74-8.

127. Loeffelbein DJ, Rau A, Wolff KD. Impression technique for monitoring and virtual treatment planning in nasoalveolar moulding. Br J Oral Maxillofac Surg. 2013;51(8):898-901

128. Wang J, Liu JF, Liu W, Wang JC, Wang SY, Gui L. Application of computer techniques in repair of oblique facial clefts with outer-table calvarial bone grafts. J Craniofac Surg. 2013;24(3):957-60.

129. Zheng Y, Zhang D, Qin T, Wu G. Correction of nasal deformity in infants with unilateral cleft lip and palate using multiple digital techniques. J Prosthet Dent. 2016;115(6):788-91.

130. Ritschl LM, Rau A, Güll FD, diBora B, Wolff KD, Schönberger M, Bauer FX, Wintermantel $E$, Loeffelbein DJ. Pitfalls and solutions in virtual design of nasoalveolar molding plates by using CAD/CAM technology--a preliminary clinical study. J Craniomaxillofac Surg. 2016;44(4):453-9.

131. Cho MJ, Kane AA, Hallac RR, Gangopadhyay N, Seaward JR. Liquid latex molding: a novel application of 3D printing to facilitate flap design. Cleft Palate Craniofac J. 2017;54(4):453-6.

132. Lioufas PA, Quayle MR, Leong JC, McMenamin PG. 3D printed models of cleft palate pathology for surgical education. Plast Reconstr Surg Glob Open. 2016;4(9):e1029.

133. Du F, Li B, Yin N, Cao Y, Wang Y. Volumetric analysis of alveolar bone defect using three-dimensional-printed models versus computer-aided engineering. J Craniofac Surg. 2017;28(2):383-6.

134. Wu Y, Wang G, Yang Y, Chen Y. Application of computer-aided design and customized implants in the reconstruction of pyriform aperture defects secondary to unilateral cleft lip and palate. J Craniofac Surg. 2017;28:1517-20.

135. Nicot R, Couly G, Ferri J, Levaillant JM. Three-dimensional printed haptic model from a prenatal surface-rendered oropalatal sonographic view: a new tool in the surgical planning of cleft lip/palate. Int J Oral Maxillofac Surg. 2017:47:44-7.

136. Klein M, Hein A, Lueth T, Bier J. Robot-assisted placement of craniofacial implants. Int J Oral Maxillofac Implants. 2003;18(5):712-8.

137. Hatamleh MM, Watson J. Construction of an implant-retained auricular prosthesis with the aid of contemporary digital technologies: a clinical report. J Prosthodont. 2013;22(2):132-6.

138. Watson J, Hatamleh MM. Complete integration of technology for improved reproduction of auricular prostheses. J Prosthet Dent. 2014;111(5):430-6.

139. Chen ZC, Albdour MN, Lizardo JA, Chen YA, Chen PK. Precision of threedimensional stereo-photogrammetry $\left(3 \mathrm{dMD}^{\mathrm{TM}}\right)$ in anthropometry of the auricle and its application in microtia reconstruction. J Plast Reconstr Aesthet Surg. 2015;68(5):622-31.

140. Berens AM, Newman S, Bhrany AD, Murakami C, Sie KC, Zopf DA. Computer-aided design and 3D printing to produce a costal cartilage model for simulation of auricular reconstruction. Otolaryngol Head Neck Surg. 2016;155(2):356-9.

141. Thomas DJ. Could 3D bioprinted tissues offer future hope for microtia treatment? Int J Surg. 2016;32:43-4.

142. Zhu P, Chen S. Clinical outcomes following ear reconstruction with adjuvant 3D template model. Acta Otolaryngol. 2016;136(12):1236-41.

143. Jeon B, Lee C, Kim M, Choi TH, Kim S, Kim S. Fabrication of threedimensional scan-to-print ear model for microtia reconstruction. J Surg Res. 2016;206(2):490-7.

144. Flores RL, Liss H, Raffaelli S, Humayun A, Khouri KS, Coelho PG, Witek L. The technique for 3D printing patient-specific models for auricular reconstruction. J Craniomaxillofac Surg. 2017;45(6):937-43.

145. Chen HY, Ng LS, Chang CS, Lu TC, Chen NH, Chen ZC. Pursuing Mirror image reconstruction in unilateral Microtia: customizing auricular framework by application of three-dimensional imaging and three-dimensional printing. Plast Reconstr Surg. 2017;139(6):1433-43.
146. Federspil PA. The role of auricular prostheses (Epitheses) in ear reconstruction. Facial Plast Surg. 2015;31(6):626-32.

147. Mueller A, Krishnan KG, Uhl E, Mast G. The application of rapid prototyping techniques in cranial reconstruction and preoperative planning in neurosurgery. J Craniofac Surg. 2003;14(6):899-914

148. Murray DJ, Edwards G, Mainprize JG, Antonyshyn O. Advanced technology in the management of fibrous dysplasia. J Plast Reconstr Aesthet Surg. 2008; 61(8):906-16.

149. Ching WC, Goh RC, Lin CL, Lo LJ, Chen YR. Aesthetic restoration of frontoorbital deformity with prefabricated implant utilizing modeling clay and rapid-prototyping technology. Aesthet Plast Surg. 2011;35(6):1176-9.

150. Huang D, Chen M, He D, Yang C, Yuan J, Bai G, Wang Y, Wei W, Chen Z. Preservation of the inferior alveolar neurovascular bundle in the osteotomy of benign lesions of the mandible using a digital template. Br J Oral Maxillofac Surg. 2015;53(7):637-41.

151. Darwood A, Collier J, Joshi N, Grant WE, Sauret-Jackson V, Richards R, Dawood A, Kirkpatrick N. Re-thinking 3D printing: a novel approach to guided facial contouring. J Craniomaxillofac Surg. 2015; 43(7):1256-60.

152. Kang SJ, Oh MJ, Jeon SP. A novel and easy approach for contouring surgery in patients with craniofacial fibrous dysplasia. J Craniofac Surg. 2015;26(6):1977-8.

153. Nahumi N, Shohet MR, Bederson JB, Elahi E. Frontorbital fibrous dysplasia resection and reconstruction with custom Polyetherlatone Alloplast. J Craniofac Surg. 2015;26(8):e720-2.

154. Pan J, Ye B, Hu J, Li X, Zhang Y, Li J. Application of reverse engineering template for the correction of asymmetric deformity of maxillofacial fibrous dysplasia. J Craniofac Surg. 2016;27(2):e154-7.

155. Wang R, Li G, Liu C, Jia C, Han Y. Three-dimensional printing of reduction template in the contouring of craniofacial fibrous dysplasia. J Craniofac Surg. 2016;27(7):1792-4

156. Eisenmenger LB, Wiggins RH 3rd, Fults DW 3rd, Huo EJ. Application of 3D printing in a case of osteogenesis imperfecta for patient education, anatomic understanding, preoperative planning, and intraoperative evaluation. World Neurosurg. 2017;107:1049.e1-7.

157. Bill JS, Reuther JF. Rapid prototyping in planning reconstructive surgery of the head and neck. Review and evaluation of indications in clinical use. Mund Kiefer Gesichtschir. 2004;8(3):135-53.

158. Poukens J, Haex J, Riediger D. The use of rapid prototyping in the preoperative planning of distraction osteogenesis of the cranio-maxillofacial skeleton. Comput Aided Surg. 2003:8(3):146-54.

159. Mavili ME, Canter HI, Saglam-Aydinatay B, Kamaci S, Kocadereli I. Use of three-dimensional medical modeling methods for precise planning of orthognathic surgery. J Craniofac Surg. 2007;18(4):740-7.

160. Metzger MC, Hohlweg-Majert B, Schwarz U, Teschner M, Hammer B, Schmelzeisen R. Manufacturing splints for orthognathic surgery using a three-dimensional printer. Oral Surg Oral Med Oral Pathol Oral Radiol Endod. 2008;105(2):e1-7.

161. Robiony M, Salvo I, Costa F, Zerman N, Bandera C, Filippi S, Felice M, Politi M. Accuracy of virtual reality and stereolithographic models in maxillo-facial surgical planning. J Craniofac Surg. 2008;19(2):482-9.

162. Ibrahim D, Broilo TL, Heitz C, de Oliveira MG, de Oliveira HW, Nobre SM, Dos Santos Filho JH, Silva DN. Dimensional error of selective laser sintering, three-dimensional printing and PolyJet models in the reproduction of mandibular anatomy. J Craniomaxillofac Surg. 2009;37(3):167-73.

163. Edwards SP. Computer-assisted craniomaxillofacial surgery. Oral Maxillofac Surg Clin North Am. 2010;22(1):117-34.

164. Olszewski R, Tranduy K, Reychler $H$. Innovative procedure for computer-assisted genioplasty: three-dimensional cephalometry, rapid-prototyping model and surgical splint. Int J Oral Maxillofac Surg. 2010;39(7):721-4

165. Freitas EP, Rahal SC, Teixeira CR, Silva JV, Noritomi PY, Villela CH, Yamashita $\mathrm{S}$. Rapid prototyping and inclined plane technique in the treatment of maxillofacial malformations in a fox. Can Vet J. 2010;51(3):267-70.

166. Kim BC, Lee CE, Park W, Kim MK, Zhengguo P, Yu HS, Yi CK, Lee SH. Clinical experiences of digital model surgery and the rapid-prototyped wafer for maxillary orthognathic surgery. Oral Surg Oral Med Oral Pathol Oral Radiol Endod. 2011;111(3):278-85.

167. Bai S, Bo B, Bi Y, Wang B, Zhao J, Liu Y, Feng Z, Shang H, Zhao Y. CAD/CAM surface templates as an alternative to the intermediate wafer in orthognathic surgery. Oral Surg Oral Med Oral Pathol Oral Radiol Endod. 2010;110(5):e1-7. 
168. Li B, Zhang L, Sun H, Yuan J, Shen SG, Wang X. A novel method of computer aided orthognathic surgery using individual CAD/CAM templates: a combination of osteotomy and repositioning guides. Br J Oral Maxillofac Surg. 2013;51(8):e239-44.

169. Sun H, Li B, Zhao Z, Zhang L, Shen SG, Wang X. Error analysis of a CAD/ CAM method for unidirectional mandibular distraction osteogenesis in the treatment of hemifacial microsomia. Br J Oral Maxillofac Surg. 2013;51(8): 892-7.

170. Smith EJ, Anstey JA, Venne G, Ellis RE. Using additive manufacturing in accuracy evaluation of reconstructions from computed tomography. Proc Inst Mech Eng H. 2013;227(5):551-9.

171. Adolphs N, Liu W, Keeve E, Hoffmeister B. Craniomaxillofacial surgery planning based on 3D models derived from cone-beam $C T$ data. Comput Aided Surg. 2013;18(5-6):101-8.

172. Al-Ahmad HT, M Saleh MW, Hussein AM. Evaluation of an innovative computer-assisted sagittal split ramus osteotomy to reduce neurosensory alterations following orthognathic surgery: a pilot study. Int J Med Robot. 2013;9(2):134-41.

173. Salvato G, Chiavenna C, Meazzini MC. Guide surgery osteotomy system (GSOS) a new device for treatment in orthognathic surgery. J Craniomaxillofac Surg. 2014;42(3):234-8.

174. Abdel-Moniem Barakat A, Abou-ElFetouh A, Hakam MM, El-Hawary H, Abdel-Ghany KM. Clinical and radiographic evaluation of a computergenerated guiding device in bilateral sagittal split osteotomies. J Craniomaxillofac Surg. 2014;42(5):e195-203.

175. Sun Y, Luebbers HT, Agbaje JO, Schepers S, Vrielinck L, Lambrichts I, Politis C. Accuracy of upper jaw positioning with intermediate splint fabrication after virtual planning in bimaxillary orthognathic surgery. J Craniofac Surg. 2013;24(6):1871-6.

176. Cousley RR, Turner MJ. Digital model planning and computerized fabrication of orthognathic surgery wafers. J Orthod. 2014;41(1):38-45.

177. Adolphs N, Liu W, Keeve E, Hoffmeister B. RapidSplint: virtual splint generation for orthognathic surgery - results of a pilot series. Comput Aided Surg. 2014;19(1-3):20-8.

178. Zhu M, Chai G, Li Q. Application of three-dimensional printing technique in correction of mandibular prognathism. Zhongguo Xiu Fu Chong Jian Wai Ke Za Zhi. 2014;28(3):296-9.

179. Shqaidef A, Ayoub AF, Khambay BS. How accurate are rapid prototyped (RP) final orthognathic surgical wafers? A pilot study. Br J Oral Maxillofac Surg. 2014;52(7):609-14.

180. Kang SH, Kim MK, Kim BC, Lee SH. Orthognathic Y-splint: a CAD/CAMengineered maxillary repositioning wafer assembly. Br J Oral Maxillofac Surg. 2014;52(7):667-9.

181. Ye N, Long H, Zhu S, Yang Y, Lai W, Hu J. The accuracy of computer imageguided template for mandibular angle Ostectomy. Aesthet Plast Surg. 2015; 39(1):117-23.

182. Li Y, Jiang Y, Zhang N, Xu R, Hu J, Zhu S. Clinical feasibility and efficacy of using virtual surgical planning in bimaxillary orthognathic surgery without intermediate splint. J Craniofac Surg. 2015;26(2):501-5.

183. Cassetta M, Pandolfi S, Giansanti M. Minimally invasive corticotomy in orthodontics: a new technique using a CAD/CAM surgical template. Int J Oral Maxillofac Surg. 2015;44(7):830-3.

184. Lee UL, Kwon JS, Choi YJ. Keyhole system: a computer-assisted designed and computer-assisted manufactured Maxillomandibular complex Repositioner in orthognathic surgery. J Oral Maxillofac Surg. 2015;73(10):2024-9.

185. Choi JW, Kim N. Clinical application of three-dimensional printing technology in craniofacial plastic surgery. Arch Plast Surg. 2015;42(3):267-77.

186. Fang C, Fang Z, Fan Y, Li J, Xiang F, Tao H. Application of 3D visualization, $3 \mathrm{D}$ printing and $3 \mathrm{D}$ laparoscopy in the diagnosis and surgical treatment of hepatic tumors. Nan Fang Yi Ke Da Xue Xue Bao. 2015;35(5):639-45.

187. Mendez BM, Chiodo MV, Patel PA. Customized in-Office' three-dimensional printing for virtual surgical planning in craniofacial surgery. J Craniofac Surg. 2015;26(5):1584-6.

188. He W, Tian K, Xie X, Wang X, Li Y, Wang X, Li Z. Individualized surgical templates and titanium microplates for Le fort I osteotomy by computer-aided design and computer-aided manufacturing. J Craniofac Surg. 2015;26(6):1877-81.

189. Lee JW, Lim SH, Kim MK, Kang SH. Precision of a CAD/CAM-engineered surgical template based on a facebow for orthognathic surgery: an experiment with a rapid prototyping maxillary model. Oral Surg Oral Med Oral Pathol Oral Radiol. 2015;120(6):684-92.
190. Suomalainen A, Stoor P, Mesimäki K, Kontio RK. Rapid prototyping modelling in oral and maxillofacial surgery: a two year retrospective study. J Clin Exp Dent. 2015;7(5):e605-12.

191. Pfaff MJ, Steinbacher DM. Plastic surgery applications using threedimensional planning and computer-assisted design and manufacturing. Plast Reconstr Surg. 2016;137(3):603e-16e.

192. Resnick CM, Inverso G, Wrzosek M, Padwa BL, Kaban LB, Peacock ZS. Is there a difference in cost between standard and virtual surgical planning for orthognathic surgery? J Oral Maxillofac Surg. 2016;74(9):1827-33.

193. Li B, Wei HP, Jiang TF, Shen SY, Shen GF, Wang XD. Clinical application and accuracy of the genioplasty surgical templates system for osseous genioplasty. Zhonghua Kou Qiang Yi Xue Za Zhi. 2016; 51(11):646-50.

194. Shaheen E, Sun Y, Jacobs R, Politis C. Three-dimensional printed final occlusal splint for orthognathic surgery: design and validation. Int J Oral Maxillofac Surg. 2017;46(1):67-71

195. Chen X, Li X, Xu L, Sun Y, Politis C, Egger J. Development of a computeraided design software for dental splint in orthognathic surgery. Sci Rep. 2016;6:38867.

196. Legocki AT, Duffy-Peter A, Scott AR. Benefits and limitations of entry-level 3dimensional printing of maxillofacial skeletal models. JAMA Otolaryngol Head Neck Surg. 2017;143(4):389-94.

197. Stokbro K, Aagaard E, Torkov P, Bell RB, Thygesen T. Surgical accuracy of three-dimensional virtual planning: a pilot study of bimaxillary orthognathic procedures including maxillary segmentation. Int J Oral Maxillofac Surg. 2016;45(1):8-18. https://doi.org/10.1016/j.ijom.2015.07.010.

198. Li B, Shen S, Jiang W, Li J, Jiang T, Xia JJ, Shen SG, Wang X. A new approach of splint-less orthognathic surgery using a personalized orthognathic surgical guide system: a preliminary study. Int J Oral Maxillofac Surg. 2017; 46(10):1298-305.

199. Xiao Y, Sun X, Wang L, Zhang Y, Chen K, Wu G. The application of 3D printing Technology for Simultaneous Orthognathic Surgery and Mandibular Contour Osteoplasty in the treatment of craniofacial deformities. Aesthet Plast Surg. 2017;41(6):1413-24.

200. Egger J, Wallner J, Gall M, Chen X, Schwenzer-Zimmerer K, Reinbacher K, Schmalstieg D. Computer-aided position planning of miniplates to treat facial bone defects. PLoS One. 2017;12(8):e0182839.

201. Lim SH, Kim MK, Kang SH. Genioplasty using a simple CAD/CAM (computeraided design and computer-aided manufacturing) surgical guide. Maxillofac Plast Reconstr Surg. 2015;37(1):44. https://doi.org/10.1186/s40902-015-0044-y.

202. Hou JS, Chen M, Pan CB, Tao Q, Wang JG, Wang C, Zhang B, Huang HZ. Immediate reconstruction of bilateral mandible defects: management based on computer-aided design/computer-aided manufacturing rapid prototyping technology in combination with vascularized fibular osteomyocutaneous flap. J Oral Maxillofac Surg. 2011;69(6):1792-7.

203. Lethaus B, Poort L, Böckmann R, Smeets R, Tolba R, Kessler P. Additive manufacturing for microvascular reconstruction of the mandible in 20 patients. J Craniomaxillofac Surg. 2012;40(1):43-6.

204. Rohner D, Guijarro-Martínez R, Bucher P, Hammer B. Importance of patientspecific intraoperative guides in complex maxillofacial reconstruction. J Craniomaxillofac Surg. 2013;41(5):382-90.

205. Man QW, Jia J, Liu K, Chen G, Liu B. Secondary reconstruction for mandibular osteoradionecrosis defect with fibula osteomyocutaneous flap flowthrough from radial forearm flap using stereolithographic 3-dimensiona printing modeling technology. J Craniofac Surg. 2015;26(2):e190-3.

206. Inzana JA, Trombetta RP, Schwarz EM, Kates SL, Awad HA. 3D printed bioceramics for dual antibiotic delivery to treat implant-associated bone infection. Eur Cell Mater. 2015;30:232-47.

207. Wu W, Ye C, Zheng Q, Wu G, Cheng Z. A therapeutic delivery system for chronic osteomyelitis via a multi-drug implant based on three-dimensional printing technology. J Biomater Appl. 2016;31(2):250-60.

208. Mercuri LG, Wolford LM, Sanders B, White RD, Hurder A, Henderson W. Custom CAD/CAM total temporomandibular joint reconstruction system: preliminary multicenter report. J Oral Maxillofac Surg. 1995;53(2):106-15.

209. Undt G, Wild K, Reuther G, Ewers R. MRI-based stereolithographic models of the temporomandibular joint: technical innovation. J Craniomaxillofac Surg. 2000;28(5):258-63.

210. Mercuri LG, Wolford LM, Sanders B, White RD, Giobbie-Hurder A. Long-term follow-up of the CAD/CAM patient fitted total temporomandibular joint reconstruction system. J Oral Maxillofac Surg. 2002;60(12):1440-8. 
211. Xia JJ, Gateno J, Teichgraeber JF. Three-dimensional computer-aided surgical simulation for maxillofacial surgery. Atlas Oral Maxillofac Surg Clin North Am. 2005;13(1):25-39.

212. Keith DA. Custom-made total temporomandibular joint prostheses. Atlas Oral Maxillofac Surg Clin North Am. 2005;13(1):83-9.

213. van der Wal KG. Dissertations 25 years after the date 7. Temporomandibular joint ankylosis. Ned Tijdschr Tandheelkd. 2005;112(10):380-4.

214. Christensen RW, Walker CR, Dollar JV. New hope for Treacher-Collins syndrome: a surgical case report. Surg Technol Int. 2005;14:319-27.

215. Worrall SF, Christensen RW. Alloplastic reconstruction of the temporomandibular joint in treatment of craniofacial developmental or congenital anomalies: a surgical case report. Surg Technol Int. 2006;15:291-301.

216. Lee JW, Fang JJ, Chang LR, Yu CK. Mandibular defect reconstruction with the help of mirror imaging coupled with laser stereolithographic modeling technique. J Formos Med Assoc. 2007;106(3):244-50.

217. Mercuri LG, Edibam NR, Giobbie-Hurder A. Fourteen-year follow-up of a patient-fitted total temporomandibular joint reconstruction system. J Oral Maxillofac Surg. 2007;65(6):1140-8.

218. Pearce CS, Cooper C, Speculand B. One stage management of ankylosis of the temporomandibular joint with a custom-made total joint replacement system. Br J Oral Maxillofac Surg. 2009;47(7):530-4.

219. Chaware SM, Bagaria V, Kuthe A. Application of the rapid prototyping technique to design a customized temporomandibular joint used to treat temporomandibular ankylosis. Indian J Plast Surg. 2009;42(1):85-93.

220. Bell RB. Computer planning and intraoperative navigation in craniomaxillofacial surgery. Oral Maxillofac Surg Clin North Am. 2010;22(1):135-56.

221. Zizelmann C, Bucher P, Rohner D, Gellrich NC, Kokemueller H, Hammer B. Virtual restoration of anatomic jaw relationship to obtain a precise 3D model for total joint prosthesis construction for treatment of TMJ ankylosis with open bite. Int J Oral Maxillofac Surg. 2010;39(10):1012-5.

222. Chandran R, Keeler GD, Christensen AM, Weimer KA, Caloss R. Application of virtual surgical planning for total joint reconstruction with a stock alloplast system. J Oral Maxillofac Surg. 2011;69(1):285-94.

223. Zhang S, Liu X, Xu Y, Yang C, Undt G, Chen M, Haddad MS, Yun B. Application of rapid prototyping for temporomandibular joint reconstruction. J Oral Maxillofac Surg. 2011;69(2):432-8.

224. Keller EE, Baltali E, Liang X, Zhao K, Huebner M, An KN. Temporomandibular custom hemijoint replacement prosthesis: prospective clinical and kinematic study. J Oral Maxillofac Surg. 2012;70(2):276-88.

225. Patel A, Otterburn D, Saadeh P, Levine J, Hirsch DL. 3D volume assessment techniques and computer-aided design and manufacturing for preoperative fabrication of implants in head and neck reconstruction. Facial Plast Surg Clin North Am. 2011;19(4):683-709.

226. Gelesko S, Markiewicz MR, Weimer K, Bell RB. Computer-aided orthognathic surgery. Atlas Oral Maxillofac Surg Clin North Am. 2012;20(1):107-18.

227. Deshmukh TR, Kuthe AM, Chaware SM, Bagaria V, Ingole DS. A novel rapid prototyping and finite element method-based development of the patientspecific temporomandibular joint implant. Comput Methods Biomech Biomed Engin. 2012;15(4):363-70.

228. Marinescu C. CAD/CAM restorative principles. Dent Today. 2012;31(4):130 132-3.

229. Gonçalves JR, Gomes LC, Vianna AP, Rodrigues DB, Gonçalves DA, Wolford LM. Airway space changes after maxillomandibular counterclockwise rotation and mandibular advancement with TMJ concepts total joint prostheses: three-dimensional assessment. Int J Oral Maxillofac Surg. 2013; 42(8):1014-22.

230. Villegas C, Janakiraman N, Nanda R, Uribe F. Management of unilateral condylar hyperplasia with a high condylectomy, skeletal anchorage, and a CAD/CAM alloplast. J Clin Orthod. 2013;47(6):365-74.

231. Schneider R, Burton R. Coordinated reconstruction with bilateral condylar replacement and dental implant rehabilitation: a clinical report. J Prosthet Dent. 2014;111(2):101-6.

232. Haq J, Patel N, Weimer K, Matthews NS. Single stage treatment of ankylosis of the temporomandibular joint using patient-specific total joint replacement and virtual surgical planning. Br J Oral Maxillofac Surg. 2014;52(4):350-5.

233. Rodrigues DB, Wolford LM, Malaquias P, Campos PS. Concomitant treatment of mandibular ameloblastoma and bilateral temporomandibular joint osteoarthritis with bone graft and total joint prostheses. J Oral Maxillofac Surg. 2015;73(1):63-74

234. Green JM 3rd, Lawson ST, Liacouras PC, Wise EM, Gentile MA, Grant GT. Custom anatomical 3D spacer for temporomandibular joint resection and reconstruction. Craniomaxillofac Trauma Reconstr. 2016;9(1):82-7.
235. Ryu J, Cho J, Kim HM. Bilateral temporomandibular joint replacement using computer-assisted surgical simulation and three-dimensional printing. J Craniofac Surg. 2016;27(5):e450-2.

236. Pho Duc JM, Hüning SV, Grossi ML. Parallel randomized controlled clinical trial in patients with temporomandibular disorders treated with a CAD/CAM versus a conventional stabilization splint. Int J Prosthodont. 2016;29(4):34050

237. Sawh-Martinez R, Parsaei $Y$, Wu R, Lin A, Metzler P, DeSesa C, Steinbacher DM. Improved temporomandibular joint position after 3-dimensional planned mandibular reconstruction. J Oral Maxillofac Surg. 2017;75(1):197206.

238. Tarsitano A, Battaglia S, Ramieri V, Cascone P, Ciocca L, Scotti R, Marchetti C. Short-term outcomes of mandibular reconstruction in oncological patients using a CAD/CAM prosthesis including a condyle supporting a fibular free flap. J Craniomaxillofac Surg. 2017:45(2):330-7.

239. Ritschl LM, Mücke T, Fichter A, Güll FD, Schmid C, Duc JMP, Kesting MR, Wolff KD, Loeffelbein DJ. Functional outcome of CAD/CAM-assisted versus conventional microvascular, fibular free flap reconstruction of the mandible: a retrospective study of 30 cases. J Reconstr Microsurg. 2017;33(4):281-91.

240. Ackland DC, Robinson D, Redhead M, Lee PV, Moskaljuk A, Dimitroulis G. A personalized 3D-printed prosthetic joint replacement for the human temporomandibular joint: from implant design to implantation. J Mech Behav Biomed Mater. 2017;69:404-11.

241. Farzad P. Reconstruction of nongrowing hemifacial microsomia patient with custom-made unilateral temporomandibular joint total joint prosthesis and orthognathic surgery. J Oral Biol Craniofac Res. 2017;7(1):62-6.

242. Hu Y, Zhang L, He D, Yang C, Chen M, Zhang S, Li H, Ellis lii E. Simultaneous treatment of temporomandibular joint ankylosis with severe mandibular deficiency by standard TMJ prosthesis. Sci Rep. 2017;7:45271.

243. Kozakiewicz M, Wach T, Szymor P, Zieliński R. Two different techniques of manufacturing TMJ replacements - a technical report. J Craniomaxillofac Surg. 2017:5(9):1432-7.

244. Ciocca L, Marchetti C, Mazzoni S, Baldissara P, Gatto MR, Cipriani R, Scotti R, Tarsitano A. Accuracy of fibular sectioning and insertion into a rapidprototyped bone plate, for mandibular reconstruction using CAD-CAM technology. J Craniomaxillofac Surg. 2015;43(1):28-33.

245. Chen MJ, Yang C, Huang D, He DM, Wang YW, Zhang WH. Modified technique for preservation of inferior alveolar nerve during mandibulectomy. Head Neck. 2017;39(12):2562-6. https://doi.org/10.1002/hed.24924.

246. Eckardt A, Swennen GR. Virtual planning of composite mandibular reconstruction with free fibula bone graft. J Craniofac Surg. 2005;16(6):1137-40.

247. Westendorff C, Kaminsky J, Ernemann U, Reinert S, Hoffmann J. Imageguided sphenoid wing meningioma resection and simultaneous computerassisted cranio-orbital reconstruction: technical case report. Neurosurgery. 2007;60(2 Suppl 1):ONSE173-4.

248. Hu YJ, Hardianto A, Li SY, Zhang ZY, Zhang CP. Reconstruction of a palatomaxillary defect with vascularized iliac bone combined with a superficial inferior epigastric artery flap and zygomatic implants as anchorage. Int J Oral Maxillofac Surg. 2007;36(9):854-7.

249. Xu X, Ping FY, Chen J, Yan FG, Mao HQ, Shi YH, Zhao ZY. Application of CAD/CAM techniques in mandible large-scale defect and reconstruction with vascularized fibular bone graft. Zhejiang Da Xue Xue Bao Yi Xue Ban. 2007;36(5):498-502.

250. Singare S, Liu Y, Li D, Lu B, Wang J, He S. Individually prefabricated prosthesis for maxilla Reconstuction. J Prosthodont. 2008;17(2):135-40.

251. Xu X, Ping FY, Chen J, Yan JL, Yan FG. Application of computer aided design/computer aided manufactured techniques in mandible defect reconstruction. Zhonghua Kou Qiang Yi Xue Za Zhi. 2007;42(8):492-5.

252. Wu CT, Lee ST, Chen JF, Lin KL, Yen SH. Computer-aided design for threedimensional titanium mesh used for repairing skull base bone defect in pediatric neurofibromatosis type 1. A novel approach combining biomodeling and neuronavigation. Pediatr Neurosurg. 2008;44(2):133-9.

253. Cohen A, Laviv A, Berman P, Nashef R, Abu-Tair J. Mandibular reconstruction using stereolithographic 3-dimensional printing modeling technology. Oral Surg Oral Med Oral Pathol Oral Radiol Endod. 2009;108(5):661-6.

254. Juergens P, Krol Z, Zeilhofer HF, Beinemann J, Schicho K, Ewers R, Klug C. Computer simulation and rapid prototyping for the reconstruction of the mandible. J Oral Maxillofac Surg. 2009;67(10):2167-70.

255. Tong D, Huang MW, Zhang JG, Feng HL, Li YS. Clinical application of computer-aided design and rapid prototyping technique for radioactive seeds contained maxillary device. Beijing Da Xue Xue Bao. 2010;42(1):63-6. 
256. Matsuo A, Chiba H, Takahashi H, Toyoda J, Abukawa H. Clinical application of a custom-made bioresorbable raw particulate hydroxyapatite/poly-L-lactide mesh tray for mandibular reconstruction. Odontology. 2010;98(1):85-8.

257. Cheng HT, Wu Cl, Tseng CS, Chen HC, Lee WS, Chen PK, Chang SC. The occlusion-adjusted prefabricated 3D mirror image templates by computer simulation: the image-guided navigation system application in difficult cases of head and neck reconstruction. Ann Plast Surg. 2009;63(5):517-21.

258. Zhou LB, Shang HT, He LS, Bo B, Liu GC, Liu YP, Zhao JL. Accurate reconstruction of discontinuous mandible using a reverse engineering/ computer-aided design/rapid prototyping technique: a preliminary clinical study. J Oral Maxillofac Surg. 2010;68(9):2115-21.

259. Roser SM, Ramachandra S, Blair H, Grist W, Carlson GW, Christensen AM, Weimer KA, Steed MB. The accuracy of virtual surgical planning in free fibula mandibular reconstruction: comparison of planned and final results. J Oral Maxillofac Surg. 2010;68(11):2824-32.

260. Hou JS, Chen M, Pan CB, Wang M, Wang JG, Zhang B, Tao Q, Wang C, Huang $\mathrm{HZ}$. Application of CAD/CAM-assisted technique with surgical treatment in reconstruction of the mandible. J Craniomaxillofac Surg. 2012; 40(8):e432-7.

261. Ciocca L, Mazzoni S, Fantini M, Marchetti C, Scotti R. The design and rapid prototyping of surgical guides and bone plates to support iliac free flaps for mandible reconstruction. Plast Reconstr Surg. 2012;129(5):859e-61e.

262. Ciocca L, Mazzoni S, Fantini M, Persiani F, Marchetti C, Scotti R. CAD/CAM guided secondary mandibular reconstruction of a discontinuity defect after ablative cancer surgery. J Craniomaxillofac Surg. 2012;40(8):e511-5.

263. Zheng GS, Su YX, Liao GQ, Chen ZF, Wang L, Jiao PF, Liu HC, Zhong YQ, Zhang TH, Liang YJ. Mandible reconstruction assisted by preoperative virtual surgical simulation. Oral Surg Oral Med Oral Pathol Oral Radiol. 2012; 113(5):604-11.

264. Yu HB, Zhang SL, Wang XD, Lin YP, Wang CT, Shen GF. Application of computerassisted navigation in oral and maxillofacial surgery: retrospective analysis of 104 consecutive cases. Shanghai Kou Qiang Yi Xue. 2012;21(4):416-21.

265. Wang WH, Zhu J, Deng JY, Xia B, Xu B. Three-dimensional virtual technology in reconstruction of mandibular defect including condyle using double-barrel vascularized fibula flap. J Craniomaxillofac Surg. 2013;41(5):417-22.

266. Yu H, Shen SG, Wang X, Zhang L, Zhang S. The indication and application of computer-assisted navigation in oral and maxillofacial surgery-Shanghai's experience based on 104 cases. J Craniomaxillofac Surg. 2013;41(8):770-4.

267. Thomas CV, McMillan KG, Jeynes P, Martin T, Parmar S. Use of a titanium cutting guide to assist with raising and inset of a DCIA free flap. $\mathrm{Br} J$ Oral Maxillofac Surg. 2013;51(8):958-61.

268. Bullock P, Dunaway D, McGurk L, Richards R. Integration of image guidance and rapid prototyping technology in craniofacial surgery. Int J Oral Maxillofac Surg. 2013;42(8):970-3.

269. Coppen C, Weijs W, Bergé SJ, Maal TJ. Oromandibular reconstruction using 3D planned triple template method. J Oral Maxillofac Surg. 2013;71(8):e243-7.

270. Yan G, Wang X, Tan X, Wang X, Yang M, Lu L. Study on accuracy of virtual surgical planning in free fibula mandibular reconstruction by using SurgiCase software. Zhongguo Xiu Fu Chong Jian Wai Ke Za Zhi. 2013;27(8): 1006-9

271. Matros E, Albornoz CR, Rensberger M, Weimer K, Garfein ES. Computerassisted design and computer-assisted modeling technique optimization and advantages over traditional methods of osseous flap reconstruction. J Reconstr Microsurg. 2014;30(5):289-96.

272. Ciocca L, Scotti R. Oculo-facial rehabilitation after facial cancer removal: updated CAD/CAM procedures: a pilot study. Prosthetics Orthot Int. 2014; 38(6):505-9.

273. Bai G, He D, Yang C, Lu C, Huang D, Chen M, Yuan J. Effect of digital template in the assistant of a giant condylar osteochondroma resection. J Craniofac Surg. 2014;25(3):e301-4.

274. Succo G, Berrone M, Battiston B, Tos P, Goia F, Appendino P, Crosetti E. Step-by-step surgical technique for mandibular reconstruction with fibular free flap: application of digital technology in virtual surgical planning. Eur Arch Otorhinolaryngol. 2015;272(6):1491-501.

275. Yu D, Liu J, Zhu H, Li Z, Huang X, Wei D, Lin Y, He J, Zhao W. Application of three-dimensional printing technique in repair and reconstruction of maxillofacial bone defect. Zhongguo Xiu Fu Chong Jian Wai Ke Za Zhi. 2014;28(3):292-5.

276. Shu DL, Liu XZ, Guo B, Ran W, Liao X, Zhang YY. Accuracy of using computer-aided rapid prototyping templates for mandible reconstruction with an iliac crest graft. World J Surg Oncol. 2014;12:190.
277. Shengwei H, Zhiyong W, Qingang H, Wei H. Combined use of an anterolateral thigh flap and rapid prototype modeling to reconstruct maxillary oncologic resections and midface defects. J Craniofac Surg. 2014; 25(4):1147-9.

278. Kim MS, Lee JY, Shin SW. Fabricating an obturator using rapid prototyping to design the framework: a case report. Int J Prosthodont. 2014;27(5):43941.

279. Jiao T, Zhu C, Dong X, Gu X. Rehabilitation of maxillectomy defects with obturator prostheses fabricated using computer-aided design and rapid prototyping: a pilot study. Int J Prosthodont. 2014;27(5):480-6.

280. Berrone M, Crosetti E, Succo G. Repositioning template for mandibular reconstruction with fibular free flaps: an alternative technique to pre-plating and virtual surgical planning. Acta Otorhinolaryngol Ital. 2014;34(4):278-82.

281. Azuma M, Yanagawa T, Ishibashi-Kanno N, Uchida F, Ito T, Yamagata K, Hasegawa S, Sasaki K, Adachi K, Tabuchi K, Sekido M, Bukawa H. Mandibular reconstruction using plates prebent to fit rapid prototyping 3-dimensional printing models ameliorates contour deformity. Head Face Med. 2014;10:45.

282. Cornelius CP, Smolka W, Giessler GA, Wilde F, Probst FA. Patient-specific reconstruction plates are the missing link in computer-assisted mandibular reconstruction: a showcase for technical description. J Craniomaxillofac Surg. 2015;43(5):624-9.

283. Reiser V, Alterman M, Shuster A, Kleinman S, Shlomi B, Yanko-Arzi R, Zaretski A, Amir A, Fliss DM. V-stand--a versatile surgical platform for oromandibular reconstruction using a 3-dimensional virtual modeling system. J Oral Maxillofac Surg. 2015;73(6):1211-26.

284. Kääriäinen M, Kuuskeri M, Gremoutis G, Kuokkanen H, Miettinen A, Laranne J. Utilization of three-dimensional computer-aided preoperative virtual planning and manufacturing in maxillary and mandibular reconstruction with a microvascular fibula flap. J Reconstr Microsurg. 2016;32(2):137-41.

285. Chen XB, Liu ZG, Yuan JB, Tian HW. Application of three-dimensional virtual technology in mandibular defects reconstruction with free fibular flap. Shanghai Kou Qiang Yi Xue. 2015;24(4):460-4.

286. Liu J, Zhang B, Yan D, Yu X, Lin M, Li Z, Yin Y, Xu Z. Digital and threedemention print technique in reconstruction for complex defect after resection of jaw neoplasms. Zhonghua Er Bi Yan Hou Tou Jing Wai Ke Za Zhi. 2015;50(6):473-6.

287. Nkenke E, Agaimy A, Vairaktaris E, Lell M, von Wilmowsky C, Eitner S. Case history report: immediate rehabilitation with a prefabricated fibula flap following removal of a locally aggressive maxillary tumor. Int J Prosthodont. 2016;29(1):53-8

288. Yu Y, Zhang WB, Wang Y, Liu XJ, Guo CB, Peng X. A revised approach for mandibular reconstruction with the vascularized iliac crest flap using virtual surgical planning and surgical navigation. J Oral Maxillofac Surg. 2016;74(6): 1285.e1-1285.e11.

289. Anchieta MV, Salles FA, Cassaro BD, Quaresma MM, Santos BF. Skull reconstruction after resection of bone tumors in a single surgical time by the association of the techniques of rapid prototyping and surgical navigation. Int J Comput Assist Radiol Surg. 2016;11(10):1919-25.

290. Chang El, Hanasono MM. State-of-the-art reconstruction of midface and facial deformities. J Surg Oncol. 2016;113(8):962-70.

291. Shui W, Zhou M, Chen S, Pan Z, Deng Q, Yao Y, Pan H, He T, Wang X. The production of digital and printed resources from multiple modalities using visualization and three-dimensional printing techniques. Int J Comput Assist Radiol Surg. 2017;12(1):13-23.

292. Brandmeir NJ, Mclnerney J, Zacharia BE. The use of custom 3D printed stereotactic frames for laser interstitial thermal ablation: technical note. Neurosurg Focus. 2016;41(4):E3.

293. Wiedermann JP, Joshi AS, Jamshidi A, Conchenour C, Preciado D. Utilization of a submental island flap and 3D printed model for skull base reconstruction: infantile giant cranio-cervicofacial teratoma. Int J Pediatr Otorhinolaryngol. 2017;92:143-5.

294. Leiggener C, Messo E, Thor A, Zeilhofer HF, Hirsch JM. A selective laser sintering guide for transferring a virtual plan to real time surgery in composite mandibular reconstruction with free fibula osseous flaps. Int J Oral Maxillofac Surg. 2009;38(2):187-92.

295. Liu XJ, Gui L, Mao C, Peng X, Yu GY. Applying computer techniques in maxillofacial reconstruction using a fibula flap: a messenger and an evaluation method. J Craniofac Surg. 2009;20(2):372-7.

296. Modabber A, Gerressen M, Stiller MB, Noroozi N, Füglein A, Hölzle F, Riediger D, Ghassemi A. Computer-assisted mandibular reconstruction with vascularized iliac crest bone graft. Aesthet Plast Surg. 2012;36(3):653-9. 
297. Ayoub N, Ghassemi A, Rana M, Gerressen M, Riediger D, Hölzle F, Modabber A. Evaluation of computer-assisted mandibular reconstruction with vascularized iliac crest bone graft compared to conventional surgery: a randomized prospective clinical trial. Trials. 2014;15:114.

298. Rude K, Thygesen TH, Sørensen JA. Reconstruction of the maxilla using a fibula graft and virtual planning techniques. BMJ Case Rep. 2014. https://doi. org/10.1136/bcr-2014-203601

299. Sieira Gil R, Roig AM, Obispo CA, Morla A, Pagès CM, Perez JL. Surgical planning and microvascular reconstruction of the mandible with a fibular flap using computer-aided design, rapid prototype modelling, and precontoured titanium reconstruction plates: a prospective study. $\mathrm{Br} J$ Oral Maxillofac Surg. 2015;53(1):49-53.

300. Suchyta M, Mardini S. Innovations and future directions in head and neck microsurgical reconstruction. Clin Plast Surg. 2017:44(2):325-44.

301. Stoetzer M, Rana M, von See C, Eckardt AM, Gellrich NC. Reconstruction of defects of maxillary sinus wall after removal of a huge odontogenic lesion using prebended 3D titanium-mesh and CAD/CAM technique. Head Face Med. 2011;7:21.

302. Tasopoulos T, Kouveliotis G, Polyzois G, Karathanasi V. Fabrication of a 3D printing definitive obturator prosthesis: a clinical report. Acta Stomatol Croat. 2017;51(1):53-8.

303. Antonelli JA. Innovations in surgical stone disease. Curr Opin Urol. 2016; 26(3):240-7.

304. Atalay HA, Canat HL, Ülker V, Alkan I, Özkuvanci Ü, Altunrende F. Impact of personalized three-dimensional -3D- printed pelvicalyceal system models on patient information in percutaneous nephrolithotripsy surgery: a pilot study. Int Braz J Urol. 2017:43:470-5. https://doi.org/10.1590/S1677-5538.IBJU.2016.0441.

305. Atalay HA, Ülker V, Alkan İ, Canat HL, Özkuvancı Ü, Altunrende F. Impact of three-dimensional printed Pelvicaliceal system models on residents' understanding of Pelvicaliceal system anatomy before percutaneous Nephrolithotripsy surgery: a pilot study. J Endourol. 2016;30:1132-7. https:// doi.org/10.1089/end.2016.0307.

306. Bruyère $F$, Leroux $C$, Brunereau L, Lermusiaux $P$. Rapid prototyping model for percutaneous nephrolithotomy training. J Endourol. 2008;22:91-6. https://doi.org/10.1089/end.2007.0025.

307. Mishra S, Jagtap J, Sabnis RB, Desai MR. Training in percutaneous nephrolithotomy. Curr Opin Urol. 2013;23:147-51. https://doi.org/10.1097/ MOU.0b013e32835d4e37.

308. Powers MK, Lee BR, Silberstein J. Three-dimensional printing of surgical anatomy. Curr Opin Urol. 2016;26:283-8. https://doi.org/10.1097/MOU. 0000000000000274.

309. Sweet RM. The CREST simulation development process: training the next generation. J Endourol. 2017;31:S69-75. https://doi.org/10.1089/end.2016.0613.

310. Westerman ME, Matsumoto JM, Morris JM, Leibovich BC. Three-dimensional printing for renal Cancer and surgical planning. Eur Urol Focus. 2016;2:5746. https://doi.org/10.1016/j.euf.2016.12.009.

311. Wake N, Rude T, Kang SK, Stifelman MD, Borin JF, Sodickson DK, Huang WC, Chandarana H. 3D printed renal cancer models derived from MRI data: application in pre-surgical planning. Abdom Radiol (NY). 2017;42:1501-9. https://doi.org/10.1007/s00261-016-1022-2.

312. Golab A, Smektala T, Kaczmarek K, Stamirowski R, Hrab M, Slojewski M. Laparoscopic partial nephrectomy supported by training involving personalized silicone replica poured in three-dimensional printed casting Mold. J Laparoendosc Adv Surg Tech A. 2017;27:420-2. https://doi.org/10. 1089/lap.2016.0596.

313. Von Rundstedt F-C, Scovell JM, Agrawal S, Zaneveld J, Link RE. Utility of patient-specific silicone renal models for planning and rehearsal of complex tumour resections prior to robot-assisted laparoscopic partial nephrectomy. BJU Int. 2017;119:598-604. https://doi.org/10.1111/bju.13712.

314. Smektala T, Goląb A, Królikowski M, Slojewski M. Low cost silicone renal replicas for surgical training - technical note. Arch Esp Urol. 2016;69:434-6.

315. Golab A, Slojewski M, Brykczynski M, Lukowiak M, Boehlke M, Matias D, Smektala T. Three-dimensional printing as an interdisciplinary communication tool: preparing for removal of a Giant renal tumor and atrium neoplastic mass. Heart Surg Forum. 2016;19:E185-6.

316. Jung JP, Bhuiyan DB, Ogle BM. Solid organ fabrication: comparison of decellularization to 3D bioprinting. Biomater Res. 2016;20:27. https://doi.org/ 10.1186/s40824-016-0074-2.

317. Komai Y, Sugimoto M, Gotohda N, Matsubara N, Kobayashi T, Sakai Y, Shiga Y, Saito N. Patient-specific 3-dimensional printed kidney designed for "4D" surgical navigation: a novel aid to facilitate minimally invasive off-clamp partial nephrectomy in complex tumor cases. Urology. 2016;91:226-33. https://doi.org/10.1016/j.urology.2015.11.060.

318. Bernhard J-C, Isotani S, Matsugasumi T, Duddalwar V, Hung AJ, Suer E, Baco E, Satkunasivam R, Djaladat H, Metcalfe C, Hu B, Wong K, Park D, Nguyen M, Hwang D, Bazargani ST, de Castro Abreu AL, Aron M, Ukimura O, Gill IS. Personalized 3D printed model of kidney and tumor anatomy: a useful tool for patient education. World J Urol. 2016;34:337-45. https://doi.org/10.1007/ s00345-015-1632-2.

319. Knoedler M, Feibus AH, Lange A, Maddox MM, Ledet E, Thomas R, Silberstein UL. Individualized physical 3-dimensional kidney tumor models constructed from 3dimensional printers result in improved trainee anatomic understanding. Urology. 2015;85:1257-61. https://doi.org/10.1016/j.urology.2015.02.053.

320. Zhang Y, Ge H, Li N, Yu C, Guo H, Jin S, Liu J, Na Y. Evaluation of threedimensional printing for laparoscopic partial nephrectomy of renal tumors: a preliminary report. World J Urol. 2016;34:533-7. https://doi.org/10.1007/ s00345-015-1530-7.

321. Stone L. Kidney cancer: a model for the masses--3D printing of kidney tumours. Nat Rev Urol. 2014;11:428. https://doi.org/10.1038/nrurol.2014.167.

322. Silberstein JL, Maddox MM, Dorsey P, Feibus A, Thomas R, Lee BR. Physical models of renal malignancies using standard cross-sectional imaging and 3dimensional printers: a pilot study. Urology. 2014;84:268-72. https://doi.org/ 10.1016/j.urology.2014.03.042.

323. Challoner A, Erolin C. Creating pathology models from MRI data: a comparison of virtual 3D modelling and rapid prototyping techniques. J Vis Commun Med. 2013;36:11-9. https://doi.org/10.3109/17453054.2013.790011.

324. Cernat E, Docquier P-L, Paul L, Banse X, Codorean I-B. Patient specific instruments for complex tumor resection-reconstruction surgery within the pelvis: a series of 4 cases. Chirurgia (Bucur). 2016;111:439-44. https://doi.org/ 10.21614/chirurgia.111.5.439.

325. Srougi V, Rocha BA, Tanno FY, Almeida MQ, Baroni RH, Mendonça BB, Srougi M, Fragoso MC, Chambô JL. The use of three-dimensional printers for partial adrenalectomy: estimating the resection limits. Urology. 2016;90: 217-20. https://doi.org/10.1016/j.urology.2015.11.043.

326. Wendler JJ, Klink F, Seifert S, Fischbach F, Jandrig B, Porsch M, Pech M, Baumunk D, Ricke J, Schostak M, Liehr U-B. Irreversible electroporation of prostate Cancer: patient-specific pretreatment simulation by electric field measurement in a 3D bioprinted textured prostate Cancer model to achieve optimal electroporation parameters for image-guided focal ablation. Cardiovasc Intervent Radiol. 2016;39:1668-71. https://doi.org/10.1007/ s00270-016-1390-6.

327. Shin T, Ukimura O, Gill IS. Three-dimensional printed model of prostate anatomy and targeted biopsy-proven index tumor to facilitate nervesparing prostatectomy. Eur Urol. 2016;69:377-9. https://doi.org/10.1016/j. eururo.2015.09.024.

328. Kadimisetty K, Mosa IM, Malla S, Satterwhite-Warden JE, Kuhns TM, Faria RC, Lee NH, Rusling JF. 3D-printed supercapacitor-powered electrochemiluminescent protein immunoarray. Biosens Bioelectron. 2016; 77:188-93. https://doi.org/10.1016/j.bios.2015.09.017.

329. Fitzgerald KA, Guo J, Tierney EG, Curtin CM, Malhotra M, Darcy R, O'Brien FJ, O'Driscoll CM. The use of collagen-based scaffolds to simulate prostate cancer bone metastases with potential for evaluating delivery of nanoparticulate gene therapeutics. Biomaterials. 2015;66:53-66. https://doi. org/10.1016/j.biomaterials.2015.07.019.

330. Zou W, Fisher T, Zhang M, Kim L, Chen T, Narra V, Swann B, Singh R, Siderit R, Yin L, Teo B-KK, McKenna M, McDonough J, Ning YJ. Potential of 3D printing technologies for fabrication of electron bolus and proton compensators. J Appl Clin Med Phys. 2015;16:4959.

331. Li P, Jiang S, Yu Y, Yang J, Yang Z. Biomaterial characteristics and application of silicone rubber and PVA hydrogels mimicked in organ groups for prostate brachytherapy. J Mech Behav Biomed Mater. 2015;49:220-34. https://doi.org/10.1016/j.jmbbm.2015.05.012.

332. Priester A, Natarajan S, Le JD, Garritano J, Radosavcev B, Grundfest W, Margolis DJ, Marks LS, Huang J. A system for evaluating magnetic resonance imaging of prostate cancer using patient-specific 3D printed molds. Am J Clin Exp Urol. 2014;2:127-35.

333. Harrison KM, Ebert MA, Kron T, Howlett SJ, Cornes D, Hamilton CS, Denham JW. Design, manufacture, and evaluation of an anthropomorphic pelvic phantom purpose-built for radiotherapy dosimetric intercomparison. Med Phys. 2011;38:5330-7. https://doi.org/10.1118/1.3626573.

334. Henry OY, Fragoso A, Beni V, Laboria N, Sánchez JLA, Latta D, Von Germar F, Drese K, Katakis I, O'Sullivan CK. Design and testing of a packaged microfluidic 
cell for the multiplexed electrochemical detection of cancer markers. Electrophoresis. 2009:30:3398-405. https://doi.org/10.1002/elps.200900368.

335. Sayed Aluwee SAZB, Zhou X, Kato H, Makino H, Muramatsu C, Hara T, Matsuo M, Fujita H. Evaluation of pre-surgical models for uterine surgery by use of three-dimensional printing and mold casting. Radiol Phys Technol. 2017;10:279-85. https://doi.org/10.1007/s12194-017-0397-2.

336. Ji Z, Jiang YL, Guo FX, Peng R, Sun HT, Fan JH, Wang JJ. Dosimetry verification of radioactive seed implantation with $3 \mathrm{D}$ printing template and CT guidance for paravertebral/retroperitoneal malignant tumor. Zhonghua Yi Xue Za Zhi. 2017:97:996-1000.

337. Kadoya N, Miyasaka Y, Nakajima Y, Kuroda Y, Ito K, Chiba M, Sato K, Dobashi S, Yamamoto T, Takahashi N, Kubozono M, Takeda K, Jingu K. Evaluation of deformable image registration between external beam radiotherapy and HDR brachytherapy for cervical cancer with a 3D-printed deformable pelvis phantom. Med Phys. 2017;44:1445-55. https://doi.org/10.1002/mp.12168.

338. Baek M-H, Kim D-Y, Kim N, Rhim CC, Kim J-H, Nam J-H. Incorporating a 3dimensional printer into the management of early-stage cervical cancer. J Surg Oncol. 2016;114:150-2. https://doi.org/10.1002/jso.24292.

339. Lindegaard JC, Madsen ML, Traberg A, Meisner B, Nielsen SK, Tanderup K Spejlborg H, Fokdal LU, Nørrevang O. Individualised 3D printed vaginal template for MRI quided brachytherapy in locally advanced cervical cancer. Radiother Oncol. 2016;1 18:173-5. https://doi.org/10.1016/..radonc.2015.12.012.

340. Bartellas M, Ryan S, Doucet G, Murphy D, Turner J. Three-dimensional printing of a hemorrhagic cervical Cancer model for postgraduate gynecological training. Cureus. 2017;9:e950. https://doi.org/10.7759/cureus.950.

341. Zhao Y, Yao R, Ouyang L, Ding H, Zhang T, Zhang K, Cheng S, Sun W. Three-dimensional printing of Hela cells for cervical tumor model in vitro. Biofabrication. 2014;6:035001. https://doi.org/10.1088/1758-5082/6/3/035001.

342. Ajao MO, Clark NV, Kelil T, Cohen SL, Einarsson J. Case report: threedimensional printed model for deep infiltrating endometriosis. J Minim Invasive Gynecol. 2017;24:1239-42. https://doi.org/10.1016/j.jmig.2017.06.006.

343. Sethi R, Cunha A, Mellis K, Siauw T, Diederich C, Pouliot J, Hsu I-C. Clinical applications of custom-made vaginal cylinders constructed using threedimensional printing technology. J Contemp Brachytherapy. 2016;8:208-14. https://doi.org/10.5114/jcb.2016.60679.

344. Park C-J, Kim H-W, Jeong S, Seo S, Park Y, Moon HS, Lee J-H. Anti-reflux ureteral stent with polymeric flap valve using three-dimensional printing: an in vitro study. J Endourol. 2015;29:933-8. https://doi.org/10.1089/end.2015. 0154.

345. Bagaria V, Deshpande S, Rasalkar DD, Kuthe A, Paunipagar BK. Use of rapid prototyping and three-dimensional reconstruction modeling in the management of complex fractures. Eur J Radiol. 2011;80:814-20. https://doi. org/10.1016/j.ejrad.2010.10.007

346. Bizzotto N, Tami I, Tami A, Spiegel A, Romani D, Corain M, Adani R, Magnan B. 3D printed models of distal radius fractures. Injury. 2016;47:976-8. https:// doi.org/10.1016/j.injury.2016.01.013.

347. Bizzotto N, Sandri A, Regis D, Romani D, Tami I, Magnan B. Threedimensional printing of bone fractures: a new tangible realistic way for preoperative planning and education. Surg Innov. 2015;22:548-51. https:// doi.org/10.1177/1553350614547773.

348. Brown GA, Firoozbakhsh K, DeCoster TA, Reyna JR, Moneim M. Rapid prototyping: the future of trauma surgery? J Bone Joint Surg Am. 2003;85-A Suppl 4:49-55

349. Chana-Rodríguez F, Mañanes RP, Rojo-Manaute J, Gil P, Martínez-Gómiz JM, Vaquero-Martín J. 3D surgical printing and pre contoured plates for acetabular fractures. Injury. 2016;47:2507-11. https://doi.org/10.1016/j.injury.2016.08.027.

350. Chen C, Cai L, Zhang C, Wang J, Guo X, Zhou Y. Treatment of die-punch fractures with 3D printing technology. J Investig Surg. 2017;19:1-8. https:// doi.org/10.1080/08941939.2017.1339150.

351. Chen H, Wang G, Li R, Sun Y, Wang F, Zhao H, Zhang P, Zhang X. A novel navigation template for fixation of acetabular posterior column fractures with antegrade lag screws: design and application. Int Orthop. 2016;40:82734. https://doi.org/10.1007/s00264-015-2813-8.

352. Chen X, Chen X, Zhang G, Lin H, Yu Z, Wu C, Li X, Lin Y, Huang W. Accurate fixation of plates and screws for the treatment of acetabular fractures using 3D-printed guiding templates: an experimental study. Injury. 2017;48:114754. https://doi.org/10.1016/j.injury.2017.03.009.

353. Choy WJ, Mobbs RJ, Wilcox B, Phan S, Phan K, Sutterlin CE. Reconstruction of thoracic spine using a personalized 3D-printed vertebral body in adolescent with T9 primary bone tumor. World Neurosurg. 2017;105:1032. e13-7. https://doi.org/10.1016/j.wneu.2017.05.133.
354. Chung K, Huang B, Choi CH, Park YW, Kim HN. Utility of 3D printing for complex distal Tibial fractures and malleolar avulsion fractures: technical tip. Foot Ankle Int. 2015;36:1504-10. https://doi.org/10.1177/1071100715595695.

355. Chung KJ, Hong DY, Kim YT, Yang I, Park YW, Kim HN. Preshaping plates for minimally invasive fixation of calcaneal fractures using a real-size 3D-printed model as a preoperative and intraoperative tool. Foot Ankle Int. 2014;35: 1231-6. https://doi.org/10.1177/1071100714544522.

356. De Muinck Keizer RJO, Lechner KM, Mulders M a M, Schep NWL, Eygendaal D, Goslings JC. Three-dimensional virtual planning of corrective osteotomies of distal radius malunions: a systematic review and meta-analysis. Strategies Trauma Limb Reconstr. 2017;12:77-89. https://doi.org/10.1007/s11751-017-0284-8.

357. Deshmukh TR, Kuthe AM, Vaibhav B. Preplanning and simulation of surgery using rapid modelling. J Med Eng Technol. 2010;34:291-4. https://doi.org/ 10.3109/03091901003753058

358. Du H, Tian X, Li T, Yang J, Li K, Pei G, Xie L. Use of patient-specific templates in hip resurfacing arthroplasty: experience from sixteen cases. Int Orthop. 2013;37:777-82. https://doi.org/10.1007/s00264-013-1842-4.

359. Duncan JM, Nahas S, Akhtar K, Daurka J. The use of a 3D printer in pre-operative planning for a patient requiring acetabular reconstructive surgery. J Orthop Case Rep. 2015;5:23-5. https://doi.org/10.13107/jocr. 2250-0685.247.

360. Frame M, Huntley JS. Rapid prototyping in orthopaedic surgery: a user's guide. ScientificWorldJournal. 2012;2012:838575. https://doi.org/10.1100/ 2012/838575.

361. Fuller SM, Butz DR, Vevang CB, Makhlouf MV. Application of 3-dimensional printing in hand surgery for production of a novel bone reduction clamp. J Hand Surg Am. 2014;39:1840-5. https://doi.org/10.1016/j.jhsa.2014.06.009.

362. Giannetti S, Bizzotto N, Stancati A, Santucci A. Minimally invasive fixation in tibial plateau fractures using an pre-operative and intra-operative real size $3 \mathrm{D}$ printing. Injury. 2017;48:784-8. https://doi.org/10.1016/j.injury.2016.11.015.

363. Gittard SD, Narayan RJ, Lusk J, Morel P, Stockmans F, Ramsey M, Laverde C, Phillips J, Monteiro-Riviere NA, Ovsianikov A, Chichkov BN. Rapid prototyping of scaphoid and lunate bones. Biotechnol J. 2009;4:129-34. https://doi.org/10.1002/biot.200800233.

364. Haefeli M, Schaefer DJ, Schumacher R, Müller-Gerbl M, Honigmann P. Titanium template for scaphoid reconstruction. J Hand Surg Eur Vol. 2015; 40:526-33. https://doi.org/10.1177/1753193414549008.

365. Hamada Y, Gotani H, Sasaki K, Tanaka Y, Egawa H, Kanchanathepsak T. Corrective osteotomy of Malunited Diaphyseal fractures of the forearm simplified using 3-dimensional $C T$ data: proposal of our simple strategy through case presentation. Hand (N Y). 2017;12:NP95-8. https://doi.org/10. $1177 / 1558944717692087$

366. Hamid KS, Parekh SG, Adams SB. Salvage of severe foot and ankle trauma with a 3D printed scaffold. Foot Ankle Int. 2016;37:433-9. https://doi.org/10. 1177/1071100715620895

367. Honigmann P, Thieringer F, Steiger R, Haefeli M, Schumacher R, Henning J. A simple 3-dimensional printed aid for a corrective palmar opening wedge osteotomy of the distal radius. J Hand Surg Am. 2016;41:464-9. https://doi. org/10.1016/j.jhsa.2015.12.022.

368. Hsieh M-K, Chen AC-Y, Cheng C-Y, Chou Y-C, Chan Y-S, Hsu K-Y. Repositioning osteotomy for intra-articular malunion of distal radius with radiocarpal and/or distal radioulnar joint subluxation. J Trauma. 2010;69: 418-22. https://doi.org/10.1097/TA.0b013e3181ca0834.

369. Hsu AR, Ellington JK. Patient-specific 3-dimensional printed titanium truss cage with Tibiotalocalcaneal arthrodesis for salvage of persistent distal tibia nonunion. Foot Ankle Spec. 2015;8:483-9. https://doi.org/10.1177/ 1938640015593079

370. Huang H, Hsieh M-F, Zhang G, Ouyang H, Zeng C, Yan B, Xu J, Yang Y, Wu Z, Huang W. Improved accuracy of 3D-printed navigational template during complicated tibial plateau fracture surgery. Australas Phys Eng Sci Med. 2015;38:109-17. https://doi.org/10.1007/s13246-015-0330-0.

371. Huang H, Zhang G, Ouyang H, Yang Y, Wu Z, Xu J, Xie P, Huang W. Internal fixation surgery planning for complex tibial plateau fracture based on digital design and 3D printing. Nan Fang Yi Ke Da Xue Xue Bao. 2015;35:218-22.

372. Huang $M$, Ding $H$, Huang $M$, Wang $H$, Teng Q. PRELIMINARY APPLICATION OF THREE-DIMENSIONAL PRINTING PERSONALIZED EXTERNAL FIXATOR IN SERIOUS TIBIOFIBULA FRACTURES. Zhongguo Xiu Fu Chong Jian Wai Ke Za Zhi. 2016:30:156-60.

373. Huang S-L, Wen B, Bian W-G, Yan H-W. Reconstruction of comminuted long-bone fracture using CF/CPC scaffolds manufactured by rapid prototyping. Med Sci Monit. 2012;18:BR435-40. 
374. Hurson C, Tansey A, O'Donnchadha B, Nicholson P, Rice J, McElwain J. Rapid prototyping in the assessment, classification and preoperative planning of acetabular fractures. Injury. 2007;38:1158-62. https://doi.org/10.1016/j.injury. 2007.05.020.

375. Jeong H-S, Park K-J, Kil K-M, Chong S, Eun H-J, Lee T-S, Lee J-P. Minimally invasive plate osteosynthesis using 3D printing for shaft fractures of clavicles: technical note. Arch Orthop Trauma Surg. 2014;134:1551-5. https:// doi.org/10.1007/s00402-014-2075-8.

376. Kacl GM, Zanetti M, Amgwerd M, Trentz O, Seifert B, Stucki H, Hodler J. Rapid prototyping (stereolithography) in the management of intra-articular calcaneal fractures. Eur Radiol. 1997;7:187-91. https://doi.org/10.1007/ s003300050132.

377. Kataoka T, Oka K, Miyake J, Omori S, Tanaka H, Murase T. 3-dimensional prebent plate fixation in corrective osteotomy of malunited upper extremity fractures using a real-sized plastic bone model prepared by preoperative computer simulation. J Hand Surg Am. 2013;38:909-19. https://doi.org/10. 1016/j.jhsa.2013.02.024

378. Kim HN, Liu XN, Noh KC. Use of a real-size 3D-printed model as a preoperative and intraoperative tool for minimally invasive plating of comminuted midshaft clavicle fractures. J Orthop Surg Res. 2015;10:91. https://doi.org/10.1186/s13018-015-0233-5.

379. Kunz M, Ma B, Rudan JF, Ellis RE, Pichora DR. Image-guided distal radius osteotomy using patient-specific instrument guides. J Hand Surg Am. 2013; 38:1618-24. https://doi.org/10.1016/j.jhsa.2013.05.018.

380. Lazarus P, Pire E, Sapa C, Ruffenach L, Saur M, Liverneaux P, Hidalgo Diaz JJ. Design and evaluation of a new synthetic wrist procedural simulator (Wristsim ${ }^{\oplus}$ ) for training of distal radius fracture fixation by volar plating. Hand Surg Rehabil. 2017;36:275-80. https://doi.org/10.1016/j.hansur.2017.03. 002.

381. Li B, Chen B, Zhang Y, Wang X, Wang F, Xia H, Yin Q. Comparative use of the computer-aided angiography and rapid prototyping technology versus conventional imaging in the management of the tile $\mathrm{C}$ pelvic fractures. Int Orthop. 2016;40:161-6. https://doi.org/10.1007/s00264-015-2800-0.

382. Li Z, Li Z, Xu R, Li M, Li J, Liu Y, Sui D, Zhang W, Chen Z. Three-dimensional printing models improve understanding of spinal fracture--a randomized controlled study in China. Sci Rep. 2015;5:11570. https:/doi.org/10.1038/srep11570.

383. Liu X, Zeng C-J, Lu J-S, Lin X-C, Huang H-J, Tan X-Y, Cai D-Z. Application of 3D printing and computer-assisted surgical simulation in preoperative planning for acetabular fracture. Nan Fang Yi Ke Da Xue Xue Bao. 2017;37:378-82.

384. Liu Z-J, Jia J, Zhang Y-G, Tian W, Jin X, Hu Y-C. Internal fixation of complicated acetabular fractures directed by preoperative surgery with 3D printing models. Orthop Surg. 2017;9:257-60. https://doi.org/10.1111/os.12324.

385. Lou Y, Cai L, Wang C, Tang Q, Pan T, Guo X, Wang J. Comparison of traditional surgery and surgery assisted by three dimensional printing technology in the treatment of tibial plateau fractures. Int Orthop. 2017;41: 1875-80. https://doi.org/10.1007/s00264-017-3445-y.

386. Maini L, Sharma A, Jha S, Sharma A, Tiwari A. Three-dimensional printing and patient-specific pre-contoured plate: future of acetabulum fracture fixation? Eur J Trauma Emerg Surg. 2018;44:215-24. https://doi.org/10.1007/ s00068-016-0738-6.

387. Manganaro MS, Morag Y, Weadock WJ, Yablon CM, Gaetke-Udager K, Stein EB. Creating three-dimensional printed models of acetabular fractures for use as educational tools. Radiographics. 2017;37:871-80. https://doi.org/10. 1148/rg.2017160129.

388. Omar M, Zeller A-N, Gellrich N-C, Rana M, Krettek C, Liodakis E. Application of a customized 3D printed reduction aid after external fixation of the femur and tibia: technical note. Int J Med Robot. 2017;13(4). https://doi.org/ 10.1002/rcs.1803.

389. Otsuki B, Takemoto M, Kawanabe K, Awa Y, Akiyama H, Fujibayashi S, Nakamura T, Matsuda S. Developing a novel custom cutting guide for curved peri-acetabular osteotomy. Int Orthop. 2013;37:1033-8. https://doi. org/10.1007/s00264-013-1873-x.

390. Oxley B, Behr S. Stabilisation of a cranial cervical vertebral fracture using a 3D-printed patient-specific drill guide. J Small Anim Pract. 2016;57:277. https://doi.org/10.1111/jsap.12469.

391. Qiao F, Li D, Jin Z, Gao Y, Zhou T, He J, Cheng L. Application of 3D printed customized external fixator in fracture reduction. Injury. 2015;46:1150-5. https://doi.org/10.1016/j.injury.2015.01.020.

392. Rankin TM, Giovinco NA, Cucher DJ, Watts G, Hurwitz B, Armstrong DG. Three-dimensional printing surgical instruments: are we there yet? J Surg Res. 2014;189:193-7. https://doi.org/10.1016/j.jss.2014.02.020.
393. Sanghavi PS, Jankharia BG. Holding versus seeing pathology. Threedimensional printing of the bony pelvis for preoperative planning of a complex pelvis fracture: a case report. Indian J Radiol Imaging. 2016;26:397401. https://doi.org/10.4103/0971-3026.190414.

394. Schweizer A, Fürnstahl P, Nagy L. Three-dimensional correction of distal radius intra-articular malunions using patient-specific drill guides. J Hand Surg Am. 2013;38:2339-47. https://doi.org/10.1016/j.jhsa.2013.09.023.

395. Shuang F, Hu W, Shao Y, Li H, Zou H. Treatment of intercondylar humeral fractures with 3D-printed Osteosynthesis plates. Medicine (Baltimore). 2016; 95:e2461. https://doi.org/10.1097/MD.0000000000002461.

396. Storelli DAR, Bauer AS, Lattanza LL, McCarroll HR. The use of computeraided design and 3-dimensional models in the treatment of forearm malunions in children. Tech Hand Up Extrem Surg. 2015;19:23-6. https://doi. org/10.1097/BTH.0000000000000070.

397. Tricot M, Duy KT, Docquier P-L. 3D-corrective osteotomy using surgical guides for posttraumatic distal humeral deformity. Acta Orthop Belg. 2012;78:538-42.

398. Upex P, Jouffroy P, Riouallon G. Application of 3D printing for treating fractures of both columns of the acetabulum: benefit of pre-contouring plates on the mirrored healthy pelvis. Orthop Traumatol Surg Res. 2017;103: 331-4. https://doi.org/10.1016/j.otsr.2016.11.021.

399. Wu X-B, Wang J-Q, Zhao C-P, Sun X, Shi Y, Zhang Z-A, Li Y-N, Wang M-Y. Printed three-dimensional anatomic templates for virtual preoperative planning before reconstruction of old pelvic injuries: initial results. Chin Med J. 2015;128:477-82. https://doi.org/10.4103/0366-6999.151088.

400. Yang L, Shang X-W, Fan J-N, He Z-X, Wang J-J, Liu M, Zhuang Y, Ye C. Application of 3D printing in the surgical planning of Trimalleolar fracture and doctor-patient communication. Biomed Res Int. 2016;2016:2482086. https://doi.org/10.1155/2016/2482086

401. Yang P, Du D, Zhou Z, Lu N, Fu Q, Ma J, Zhao L, Chen A. 3D printingassisted osteotomy treatment for the malunion of lateral tibial plateau fracture. Injury. 2016;47:2816-21. https://doi.org/10.1016/j.injury.2016.09.025.

402. Yin H-W, Xu J, Xu W-D. 3-dimensional printing-assisted percutaneous fixation for acute scaphoid fracture: 1-shot procedure. J Hand Surg Am. 2017:42:301.e1-5. https://doi.org/10.1016/j.jhsa.2017.01.017.

403. You W, Liu $\sqcup$, Chen HX, Xiong JY, Wang DM, Huang JH, Ding JL, Wang DP. Application of 3D printing technology on the treatment of complex proximal humeral fractures (Neer3-part and 4-part) in old people. Orthop Traumatol Surg Res. 2016;102:897-903. https://doi.org/10.1016/j.otsr.2016.06.009.

404. Zeng C, Xing W, Wu Z, Huang H, Huang W. A combination of threedimensional printing and computer-assisted virtual surgical procedure for preoperative planning of acetabular fracture reduction. Injury. 2016;47:22237. https://doi.org/10.1016/j.injury.2016.03.015.

405. Zeng C, Xiao J, Wu Z, Huang W. Evaluation of three-dimensional printing for internal fixation of unstable pelvic fracture from minimal invasive Para-rectus abdominis approach: a preliminary report. Int J Clin Exp Med. 2015;8:13039-44.

406. Zhang Y, Lu S, Xu Y, Shi J, Li Y, Feng Z. Application of navigation template to fixation of sacral fracture using three-dimensional reconstruction and reverse engineering technique. Chin J Traumatol. 2009;12:214-7.

407. Park CH, Rios HF, Taut AD, Padial-Molina M, Flanagan CL, Pilipchuk SP, Hollister SJ, Giannobile WV. Image-based, fiber guiding scaffolds: a platform for regenerating tissue interfaces. Tissue Eng Part C Methods. 2014;20:53342. https://doi.org/10.1089/ten.TEC.2013.0619.

408. Sha Y, Wang H, Ding J, Tang H, Li C, Luo H, Liu J, Xu Y. A novel patient-specific navigational template for anatomical reconstruction of the lateral ankle ligaments. Int Orthop. 2016;40:59-64. https://doi.org/10.1007/s00264-015-2817-4.

409. Bicanic G, Barbaric K, Bohacek I, Aljinovic A, Delimar D. Current concept in dysplastic hip arthroplasty: techniques for acetabular and femoral reconstruction. World J Orthop. 2014;5:412-24. https://doi.org/10.5312/wjo.v5.14.412.

410. Pressel T, Max S, Pfeifer R, Ostermeier S, Windhagen $H$, Hurschler C. A rapid prototyping model for biomechanical evaluation of pelvic osteotomies. Biomed Tech (Berl). 2008;53:65-9.

411. Tong K, Zhang Y, Zhang S, Yu B. Application of computer-aided osteotomy template design in treatment of developmental dysplasia of the hip with steel osteotomy. Nan Fang Yi Ke Da Xue Xue Bao. 2013;33:906-9.

412. Xu J, Li D, Ma R, Barden B, Ding Y. Application of rapid prototyping pelvic model for patients with DDH to facilitate arthroplasty planning: a pilot study. J Arthroplast. 2015;30:1963-70. https://doi.org/10.1016/j.arth.2015.05.033.

413. Zhang YZ, Chen B, Lu S, Yang Y, Zhao JM, Liu R, Li YB, Pei GX. Preliminary application of computer-assisted patient-specific acetabular navigational template for total hip arthroplasty in adult single development dysplasia of the hip. Int J Med Robot. 2011;7:469-74. https://doi.org/10.1002/rcs.423. 
414. Zheng P, Yao Q, Xu P, Wang L. Application of computer-aided design and 3D-printed navigation template in locking compression pediatric hip PlateTM placement for pediatric hip disease. Int J Comput Assist Radiol Surg. 2017;12:865-71. https://doi.org/10.1007/s11548-017-1535-3.

415. Aranda $J$, Jiménez MF, Rodríguez M, Varela G. Tridimensional titaniumprinted custom-made prosthesis for sternocostal reconstruction. Eur J Cardiothorac Surg. 2015;48:e92-4. https://doi.org/10.1093/ejcts/ezv265.

416. Docquier PL, Paul L, Cartiaux O, Delloye C, Banse X. Computer-assisted resection and reconstruction of pelvic tumor sarcoma. Sarcoma. 2010;2010:125162.

417. Bastian L, Hüfner T, Mössinger E, Geerling J, Goesling T, Busche M, Kendoff D, Bading S, Rosenthal H, Krettek C. Integration of modern technologies in therapy of sarcomas of the pelvis. Computer-assisted hemipelvectomy and implantation of a "custom-made" Bonit gentamycin coated partial pelvic prosthesis. Unfallchirurg. 2003;106:956-62. https://doi.org/10.1007/s00113-003-0680-z.

418. Bellanova L, Paul L, Docquier P-L. Surgical guides (patient-specific instruments) for pediatric tibial bone sarcoma resection and allograft reconstruction. Sarcoma. 2013;2013:787653. https://doi.org/10.1155/2013/787653.

419. Cartiaux O, Paul L, Francq BG, Banse X, Docquier P-L. Improved accuracy with 3D planning and patient-specific instruments during simulated pelvic bone tumor surgery. Ann Biomed Eng. 2014;42:205-13. https://doi.org/10. 1007/s10439-013-0890-7.

420. Chen X, Xu L, Wang W, Li X, Sun Y, Politis C. Computer-aided design and manufacturing of surgical templates and their clinical applications: a review. Expert Rev Med Devices. 2016;13:853-64. https://doi.org/10.1080/17434440.2016.1218758.

421. Dai K-R, Yan M-N, Zhu Z-A, Sun Y-H. Computer-aided custom-made hemipelvic prosthesis used in extensive pelvic lesions. J Arthroplast. 2007;22: 981-6. https://doi.org/10.1016/j.arth.2007.05.002.

422. Guenette JP, Himes N, Giannopoulos AA, Kelil T, Mitsouras D, Lee TC. Computerbased vertebral tumor Cryoablation planning and procedure simulation involving two cases using MRI-visible 3D printing and advanced visualization. AJR Am J Roentgenol. 2016;207:1128-31. https://doi.org/10.2214/AJR.16.16059.

423. Helguero CG, Kao I, Komatsu DE, Shaikh S, Hansen D, Franco J, Khan F. Improving the accuracy of wide resection of bone tumors and enhancing implant fit: a cadaveric study. J Orthop. 2015;12:S188-94. https://doi.org/10. 1016/j.jor.2015.10.010

424. Herath HMTU, Di Silvio L, Evans JRG. Biological evaluation of solid freeformed, hard tissue scaffolds for orthopedic applications. J Appl Biomater Biomech. 2010;8:89-96.

425. Iqbal T, Shi L, Wang L, Liu Y, Li D, Qin M, Jin Z. Development of finite element model for customized prostheses design for patient with pelvic bone tumor. Proc Inst Mech Eng H. 2017;231:525-33. https://doi.org/10. 1177/0954411917692009

426. Kim D, Lim JY, Shim KW, Han JW, Yi S, Yoon DH, Kim KN, Ha Y, Ji GY, Shin DA. Sacral reconstruction with a 3D-printed implant after Hemisacrectomy in a patient with sacral osteosarcoma: 1-year follow-up result. Yonsei Med J. 2017;58:453-7. https://doi.org/10.3349/ymj.2017.58.2.453.

427. Liang $H$, Ji T, Zhang $Y$, Wang $Y$, Guo W. Reconstruction with 3D-printed pelvic endoprostheses after resection of a pelvic tumour. Bone Joint J. 2017; 99-B:267-75. https://doi.org/10.1302/0301-620X.99B2.BJJ-2016-0654.R1.

428. Lin C-L, Fang J-J, Lin R-M. Resection of giant invasive sacral schwannoma using image-based customized osteotomy tools. Eur Spine J. 2016;25:41037. https://doi.org/10.1007/s00586-016-4782-z.

429. Luo W, Huang L, Liu H, Qu W, Zhao X, Wang C, Li C, Yu T, Han Q, Wang J, Qin Y. Customized knee prosthesis in treatment of Giant cell tumors of the proximal tibia: application of 3-dimensional printing Technology in Surgical Design. Med Sci Monit. 2017;23:1691-700.

430. Ma L, Zhou Y, Zhu Y, Lin Z, Chen L, Zhang Y, Xia H, Mao C. 3D printed personalized titanium plates improve clinical outcome in microwave ablation of bone tumors around the knee. Sci Rep. 2017;7:7626. https://doi. org/10.1038/s41598-017-07243-3.

431. Ma L, Zhou Y, Zhu Y, Lin Z, Wang Y, Zhang Y, Xia H, Mao C. 3D-printed guiding templates for improved osteosarcoma resection. Sci Rep. 2016;6: 23335. https://doi.org/10.1038/srep23335.

432. Mobbs RJ, Coughlan M, Thompson R, Sutterlin CE, Phan K. The utility of 3D printing for surgical planning and patient-specific implant design for complex spinal pathologies: case report. J Neurosurg Spine. 2017;26:513-8. https://doi.org/10.3171/2016.9.SPINE16371.

433. Paiva WS, Amorim R, Bezerra DAF, Masini M. Aplication of the stereolithography technique in complex spine surgery. Arq Neuropsiquiatr. 2007;65:443-5.
434. Peters P, Langlotz F, Nolte L-P. Computer assisted screw insertion into real 3D rapid prototyping pelvis models. Clin Biomech (Bristol, Avon). 2002;17:376-82

435. Ren X, Yang L, Duan X-J. Three-dimensional printing in the surgical treatment of osteoid osteoma of the calcaneus: a case report. J Int Med Res. 2017;45:372-80. https://doi.org/10.1177/0300060516686514.

436. Tam MD, Laycock SD, Bell D, Chojnowski A. 3-D printout of a DICOM file to aid surgical planning in a 6 year old patient with a large scapular osteochondroma complicating congenital diaphyseal aclasia. J Radiol Case Rep. 2012;6:31-7. https://doi.org/10.3941/jrcr.v6i1.889.

437. Wang X, Shi J, Zhang S, Zhang Z, Li X, Li Z. Pediatric lumbar pedicle screw placement using navigation templates: a cadaveric study. Indian J Orthop. 2017;51:468-73. https://doi.org/10.4103/0019-5413.209955.

438. Wang Y-T, Yang X-J, Yan B, Zeng T-H, Qiu Y-Y, Chen S-J. Clinical application of three-dimensional printing in the personalized treatment of complex spinal disorders. Chin J Traumatol. 2016;19:31-4.

439. Wei $R$, Guo W, Ji T, Zhang $Y$, Liang $H$. One-step reconstruction with a 3Dprinted, custom-made prosthesis after total en bloc sacrectomy: a technical note. Eur Spine J. 2017;26:1902-9. https://doi.org/10.1007/s00586-016-4871z.

440. Wong KC, Kumta SM, Geel NV, Demol J. One-step reconstruction with a 3Dprinted, biomechanically evaluated custom implant after complex pelvic tumor resection. Comput Aided Surg. 2015;20:14-23. https://doi.org/10. 3109/10929088.2015.1076039.

441. Xiao J-R, Huang W-D, Yang X-H, Yan W-J, Song D-W, Wei H-F, Liu T-L, Wu Z$P$, Yang $C$. En bloc resection of primary malignant bone tumor in the cervical spine based on 3-dimensional printing technology. Orthop Surg. 2016:8:171-8. https://doi.org/10.1111/os.12234.

442. Xu N, Wei F, Liu X, Jiang L, Cai H, Li Z, Yu M, Wu F, Liu Z. Reconstruction of the upper cervical spine using a personalized 3D-printed vertebral body in an adolescent with Ewing sarcoma. Spine. 2016;41:E50-4. https://doi.org/10. 1097/BRS.0000000000001179.

443. Zhang Y, Wen L, Zhang J, Yan G, Zhou Y, Huang B. Three-dimensional printing and computer navigation assisted hemipelvectomy for en bloc resection of osteochondroma: a case report. Medicine (Baltimore). 2017;96: e6414. https://doi.org/10.1097/MD.0000000000006414.

444. Anderl W, Pauzenberger L, Schwameis E. The MyKnee ${ }^{\circledast}$ patient-specific system. Rationale, technique and results. Orthopade. 2016;45:294-301. https://doi.org/10.1007/s00132-016-3241-1.

445. Beckmann J, Steinert A, Zilkens C, Zeh A, Schnurr C, Schmitt-Sody M, Gebauer M. Partial replacement of the knee joint with patient-specific instruments and implants (ConforMIS iUni, iDuo). Orthopade. 2016;45:32230. https://doi.org/10.1007/s00132-016-3237-x.

446. Gauci MO, Boileau P, Baba M, Chaoui J, Walch G. Patient-specific glenoid guides provide accuracy and reproducibility in total shoulder arthroplasty. Bone Joint J. 2016;98-B:1080-5. https://doi.org/10.1302/0301-620X.98B8.37257.

447. Hafez MA, Chelule KL, Seedhom BB, Sherman KP. Computer-assisted total knee arthroplasty using patient-specific templating. Clin Orthop Relat Res. 2006:444:184-92. https://doi.org/10.1097/01.blo.0000201148.06454.ef.

448. Jaffry Z, Masjedi M, Clarke S, Harris S, Karia M, Andrews B, Cobb J. Unicompartmental knee arthroplasties: robot vs. patient specific instrumentation. Knee. 2014;21:428-34. https://doi.org/10.1016/j.knee.2013.11.017.

449. Kleyer A, Beyer L, Simon C, Stemmler F, Englbrecht M, Beyer C, Rech J, Manger B, Krönke G, Schett G, Hueber AJ. Development of threedimensional prints of arthritic joints for supporting patients' awareness to structural damage. Arthritis Res Ther. 2017;19:34. https://doi.org/10.1186/ s13075-017-1234-Z.

450. Köster G, Biró C. Total and unicompartmental knee replacement. Patientspecific instrumentation. Orthopade. 2016;45:302-13. https://doi.org/10. 1007/s00132-016-3245-x

451. Steinert AF, Holzapfel BM, Sefrin L, Arnholdt J, Hoberg M, Rudert M. Total knee arthroplasty. Patient-specific instruments and implants. Orthopade. 2016;45:331-40. https://doi.org/10.1007/s00132-016-3246-9.

452. Taller S, Srám J, Lukáš R, Endrych L, Džupa V. Fixation of acetabular fractures. A novel method of pre-operative omega plate contouring. Acta Chir Orthop Traumatol Cechoslov. 2014;81:212-20.

453. Tian SC, Yao QQ, Yin XD, Liu S, Zhou J, Hu J, Li JY, Shan R, Jiang HB, Wang LM. Effects of iASSIST navigation system and personal specific instrument assisted total knee arthroplasty in the treatment of osteoarthritis. Zhonghua Wai Ke Za Zhi. 2017;55:423-9. 
454. Guarino J, Tennyson S, McCain G, Bond L, Shea K, King H. Rapid prototyping technology for surgeries of the pediatric spine and pelvis: benefits analysis. J Pediatr Orthop. 2007;27:955-60. https://doi.org/10.1097/bpo.0b013e3181594ced.

455. Liu K, Zhang Q, Li X, Zhao C, Quan X, Zhao R, Chen Z, Li Y. Preliminary application of a multi-level $3 \mathrm{D}$ printing drill guide template for pedicle screw placement in severe and rigid scoliosis. Eur Spine J. 2017;26:1684-9. https:/doi.org/10.1007/ s00586-016-4926-1.

456. Lu S, Zhang YZ, Wang Z, Shi JH, Chen YB, Xu XM, Xu YQ. Accuracy and efficacy of thoracic pedicle screws in scoliosis with patient-specific drill template. Med Biol Eng Comput. 2012;50:751-8. https://doi.org/10.1007/s11517-012-0900-1.

457. Mao K, Wang Y, Xiao S, Liu Z, Zhang Y, Zhang X, Wang Z, Lu N, Shourong Z, Xifeng Z, Geng C, Baowei L. Clinical application of computer-designed polystyrene models in complex severe spinal deformities: a pilot study. Eur Spine J. 2010;19:797-802. https://doi.org/10.1007/s00586-010-1359-0.

458. Salako F, Aubin C-E, Fortin C, Labelle H. Feasibility study of patient-specific surgical templates for the fixation of pedicle screws. Stud Health Technol Inform. 2002;88:419-22.

459. Takemoto M, Fujibayashi S, Ota E, Otsuki B, Kimura H, Sakamoto T, Kawai T, Futami T, Sasaki K, Matsushita T, Nakamura T, Neo M, Matsuda S. Additivemanufactured patient-specific titanium templates for thoracic pedicle screw placement: novel design with reduced contact area. Eur Spine J. 2016;25: 1698-705. https://doi.org/10.1007/s00586-015-3908-Z.

460. Wu Z-X, Huang L-Y, Sang H-X, Ma Z-S, Wan S-Y, Cui G, Lei W. Accuracy and safety assessment of pedicle screw placement using the rapid prototyping technique in severe congenital scoliosis. J Spinal Disord Tech. 2011;24:44450. https://doi.org/10.1097/BSD.0b013e318201be2a.

461. Yang JC, Ma XY, Lin J, Wu ZH, Zhang K, Yin QS. Personalised modified osteotomy using computer-aided design-rapid prototyping to correct thoracic deformities. Int Orthop. 2011;35:1827-32. https://doi.org/10.1007/ s00264-010-1155-9.

462. Yang M, Li C, Li Y, Zhao Y, Wei X, Zhang G, Fan J, Ni H, Chen Z, Bai Y, Li M. Application of $3 \mathrm{D}$ rapid prototyping technology in posterior corrective surgery for Lenke 1 adolescent idiopathic scoliosis patients. Medicine (Baltimore). 2015;94:e582. https://doi.org/10.1097/MD.0000000000000582.

463. Zhang Y, Shi Y, Wang H, Hou S. Case-control study on accuracy and safety of patient-specific drill-guide templates used in scoliosis cases. Zhongguo Gu Shang. 2015;28:945-50.

464. Anton $\mathrm{R}$, Chen $\mathrm{C}-\mathrm{Y}$, Hung M-Y, Finol EA, Pekkan K. Experimental and computational investigation of the patient-specific abdominal aortic aneurysm pressure field. Comput Methods Biomech Biomed Engin. 2015;18: 981-92. https://doi.org/10.1080/10255842.2013.865024.

465. Bangeas P, Voulalas G, Ktenidis K. Rapid prototyping in aortic surgery. Interact Cardiovasc Thorac Surg. 2016;22:513-4. https://doi.org/10.1093/ icvts/ivv395.

466. Berry E, Marsden A, Dalgarno KW, Kessel D, Scott DJA. Flexible tubular replicas of abdominal aortic aneurysms. Proc Inst Mech Eng H. 2002;216: 211-4. https://doi.org/10.1243/0954411021536423.

467. Bisdas T, Teebken OE. Future perspectives for the role of 3D rapid prototyping aortic biomodels in vascular medicine. Vasa. 2011:40:427-8. https://doi.org/10.1024/0301-1526/a000144.

468. Burris NS, Hoff BA, Kazerooni EA, Ross BD. Vascular deformation mapping (VDM) of thoracic aortic enlargement in aneurysmal disease and dissection. Tomography. 2017;3:163-73. https://doi.org/10.18383/j.tom.2017.00015.

469. Chung M, Radacsi N, Robert C, McCarthy ED, Callanan A, Conlisk N, Hoskins $P R$, Koutsos $V$. On the optimization of low-cost FDM 3D printers for accurate replication of patient-specific abdominal aortic aneurysm geometry. 3D Print Med. 2018:4:2. https://doi.org/10.1186/s41205-017-0023-2.

470. Hertault A, Overbeck K, Sobocinski J, Azzaoui R, Fabre D, Haulon S. Recent developments in intraoperative imaging and navigation during aortic interventions. J Cardiovasc Surg. 2017;58:883-8. https://doi.org/10.23736/ S0021-9509.17.10075-3

471. Ho D, Squelch A, Sun Z. Modelling of aortic aneurysm and aortic dissection through 3D printing. J Med Radiat Sci. 2017;64:10-7. https://doi.org/10.1002/ jmrs.212.

472. Hossien A, Gesomino S, Maessen J, Autschbach R. The interactive use of multi-dimensional modeling and 3D printing in preplanning of type a aortic dissection. J Card Surg. 2016;31:441-5. https://doi.org/10.1111/jocs.12772.

473. Huang J, Li G, Wang W, Wu K, Le T. 3D printing guiding stent graft fenestration: a novel technique for fenestration in endovascular aneurysm repair. Vascular. 2017:25:442-6. https://doi.org/10.1177/1708538116682913.
474. Itagaki MW. Using 3D printed models for planning and guidance during endovascular intervention: a technical advance. Diagn Interv Radiol. 2015;21: 338-41. https://doi.org/10.5152/dir.2015.14469.

475. Jelenc M, Jelenc B, Knezevic I, Klokocovnik T. New graft sizing rings for aortic valve reimplantation procedures. Interact Cardiovasc Thorac Surg. 2018;26:1-3. https://doi.org/10.1093/icvts/ivx257.

476. Kalejs M, von Segesser LK. Rapid prototyping of compliant human aortic roots for assessment of valved stents. Interact Cardiovasc Thorac Surg. 2009; 8:182-6. https://doi.org/10.1510/icvts.2008.194134.

477. Knox K, Kerber CW, Singel SA, Bailey MJ, Imbesi SG. Rapid prototyping to create vascular replicas from CT scan data: making tools to teach, rehearse, and choose treatment strategies. Catheter Cardiovasc Interv. 2005;65:47-53. https://doi.org/10.1002/ccd.20333.

478. Koleilat I, Jaeggli M, Ewing JA, Androes M, Simionescu DT, Eidt J. Interobserver variability in physician-modified endograft planning by comparison with a three-dimensional printed aortic model. J Vasc Surg. 2016;64:1789-96. https://doi.org/10.1016/j.jvs.2015.09.044.

479. Leotta DF, Starnes BW. Custom fenestration templates for endovascular repair of juxtarenal aortic aneurysms. J Vasc Surg. 2015;61:1637-41. https:// doi.org/10.1016/j.jvs.2015.02.016.

480. Lermusiaux P, Leroux C, Tasse JC, Castellani L, Martinez R. Aortic aneurysm: construction of a life-size model by rapid prototyping. Ann Vasc Surg. 2001; 15:131-5. https://doi.org/10.1007/s100160010054.

481. Li F, Shan Y, Zhang Y, Niu G. Occlusion of an ascending aortic pseudoaneurysm with intraoperative echocardiography and a printed model. J Thorac Cardiovasc Surg. 2016;152:282-4. https://doi.org/10.1016/j.jtcvs.2016.02.031.

482. Meess KM, Izzo RL, Dryjski ML, Curl RE, Harris LM, Springer M, Siddiqui AH, Rudin S, lonita CN. 3D printed abdominal aortic aneurysm phantom for image guided surgical planning with a patient specific fenestrated endovascular graft system. Proc SPIE Int Soc Opt Eng. 2017. https://doi.org/ 10.1117/12.2253902.

483. Pepper J, Petrou M, Rega F, Rosendahl U, Golesworthy T, Treasure T. Implantation of an individually computer-designed and manufactured external support for the Marfan aortic root. Multimed Man Cardiothorac Surg. 2013;2013:mmt004. https://doi.org/10.1093/mmcts/mmt004.

484. Ruiz de Galarreta S, Anton R, Cazon A, Finol EA. A methodology for developing anisotropic AAA phantoms via additive manufacturing. J Biomech. 2017;57:161-6. https://doi.org/10.1016/j.jbiomech.2017.04.001.

485. Schmauss D, Juchem G, Weber S, Gerber N, Hagl C, Sodian R. Threedimensional printing for perioperative planning of complex aortic arch surgery. Ann Thorac Surg. 2014;97:2160-3. https://doi.org/10.1016/j. athoracsur.2014.02.011.

486. Sodian R, Schmauss D, Schmitz C, Bigdeli A, Haeberle S, Schmoeckel M, Markert M, Lueth T, Freudenthal F, Reichart B, Kozlik-Feldmann R. 3dimensional printing of models to create custom-made devices for coil embolization of an anastomotic leak after aortic arch replacement. Ann Thorac Surg. 2009:88:974-8. https://doi.org/10.1016/j.athoracsur.2009.03.014.

487. Sulaiman A, Boussel L, Taconnet F, Serfaty JM, Alsaid H, Attia C, Huet L, Douek P. In vitro non-rigid life-size model of aortic arch aneurysm for endovascular prosthesis assessment. Eur J Cardiothorac Surg. 2008;33:53-7. https://doi.org/10.1016/j.ejcts.2007.10.016.

488. Sun X, Zhang H, Zhu K, Wang C. Patient-specific three-dimensional printing for Kommerell's diverticulum. Int J Cardiol. 2018;255:184-7. https://doi.org/ 10.1016/j.ijcard.2017.12.065.

489. Taher F, Falkensammer J, McCarte J, Strassegger J, Uhlmann M, Schuch P, Assadian A. The influence of prototype testing in three-dimensional aortic models on fenestrated endograft design. J Vasc Surg. 2017;65:1591-7. https://doi.org/10.1016/j.jvs.2016.10.108.

490. Tam MD, Latham T, Brown JRI, Jakeways M. Use of a 3D printed hollow aortic model to assist EVAR planning in a case with complex neck anatomy: potential of 3D printing to improve patient outcome. J Endovasc Ther. 2014;21:760-2. https://doi.org/10.1583/14-4810L.1.

491. Tam MD, Latham TR, Lewis M, Khanna K, Zaman A, Parker M, Grunwald IQ. A pilot study assessing the impact of 3-D printed models of aortic aneurysms on management decisions in EVAR planning. Vasc Endovasc Surg. 2016:50:4-9. https://doi.org/10.1177/1538574415623651.

492. Tam MDBS, Laycock SD, Brown JRI, Jakeways M. 3D printing of an aortic aneurysm to facilitate decision making and device selection for endovascular aneurysm repair in complex neck anatomy. J Endovasc Ther. 2013;20:863-7. https://doi.org/10.1583/13-4450MR.1. 
493. Torres IO, De Luccia N. A simulator for training in endovascular aneurysm repair: the use of three dimensional printers. Eur J Vasc Endovasc Surg. 2017;54:247-53. https://doi.org/10.1016/j.ejvs.2017.05.011.

494. Treasure T, Takkenberg JJM, Golesworthy T, Rega F, Petrou M, Rosendahl U, Mohiaddin R, Rubens M, Thornton W, Lees B, Pepper J. Personalised external aortic root support (PEARS) in Marfan syndrome: analysis of 1-9 year outcomes by intention-to-treat in a cohort of the first 30 consecutive patients to receive a novel tissue and valve-conserving procedure, compared with the published results of aortic root replacement. Heart. 2014;100:969-75. https://doi.org/10.1136/heartjnl-2013-304913.

495. Valverde I, Gomez G, Coserria JF, Suarez-Mejias C, Uribe S, Sotelo J, Velasco MN, Santos De Soto J, Hosseinpour A-R, Gomez-Cia T. 3D printed models for planning endovascular stenting in transverse aortic arch hypoplasia. Catheter Cardiovasc Interv. 2015;85:1006-12. https://doi.org/10.1002/ccd.25810.

496. Wilasrusmee C, Suvikrom J, Suthakorn J, Lertsithichai P, Sitthiseriprapip K, Proprom N, Kittur DS. Three-dimensional aortic aneurysm model and endovascular repair: an educational tool for surgical trainees. Int J Angiol. 2008;17:129-33.

497. Winder RJ, Sun Z, Kelly B, Ellis PK, Hirst D. Abdominal aortic aneurysm and stent graft phantom manufactured by medical rapid prototyping. J Med Eng Technol. 2002;26:75-8. https://doi.org/10.1080/03091900210124404.

498. You JH, Kang S-G, Kim BM. A novel measurement technique for the design of fenestrated stent grafts: comparison with three-dimensional aorta models. Exp Clin Cardiol. 2013;18:48-52.

499. Yuan D, Luo H, Yang H, Huang B, Zhu J, Zhao J. Precise treatment of aortic aneurysm by three-dimensional printing and simulation before endovascular intervention. Sci Rep. 2017;7:795. https://doi.org/10.1038/ s41598-017-00644-4.

500. Han X, Wu X, Kelly M, Chen X. Fabrication and optimal Design of Biodegradable Polymeric Stents for aneurysms treatments. J Funct Biomater. 2017;8(1):E8. https://doi.org/10.3390/jfb8010008.

501. Ishibashi T, Takao H, Suzuki T, Yuki I, Kaku S, Kan I, Nishimura K, Suzuki T, Watanabe M, Karagiozov K, Murayama Y. Tailor-made shaping of microcatheters using three-dimensional printed vessel models for endovascular coil embolization. Comput Biol Med. 2016;77:59-63. https:// doi.org/10.1016/j.compbiomed.2016.07.005.

502. Lin JC, Myers E. Three-dimensional printing for preoperative planning of renal artery aneurysm surgery. J Vasc Surg. 2016;64:810. https://doi.org/10. 1016/j.jvs.2015.12.061.

503. Salloum C, Lim C, Fuentes L, Osseis M, Luciani A, Azoulay D. Fusion of information from 3D printing and surgical robot: an innovative minimally technique illustrated by the resection of a large celiac trunk aneurysm. World J Surg. 2016;40:245-7. https://doi.org/10.1007/s00268-015-3218-y.

504. Shibata E, Takao H, Amemiya S, Ohtomo K. 3D-printed visceral aneurysm models based on CT data for simulations of endovascular embolization: evaluation of size and shape accuracy. AJR Am J Roentgenol. 2017;209:2437. https://doi.org/10.2214/AJR.16.17694.

505. Takao H, Amemiya S, Shibata E, Ohtomo K. 3D printing of preoperative simulation models of a splenic artery aneurysm. Precision and Accuracy Acad Radiol. 2017;24:650-3. https://doi.org/10.1016/j.acra.2016.12.015.

506. Lashkarinia SS, Piskin S, Bozkaya TA, Salihoglu E, Yerebakan C, Pekkan K. Computational pre-surgical planning of arterial patch reconstruction: parametric limits and in vitro validation. Ann Biomed Eng. 2018. https://doi. org/10.1007/s10439-018-2043-5.

507. Shirakawa T, Yoshitatsu M, Koyama Y, Mizoguchi H, Toda K, Sawa Y. 3Dprinted aortic stenosis model with fragile and crushable calcifications for off-the-job training and surgical simulation. Multimed Man Cardiothorac Surg. 2018. https://doi.org/10.1510/mmcts.2018.018.

508. Yang Y, Liu X, Xia Y, Liu X, Wu W, Xiong H, Zhang H, Xu L, Wong KKL, Ouyang $H$, Huang W. Impact of spatial characteristics in the left stenotic coronary artery on the hemodynamics and visualization of 3D replica models. Sci Rep. 2017;7:15452. https://doi.org/10.1038/s41598-017-15620-1.

509. Jones TW, Seckeler MD. Use of 3D models of vascular rings and slings to improve resident education. Congenit Heart Dis. 2017;12(5):578-82. https:// doi.org/10.1111/chd.12486

510. Cao P, Duhamel Y, Olympe G, Ramond B, Langevin F. A new production method of elastic silicone carotid phantom based on MRI acquisition using rapid prototyping technique. Conf Proc IEEE Eng Med Biol Soc. 2013;2013: 5331-4. https://doi.org/10.1109/EMBC.2013.6610753.

511. Govsa F, Yagdi T, Ozer MA, Eraslan C, Alagoz AK. Building 3D anatomical model of coiling of the internal carotid artery derived from $C T$ angiographic data. Eur Arch Otorhinolaryngol. 2017;274:1097-102. https://doi.org/10.1007/ s00405-016-4355-0.

512. Lai SSM, Yiu BYS, Poon AKK, Yu ACH. Design of anthropomorphic flow phantoms based on rapid prototyping of compliant vessel geometries. Ultrasound Med Biol. 2013;39:1654-64. https://doi.org/10.1016/j. ultrasmedbio.2013.03.015.

513. Xie J, Li M-H, Tan H-Q, Zhu Y-Q, Li Y-D, Fan C-H, Hu D-J, Qiao R-H. Establishment of an experimental intracranial internal carotid artery model and the application in covered-stent navigability testing. AJNR Am J Neuroradiol. 2009;30:1041-5. https://doi.org/10.3174/ajnr.A1479.

514. Yedavalli RV, Loth F, Yardimci A, Pritchard WF, Oshinski JN, Sadler L, Charbel F, Alperin N. Construction of a physical model of the human carotid artery based upon in vivo magnetic resonance images. J Biomech Eng. 2001;123: 372-6.

515. Abla AA, Lawton MT. Three-dimensional hollow intracranial aneurysm models and their potential role for teaching, simulation, and training. World Neurosurg. 2015;83:35-6. https://doi.org/10.1016/j.wneu.2014.01.015.

516. Andereggen L, Gralla J, Andres RH, Weber S, Schroth G, Beck J, Widmer HR, Reinert M, Raabe A, Peterhans M. Stereolithographic models in the interdisciplinary planning of treatment for complex intracranial aneurysms. Acta Neurochir. 2016;158:1711-20. https://doi.org/10.1007/s00701-016-2892-3.

517. Anderson JR, Klucznik R, Diaz O, Zhang YJ, Britz GW, Grossman RG, Karmonik C. Quantification of velocity reduction after flow diverter placement in intracranial aneurysm: an ex vivo study with 3D printed replicas. Conf Proc IEEE Eng Med Biol Soc. 2015;2015:7300-3. https://doi.org/10.1109/EMBC. 2015.7320077

518. Anderson JR, Thompson WL, Alkattan AK, Diaz O, Klucznik R, Zhang YJ, Britz GW, Grossman RG, Karmonik C. Three-dimensional printing of anatomically accurate, patient specific intracranial aneurysm models. J Neurointerv Surg. 2016;8:517-20. https://doi.org/10.1136/neurintsurg2015-011686.

519. Benet A, Plata-Bello J, Abla AA, Acevedo-Bolton G, Saloner D, Lawton MT. Implantation of 3D-printed patient-specific aneurysm models into cadaveric specimens: a new training paradigm to allow for improvements in cerebrovascular surgery and research. Biomed Res Int. 2015;2015:939387. https://doi.org/10.1155/2015/939387.

520. Conti A, Pontoriero A, lati G, Marino D, La Torre D, Vinci S, Germano A, Pergolizzi S, Tomasello F. 3D-printing of arteriovenous malformations for Radiosurgical treatment: pushing anatomy understanding to real boundaries. Cureus. 2016;8:e594. https://doi.org/10.7759/cureus.594.

521. Dong M, Chen G, Li J, Qin K, Ding X, Peng C, Zhou D, Lin X. Threedimensional brain arteriovenous malformation models for clinical use and resident training. Medicine (Baltimore). 2018;97:e9516. https://doi.org/10. 1097/MD.0000000000009516.

522. Dong M, Chen G, Qin K, Ding X, Zhou D, Peng C, Zeng S, Deng X. Development of three-dimensional brain arteriovenous malformation model for patient communication and young neurosurgeon education. $\mathrm{Br} J$ Neurosurg. 2018:1-4. https://doi.org/10.1080/02688697.2018.1424320.

523. Erbano BO, Opolski AC, Olandoski M, Foggiatto JA, Kubrusly LF, Dietz UA, Zini C, Marinho MMMA, Leal AG, Ramina R. Rapid prototyping of threedimensional biomodels as an adjuvant in the surgical planning for intracranial aneurysms. Acta Cir Bras. 2013;28:756-61.

524. Frolich AMJ, Spallek J, Brehmer L, Buhk J-H, Krause D, Fiehler J, Kemmling A. 3D printing of intracranial aneurysms using fused deposition modeling offers highly accurate replications. AJNR Am J Neuroradiol. 2016;37:120-4. https://doi.org/10.3174/ajnr.A4486.

525. Imbesi SG, Knox K, Kerber CW. Reproducibility analysis of a new objective method for measuring arteriovenous malformation nidus size at angiography. AJNR Am J Neuroradiol. 2002;23:412-5.

526. Kaneko N, Mashiko T, Namba K, Tateshima S, Watanabe E, Kawai K. A patientspecific intracranial aneurysm model with endothelial lining: a novel in vitro approach to bridge the gap between biology and flow dynamics. J Neurointer Surg. 2018;10:306-9. https://doi.org/10.1136/neurintsurg-2017-013087.

527. Karmonik C, Anderson JR, Elias S, Klucznik R, Diaz O, Zhang YJ, Grossman RG, Britz GW. Four-dimensional phase contrast magnetic resonance imaging protocol optimization using patient-specific 3-dimensional printed replicas for in vivo imaging before and after flow diverter placement. World Neurosurg. 2017;105:775-82. https://doi.org/10.1016/j.wneu.2017.06.042.

528. Khan IS, Kelly PD, Singer RJ. Prototyping of cerebral vasculature physical models. Surg Neurol Int. 2014;5:11. https:/doi.org/10.4103/2152-7806.125858. 
529. Konno T, Mashiko T, Oguma H, Kaneko N, Otani K, Watanabe E. Rapid 3dimensional models of cerebral aneurysm for emergency surgical clipping. No Shinkei Geka. 2016:44:651-60. https://doi.org/10.11477/mf.1436203350.

530. Lan Q, Chen A, Zhang T, Li G, Zhu Q, Fan X, Ma C, Xu T. Development of three-dimensional printed Craniocerebral models for simulated neurosurgery. World Neurosurg. 2016;91:434-42. https://doi.org/10.1016/j. wneu.2016.04.069

531. Liu Y, Gao Q, Du S, Chen Z, Fu J, Chen B, Liu Z, He Y. Fabrication of cerebral aneurysm simulator with a desktop 3D printer. Sci Rep. 2017;7:44301. https://doi.org/10.1038/srep44301.

532. Mashiko T, Kaneko N, Konno T, Otani K, Nagayama R, Watanabe E. Training in cerebral aneurysm clipping using self-made 3-dimensional models. J Surg Educ. 2017;74:681-9. https://doi.org/10.1016/j.jsurg.2016.12.010.

533. Mashiko T, Otani K, Kawano R, Konno T, Kaneko N, Ito Y, Watanabe E. Development of three-dimensional hollow elastic model for cerebral aneurysm clipping simulation enabling rapid and low cost prototyping. World Neurosurg 2015;83:351-61. https://doi.org/10.1016/j.wneu.2013.10.032.

534. Namba K, Higaki A, Kaneko N, Mashiko T, Nemoto S, Watanabe E. Microcatheter shaping for intracranial aneurysm coiling using the 3dimensional printing rapid prototyping technology: preliminary result in the first 10 consecutive cases. World Neurosurg. 2015;84(1):178-86. https://doi. org/10.1016/j.wneu.2015.03.006.

535. Russ M, O'Hara R, Setlur Nagesh SV, Mokin M, Jimenez C, Siddiqui A, Bednarek D, Rudin S, lonita C. Treatment planning for image-guided neurovascular interventions using patient-specific 3D printed phantoms. Proc SPIE Int Soc Opt Eng. 2015. https://doi.org/10.1117/12.2081997.

536. Ryan JR, Almefty KK, Nakaji P, Frakes DH. Cerebral aneurysm clipping surgery simulation using patient-specific 3D printing and silicone casting. World Neurosurg. 2016;88:175-81. https://doi.org/10.1016/j.wneu.2015.12.102.

537. Shah A, Jankharia B, Goel A. Three-dimensional model printing for surgery on arteriovenous malformations. Neurol India. 2017;65:1350-4. https://doi. org/10.4103/0028-3886.217958.

538. Thawani JP, Pisapia JM, Singh N, Petrov D, Schuster JM, Hurst RW, Zager EL, Pukenas BA. Three-dimensional printed modeling of an arteriovenous malformation including blood flow. World Neurosurg. 2016;90:675-683.e2. https://doi.org/10.1016/j.wneu.2016.03.095.

539. Tsang ACO, Lai SSM, Chung WC, Tang AYS, Leung GKK, Poon AKK, Yu ACH, Chow KW. Blood flow in intracranial aneurysms treated with pipeline embolization devices: computational simulation and verification with Doppler ultrasonography on phantom models. Ultrasonography. 2015;34: 98-108. https://doi.org/10.14366/usg.14063.

540. Wang J-L, Yuan Z-G, Qian G-L, Bao W-Q, Jin G-L. 3D printing of intracranial aneurysm based on intracranial digital subtraction angiography and its clinical application. Medicine (Baltimore). 2018:97:e11103. https://doi.org/10. 1097/MD.0000000000011103.

541. Wang L, Ye X, Hao Q, Ma L, Chen X, Wang H, Zhao Y. Three-dimensional intracranial middle cerebral artery aneurysm models for aneurysm surgery and training. J Clin Neurosci. 2018;50:77-82. https://doi.org/10.1016/j.jocn. 2018.01.074

542. Weinstock P, Prabhu SP, Flynn K, Orbach DB, Smith E. Optimizing cerebrovascular surgical and endovascular procedures in children via personalized 3D printing. J Neurosurg Pediatr. 2015;31:1-6. https://doi.org/ 10.3171/2015.3.PEDS14677.

543. Wurm G, Lehner M, Tomancok B, Kleiser R, Nussbaumer K. Cerebrovascular biomodeling for aneurysm surgery: simulation-based training by means of rapid prototyping technologies. Surg Innov. 2011;18:294-306. https://doi. org/10.1177/1553350610395031.

544. Wurm G, Tomancok B, Pogady P, Holl K, Trenkler J. Cerebrovascular stereolithographic biomodeling for aneurysm surgery. Technical note J Neurosurg. 2004;100(1):139-45.

545. Yan L, Han X. 3-dimensional printing rapid prototyping for intracranial aneurysm coiling: a good example of precise medicine. World Neurosurg. 2016;86:8. https://doi.org/10.1016/j.wneu.2015.06.051.

546. Poulin E, Gardi L, Fenster A, Pouliot J, Beaulieu L. Towards real-time 3D ultrasound planning and personalized 3D printing for breast HDR brachytherapy treatment. Radiother Oncol. 2015;114(3):335-8. https://doi. org/10.1016/j.radonc.2015.02.007.

547. Chae MP, Hunter-Smith DJ, Spychal RT, Rozen WM. 3D volumetric analysis for planning breast reconstructive surgery. Breast Cancer Res Treat. 2014; 146(2):457-60. https://doi.org/10.1007/s10549-014-3028-1.
548. Schulz-Wendtland R, Harz M, Meier-Meitinger M, Brehm B, Wacker T, Hahn HK, Wagner F, Wittenberg T, Beckmann MW, Uder M, Fasching PA, Emons J. Semi-automated delineation of breast cancer tumors and subsequent materialization using three-dimensional printing (rapid prototyping). J Surg Oncol. 2017;115(3):238-42. https://doi.org/10.1002/jso.24510.

549. Park SY, Choi CH, Park JM, Chun M, Han JH, Kim Jl. A patient-specific Polylactic acid bolus made by a 3D printer for breast Cancer radiation therapy. PLoS One. 2016;11(12):e0168063. https://doi.org/10.1371/journal. pone.0168063.

550. Mehta S, Byrne N, Karunanithy N, Farhadi J. 3D printing provides unrivalled bespoke teaching tools for autologous free flap breast reconstruction. J Plast Reconstr Aesthet Surg. 2016;69(4):578-80. https://doi.org/10.1016/j.bjps. 2015.12.026.

551. Park K, Park S, Jeon MJ, Choi J, Kim JW, Cho YJ, Jang WS, Keum YS, Lee IJ. Clinical application of 3D-printed-step-bolus in post-total-mastectomy electron conformal therapy. Oncotarget. 2017;8(15):25660-8. https://doi.org/ 10.18632/oncotarget.12829.

552. Barth RJ Jr, Krishnaswamy V, Paulsen KD, Rooney TB, Wells WA, Rizzo E, Angeles CV, Marotti JD, Zuurbier RA, Black CC. A patient-specific 3D-printed form accurately transfers supine MRI-derived tumor localization information to guide breast-conserving surgery. Ann Surg Oncol. 2017;24(10):2950-6. https://doi.org/10.1245/s10434-017-5979-z.

553. ACR Appropriateness Criteria (2018) American college of radiology. https:// www.acr.org/Clinical-Resources/ACR-Appropriateness-Criteria. Accessed 30 Jun 2018.

554. Rybicki FJ. The role of the ACR appropriateness criteria in the medical literature. J Am Coll Radiol. 2018;15(5S):S1. https://doi.org/10.1016/j.jacr.2018. 03.056.

555. ICD - Classification of Diseases, Functioning, and Disability (2009) National Center for Health Statistics, Atlanta, GA. http://www.cdc.gov/nchs/icd.htm. Accessed 30 Jun 2018.

556. Mankovich NJ, Cheeseman A, Stoker NG. The display of three-dimensional anatomy with stereolithographic models. J Digit Imaging. 1990;3(3):200-3.

557. Mankovich NJ, Cheeseman A, Stoker N. The display of three dimensional anatomy with stereolithographic models. SPIE - Medical Imaging IV. 1990; 1091:183-7.

558. Mankovich NJ, Curtis D, Kugawa T, Beumer J. Comparison of computerbased fabrication of alloplastic cranial implants with conventional techniques. J prosthetic. Dentistry. 1985;55(5):606-9.

559. Ellison JS, Montgomery JS, Hafez K, Miller DC, He C, Wolf S Jr, Weizer AZ. Association of RENAL nephrectomy score with outcomes of minimally invasive partial nephrectomy. Int J Urol. 2013;20:564-70.

560. Simhan J, Smaldone MC, Tsai KJ, Canter DJ, Li T, Kutivok A, Viterbo R, Chen DYT, Greenberg R, Uzzo RG. Objective measures of renal mass anatomic complexity predict rates of major complications following partial nephrectomy. Eur Urol. 2011;60:724-30.

561. Rosenkrantz AB. Genitourinary imaging. Radiol Clin N Am. 2017;5(2):209-428.

562. Siegel RL, Miller KD, Jemal A. Cancer statistics, 2017. CA Cancer J Clin. 2017; 67(1):7-30.

563. Mitsouras D, Liacouras $P$, Imanzadeh A, Giannopoulos AA, Cai T, Kumamaru KK, George E, Wake N, Caterson EJ, Pomahac B, Ho VB, Grant GT, Rybicki FJ. Medical 3D printing for the radiologist. Radiographics. 2015;35(7):1965-88.

564. Yoo SJ, Spray T, Austin EH 3rd, Yun TJ, van Arsdell GS. Hands-on surgical training of congenital heart surgery using 3-dimensional print models. J Thorac Cardiovasc Surg. 2017;153(6):1530-40. https://doi.org/10.1016/j.jtcvs. 2016.12.054

565. Marro A, Bandukwala T, Mak W. Three-dimensional printing and medical imaging: a review of the methods and applications. Curr Probl Diagn Radiol. 2016:45(1):2-9.

566. Matsumoto JS, Morris JM, Foley TA, Williamson EE, Leng S, McGee KP, Kuhlmann JL, Nesberg LE, Vrtiska TJ. Three-dimensional physical modeling: applications and experience at Mayo Clinic. Radiographics. 2015;35(7):1989_ 2006.

567. Huang J, Li G, Wang W, Wu K, Le T. 3D printing guiding stent graft fenestration: a novel technique for fenestration in endovascular aneurysm repair. Vascular. 2016;25(4):442-6.

568. Velez E, Boyer N, Acevedo Bolton G, Hope MD, Boyle A. CT reconstructed three dimensional printed models of the right subclavian artery and aorta define ager elated changes and facilitate benchtop catheter testing. J Invasive Cardiol. 2014;26(10):E1414. 
569. Girsowicz E, Georg Y, Seiller H, Lejay A, Thaveau F, Heim F, Chakfe N. Evaluation of nitinol stents using a 3-dimensional printed superficial femoral artery model: a preliminary study. Ann Vasc Surg. 2016;33:1-10.

570. Noone AM, Howlader N, Krapcho M, Miller D, Brest A, Yu M, Ruhl J, Tatalovich Z, Mariotto A, Lewis DR, Chen HS, Feuer EJ, Cronin KA, editors. SEER Cancer statistics review, 1975-2015. Bethesda: National Cancer Institute; 2018.

571. Toriola AT, Colditz GA. Trends in breast cancer incidence and mortality in the United States: implications for prevention. Breast Cancer Res Treat. 2013: 138(3):665-73.

572. Giuliano AE, Connolly JL, Edge SB, Mittendorf EA, Rugo HS, Solin L, Weaver DL, Winchester DJ, Hortobagyi GN. Breast Cancer-major changes in the American joint committee on Cancer eighth edition cancer staging manual. CA Cancer J Clin. 2017;67(4):290-303.

573. Rungruang B, Kelley JL. Benign breast diseases: epidemiology, evaluation, and management. Clin Obstet Gynecol. 2011;54(1):110-24.

574. Goehring C, Morabia A. Epidemiology of benign breast disease, with special attention to histologic types. Epidemiol Rev. 1997;19(2):310-27.

575. Parker SJ, Wheaton M, Wallis MG, Harries SA. Why should diagnostic benign breast biopsies weight less than twenty grams? Ann R Coll Surg Engl. 2001; 83(2):113-6.

576. Litwin MS, Tan HJ. The diagnosis and treatment of prostate Cancer: a review. JAMA. 2017;317(24):2532-42.

577. Giannopoulos AA, Mitsouras D, Yoo SJ, Liu PP, Chatzizisis YS, Rybicki FJ. Applications of 3D printing in cardiovascular diseases. Nat Rev Cardiol. 2016; 13(12):701-18.

578. Christensen A, Rybicki FJ. Maintaining safety and efficacy for 3D printing in medicine. 3D Print Med. 2017;3:1.

579. Di Prima M, Coburn J, Hwang D, Kelly J, Khairuzzaman A, Ricles L. Additively manufactured medical products-the FDA perspective. 3D Print Med. 2015; 2(1):1-6.

580. FDA. Technical Considerations for Additive Manufactured Devices. https:// www.fda.gov/downloads/medicaldevices/deviceregulationandguidance/ guidancedocuments/ucm499809.pdf. Accessed 06 June 2018.

581. Leng S, McGee K, Morris J, Alexander A, Kuhlmann J, Vrieze T, McCollough $\mathrm{CH}$, Matsumoto J. Anatomic modeling using 3D printing: quality assurance and optimization. 3D Print Med. 2017;3:6.

582. George E, Liacouras P, Rybicki FJ, Mitsouras D. Measuring and establishing the accuracy and reproducibility of 3D printed medical models. Radiographics. 2017;37(5):1424-50.

583. Cai T, Rybicki FJ, Giannopoulos AA, Schultz K, Kumamaru KK, Liacouras $P$. Demehri S, Small KM, Mitsouras D. The residual STL volume as a metric to evaluate accuracy and reproducibility of anatomic models for $3 \mathrm{D}$ printing application in the validation of 3D-printable models of maxillofacial bone from reduced radiation dose CT images. 3D Print Med. 2015;1:2.

584. Giannopoulos AA, Chepelev L, Sheikh A, Wang A, Dang W, Akyuz E, Hong C, Wake N, Pietila P, Dydynski PB, Mitsouras D, Rybicki FJ. 3D printed ventricular septal defect patch: a primer for the 2015 Radiological Society of North America (RSNA) hands-on course in 3D printing. 3D Print Med. 2015;1:3.

585. Chepelev L, Hodgdon T, Gupta A, Wang A, Torres C, Krishna S, Akyuz E, Mitsouras D, Sheikh A. Medical 3D printing for vascular interventions and surgical oncology: a primer for the 2016 radiological society of North America (RSNA) hands-on course in 3D printing. 3D Print Med. 2016;2:5.

586. Chepelev L, Souza C, Althobaity W, Miguel O, Krishna S, Akyuz E, Hodgdon T, Torres C, Wake N, Alexander A, George E, Tang A, Liacouras P, Matsumoto J, Morris J, Christensen A, Mitsouras D, Rybicki F, Sheik A. Preoperative planning and tracheal stent design in thoracic surgery: a primer for the 2017 Radiological Society of North America (RSNA) hands-on course in 3D printing. 3D Print Med. 2017;3:14.

Ready to submit your research? Choose BMC and benefit from:

- fast, convenient online submission

- thorough peer review by experienced researchers in your field

- rapid publication on acceptance

- support for research data, including large and complex data types

- gold Open Access which fosters wider collaboration and increased citations

- maximum visibility for your research: over $100 \mathrm{M}$ website views per year

At BMC, research is always in progress.

Learn more biomedcentral.com/submissions 